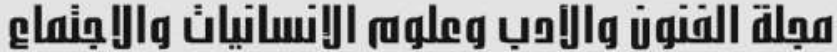

Journal of Arts, Literature, Humanities and Social Sciences www.jalhss.com

\section{وإعادة استخدامها}

\section{(حي الاحو بمدينة الرياض، المملكة العربية السعودية)}

د. عفاف عبد الحفيظ محمد رحمة الفية قسم الفولكلور-معهد الدراسات الافريقية والاسيويةــ جامعة الخرطوم ـ السودان البريد الاكتروني: afaf.rahma010@gmail.com

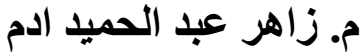

لدار الرياض للاستشارات الهندسية_الرياضــ المملكة العربية السعودية البريد الاكتروني: zahir.awad@gmail.com

الملخص

تتعرض هذه الورقة لتجربة إعادة تأهيل مباني تر اثية طينية فى حي (الدحو) الذي يقع ضمن منطقة (قصر الحكم) في وسط مدينة الرياض بالمملكة العربية السعودية و إعادة استخدامها. هدف مشروع (حي الدحو) الي الحفاظ على مباني الحي الطينية القديمة من خلال ترميمها وتأهيلها للحفاظ على التراث المعماري المتبقي لمدينة الرياض القديمة و المنمثل في هذا الحي. هذا بالإضافة الي الحفاظ على النسيج الناريخي، و اتاحة الفرص لخوض تجربة تاريخية ثقافية حياتية مميزة بزيارة الحي والتأمل في الجو التراثي الذي يفرضه ورؤية سور المدينة القديم مع بع تحسين الوصول الي مناطق الجذب المختلفة المجاورة من أسواق ومواقع تاريخية. اضطلع المشروع، بتجديد كامل للحي، مع الإبقاء على هويته ومعالمه المعمارية و العمر انية، وتأسيس بنية تحتية جديدة على مسنوى عال من المقاييس. استخدت المو اد التقليدية من طين واخثاب في اعمال التأهيل والترميم، كما استخدمت طرق البناء التقليدية وتقنياتها المتوارثة لإحياء صناعة البناء القديمة. وجرى تأهيل المباني التراثية وتهيئتها وظيفيا لإتاحة استخدامها كنزل سياحية أو وحدات فندقية، مع تزويد جميع هذه المباني بالخدمات الأساسية وإحاطتها بالمرافق الحيوية كالمطاعم و الأسواق والمقاهي و الممرات الرئيسية والمواقف الخاصة بالسيارات. مع اكتمال اعمال

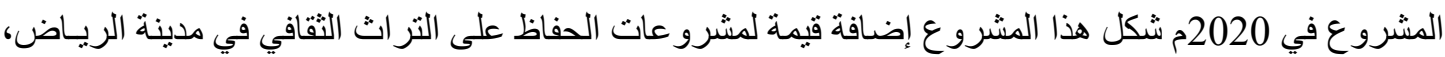
ونموذجاً حياً لتطوير وتأهيل الأحياء التاريخية والتراثية في المدن. 
 \\ $==$ \\ Preservation and Reuse of Heritage and Historical Buildings in Cities
}

\section{(Al-Daho Quarter, Riyadh, Saudi Arabia)}

\author{
Afaf Abdelhafeez Mohamed Rahma \\ Folklore Department-Institute of African and Asian Studies - University of Khartoum- \\ Sudan \\ Email: afaf.rahma010@gmail.com \\ Eng. Zahir Abdelhameed Adam \\ Dar AL Riyadh Consultant-Riyadh- Saudi Arabia \\ Email: zahir.awad@gmail.com
}

\begin{abstract}
This paper examines the experience of rehabilitating of mud heritage buildings in (AlDaho Quarter) which is located within the (Qasr Al-Hukm) area in the center of Riyadh, Saudi Arabia, and re-use them. The project of (Al-Daho Quarter) aimed at preserving the Quarter's heritage mud buildings, in addition to preserve the historic fabric and providing opportunities for a distinctive historical, cultural, life experience by visiting the Quarter and enjoying the heritage atmosphere that it evident in the old city wall. This in addition to improve access to various nearby attractive markets and historical sites. The project undertook a complete renewal of the Quarter, while preserving its identity and its architectural features, and established new infrastructure at a high level of standards. Traditional materials of clay and wood were used in rehabilitation and restoration works, and traditional building methods with its inherited techniques were also used to revive the old building industry. The heritage buildings were rehabilitated and functionally prepared to be used as tourist lodges or residences, while providing all these buildings with basic services and surrounding them with essential facilities such as restaurants, markets, cafes, and parking lots. With the completion of the project works in $2020 \mathrm{AD}$, this project was a valuable addition to the cultural heritage preservation projects in the city of Riyadh, and a living model of developing and rehabilitating historic and traditional quarters in cities.
\end{abstract}

Keywords: cultural heritage, preservation, rehabilitation, Daho Quarter. 


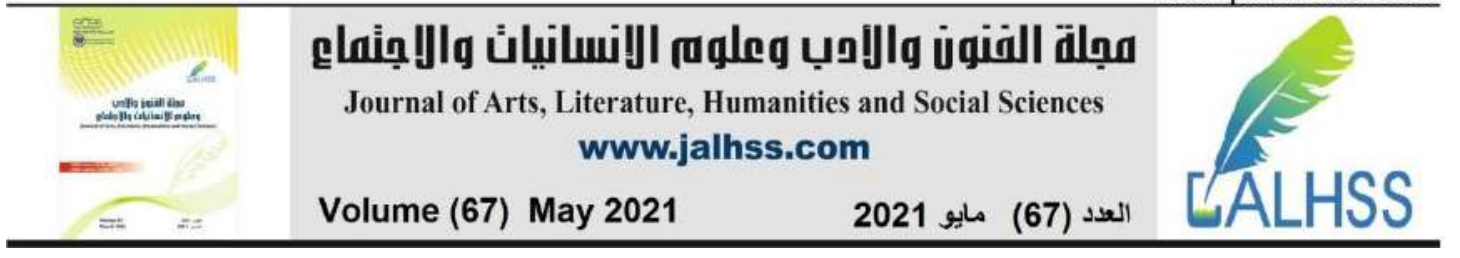

تزايدت الدعوات في النصف الثاني من القرن العشرين الى الاهتمام بحفظ و إعادة توظيف المباني التراثية

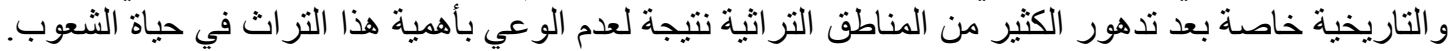

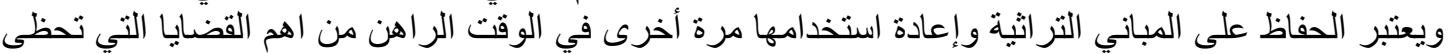

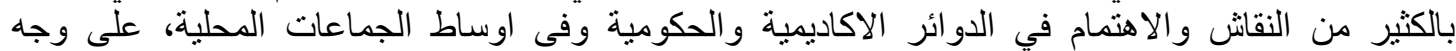

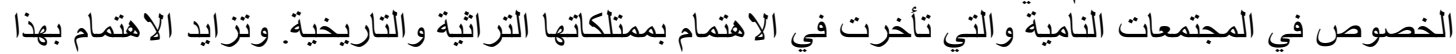

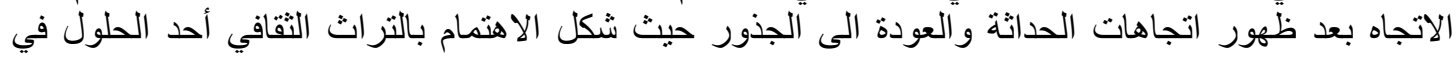
مواجهة تبار العولمة المتزايد لما بلعبه التزاث الثقافي عموما من دور في التعريف بهوية المجتمعات التاتي

\section{المبحث الأول}

قدم هذا المبحث تعريفا لبعض المصطلحات الواردة في الدراسة كما قدم تعريفا لمفهوم الحفاظ ومستوياته

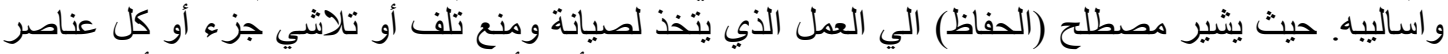

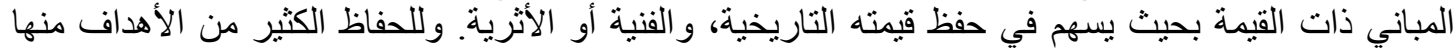

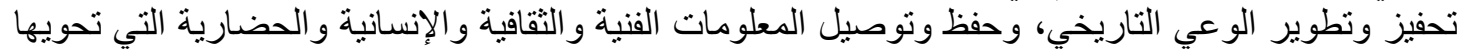

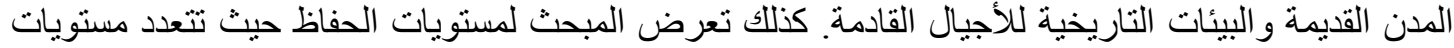

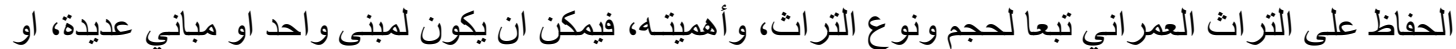

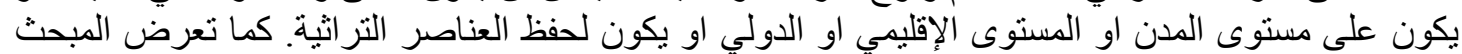

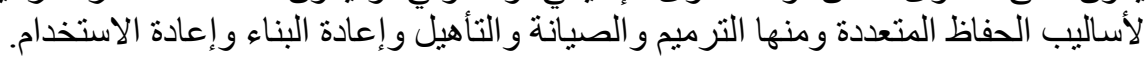

\section{المبحث الثاني}

تعرض هذا المبحث لخلفية تاريخية عن حي (الاحو) وموقعه واهميته التاريخية وطر ازه المعماري (الطراز

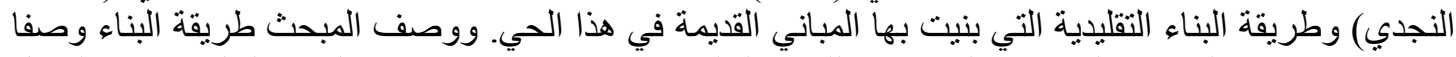

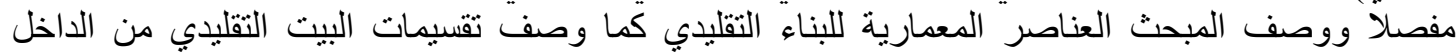

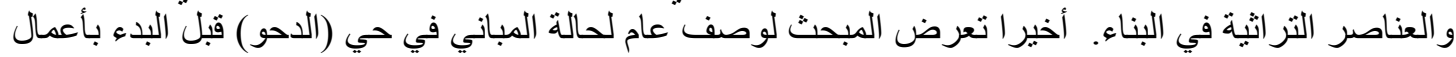

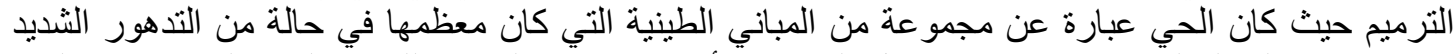

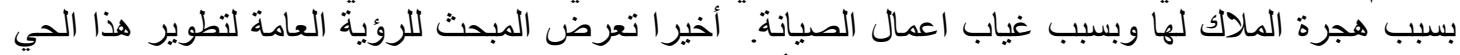

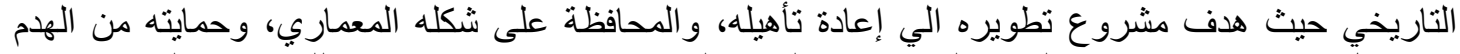

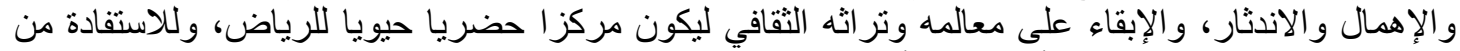

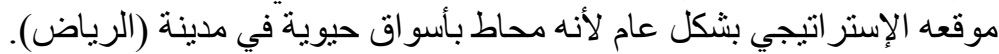

المبحث الثالث

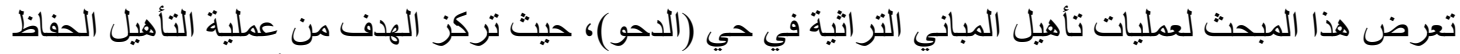

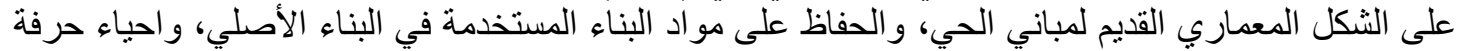

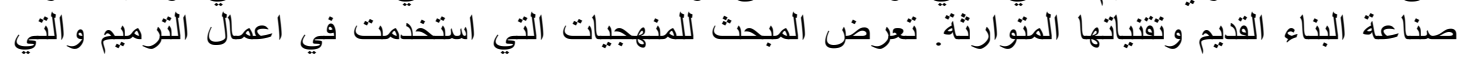

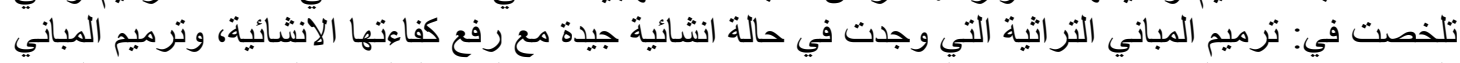

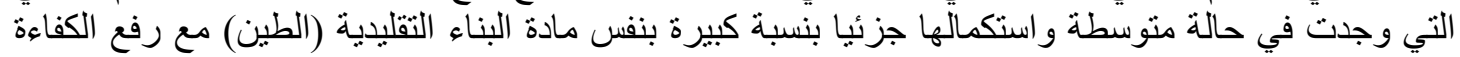

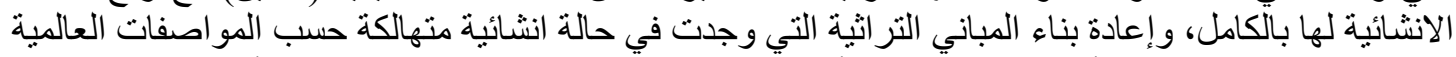

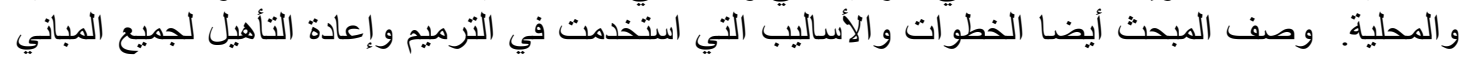
و العناصر التراثية بها. 


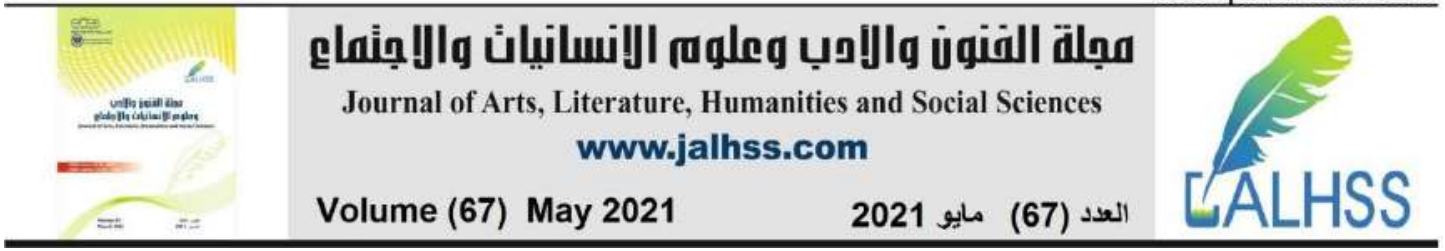

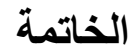

انتهت الورقة الى ان العمل في مشروع تطوير حي (الدحو) حقق رؤية متكاملة ركزت على ترميج المقاد المباني

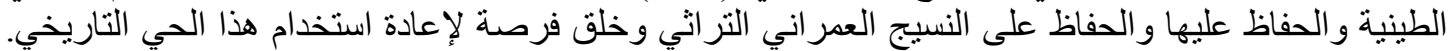

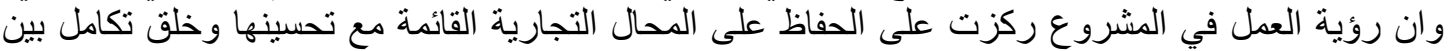

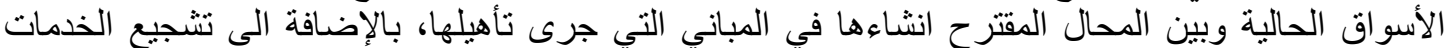

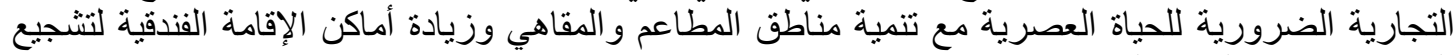
السياحة وتحقيق التنمية المستدامة.

النتائج

خلصت الورقة الى ان مشروع تطوير حي (الدحو) حقق القدر الأكبر من الحفاظ على الموروث الثقاف الثقافي للحي

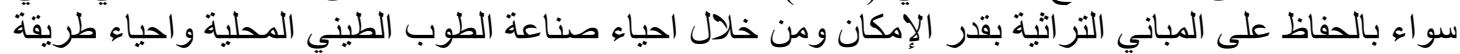

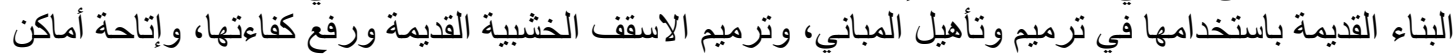

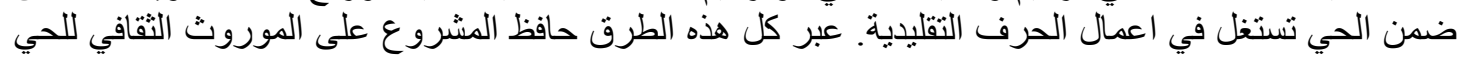

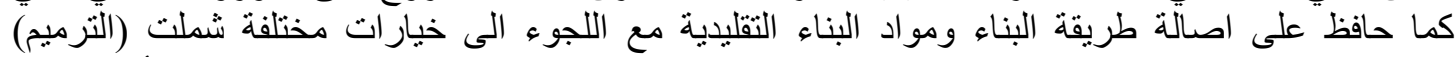

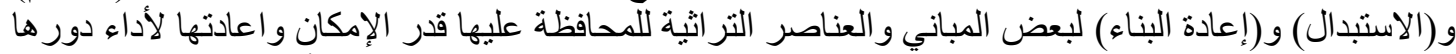

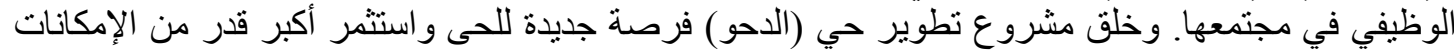

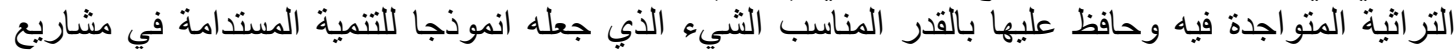

اوصت الورقة بعدد من التوصيات التي تشجع على نقل هذه التجربة المميزة في الحفاظ على التراث التئ الى مناطق

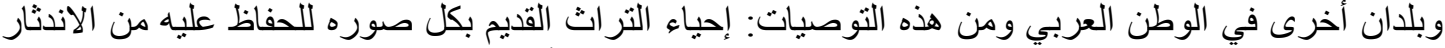

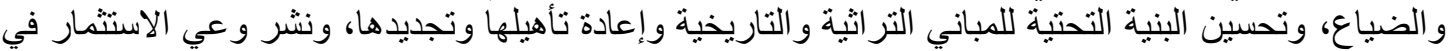

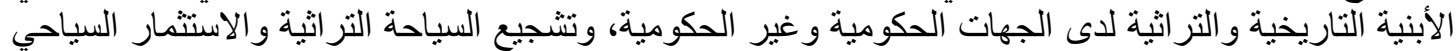

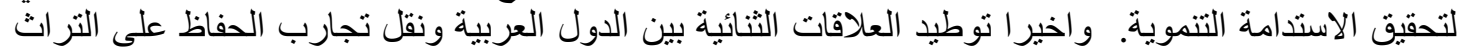

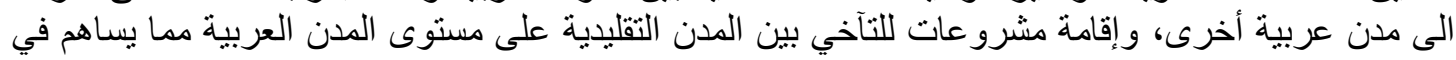

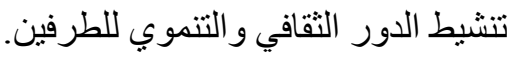

\section{تعريف المصطلحات: ت}

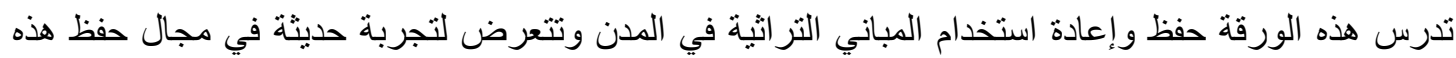

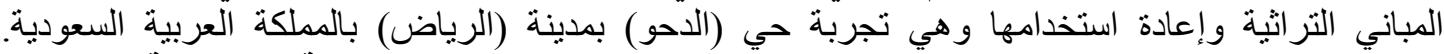

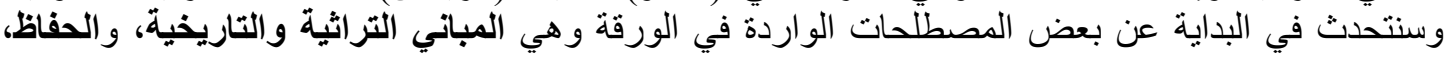

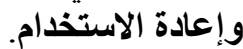

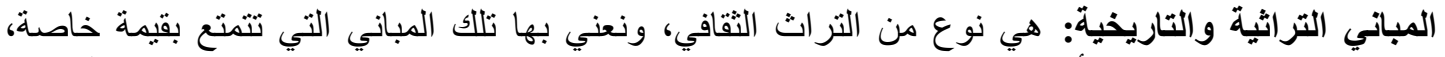

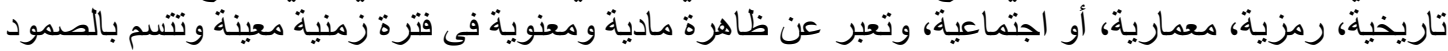

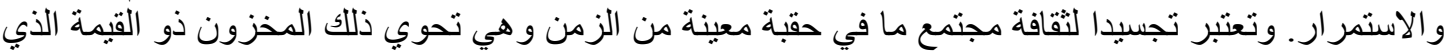

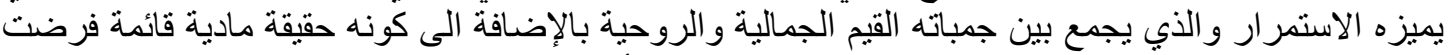

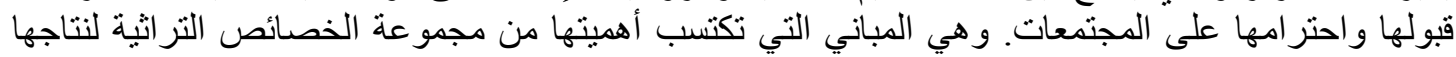

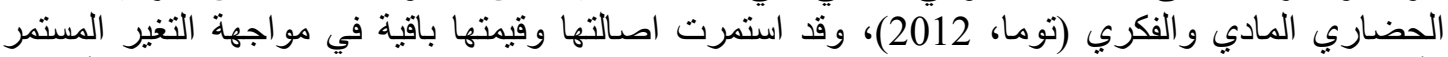

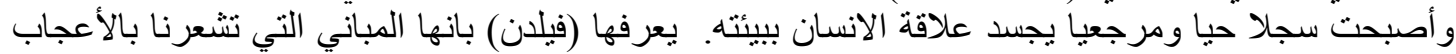

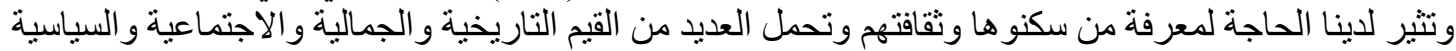
و الاقتصادية (فيلدن، 1982، 1). وتتعرض هذه المباني التراثية بمرور الزمن وبشكل مستمر لمهددات وأخطار 


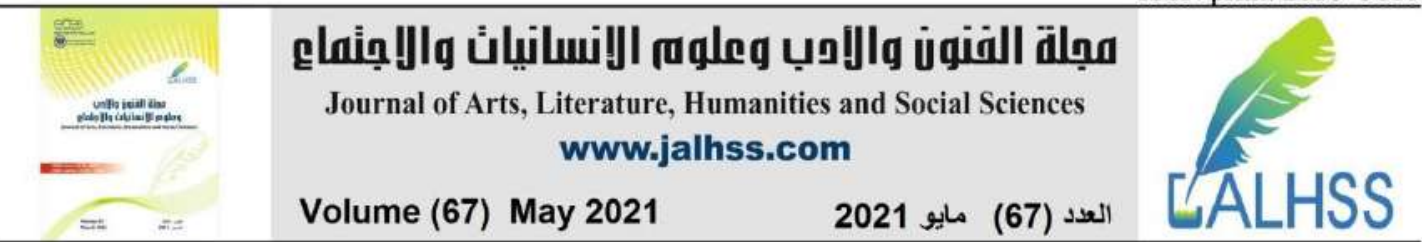

طبيعية وبشرية عديدة تؤدي إلى تدهور ها، أو ضياعها وهي في حاجة دائمة إلى اتخاذ كافة التدابير التي تكفل حمايتها، و الحفاظ عليها.

الحفاظ: يشير الحفاظ الى العمل الذي يتخذ لصبانة ومنع تلف أو تلاشي جزء أو كل عناصر المباني ذات القيمة

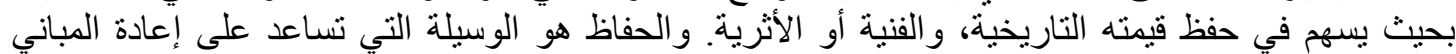

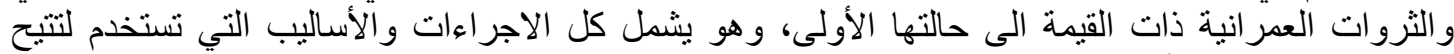

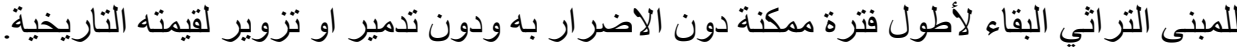

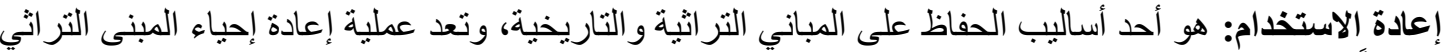

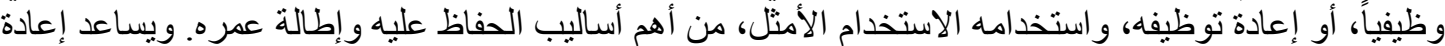

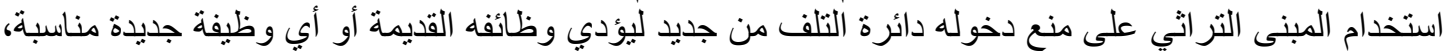
اذ لا يكفي ترميم المباني الاثرية لحفظها وانما إعادة استخدامها لتؤدي دور التئ هاما في محيطها ومجتمعها.

\section{مفهوم الحفاظ وأهدافه ومستوياته واساليبه:}

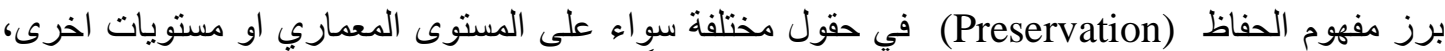

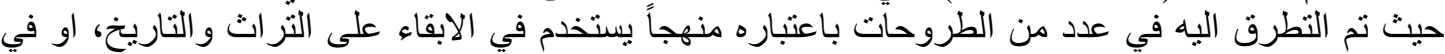

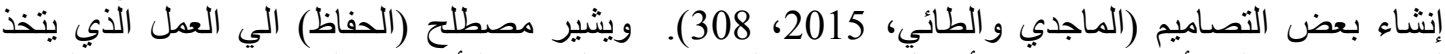

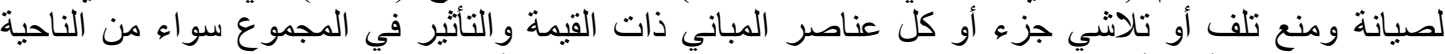

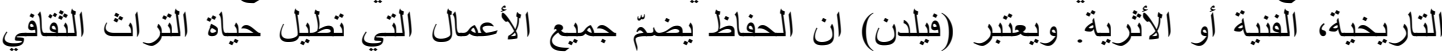

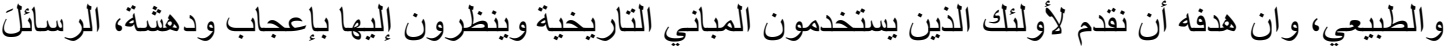

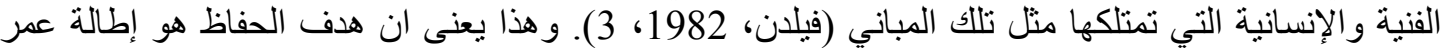

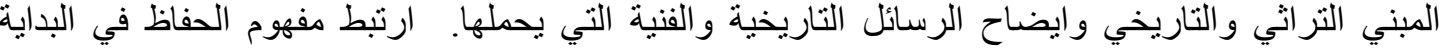

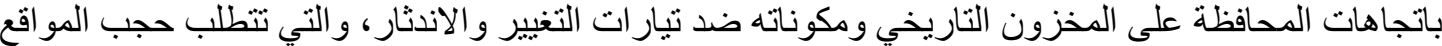

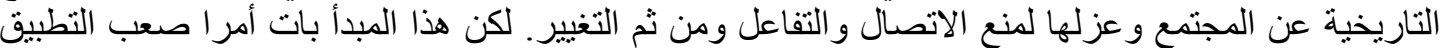

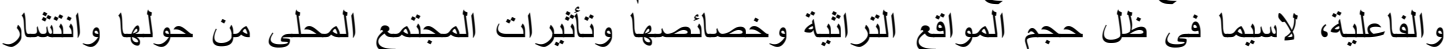

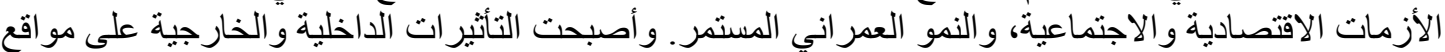

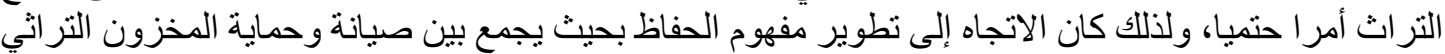

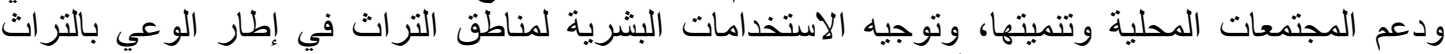

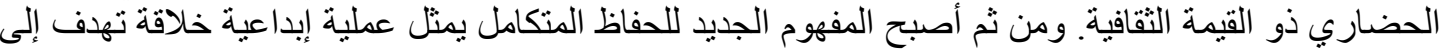

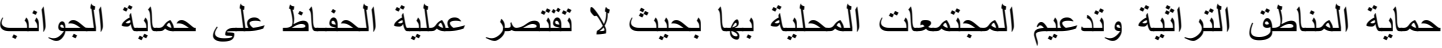

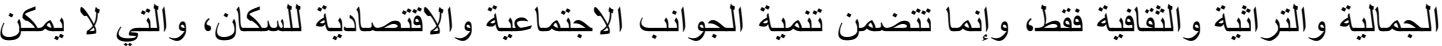

$$
\text { إهمالها (الماجدي و الطائي، 2015، 310). }
$$

و الحفاظ عملية متداخلة تضم العديد من التخصصات وتضم فريقا من المتخصصين من معماريين و أثريين

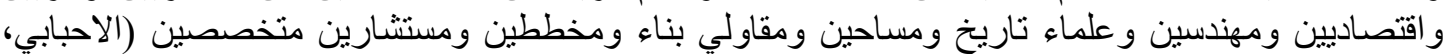

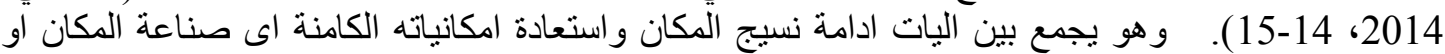

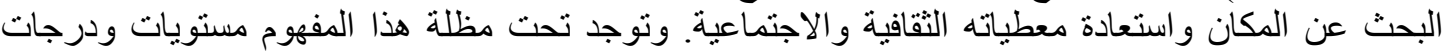

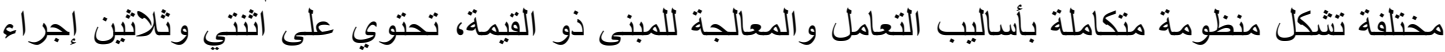

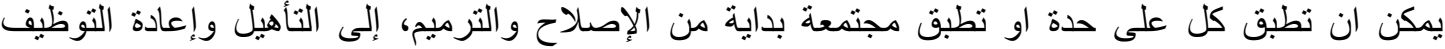

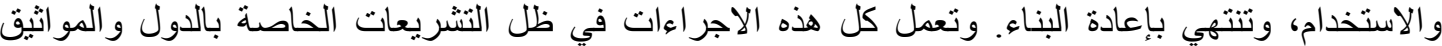

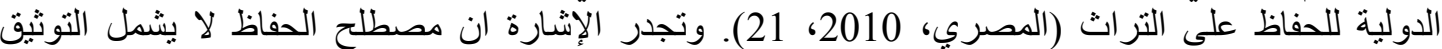

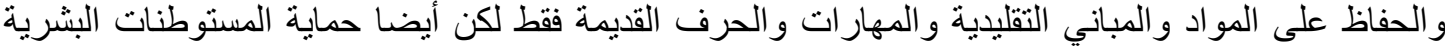

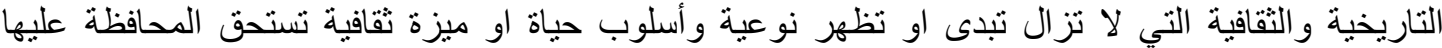

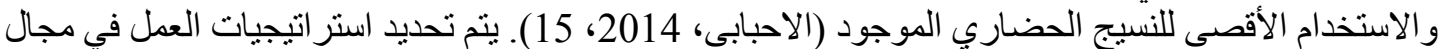

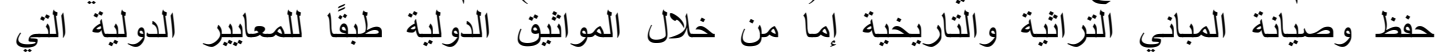




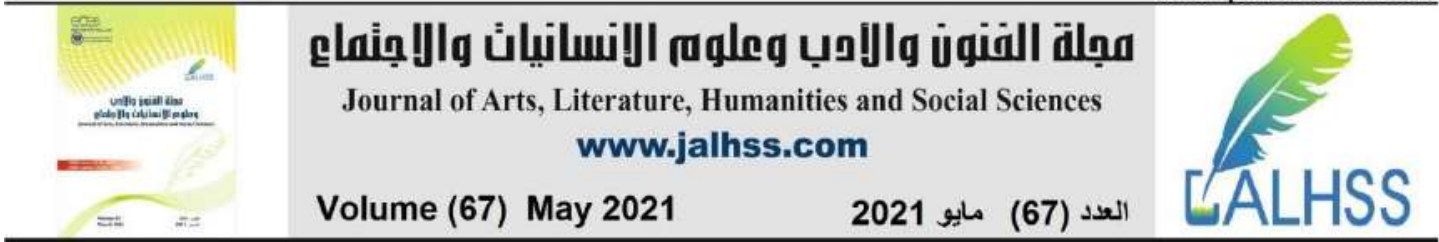

وضعتها(اليونسكو) أو من خلال إصدارات المجلس الدولي للمعالم والمواقع (ICOMOS) أو الاتفاقات

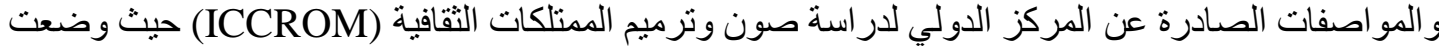
التعاريف القياسية لأساليب الحفاظ على الممتلكات الثقافية (زريق، 2006).

ويهدف الحفاظ على المباني التراثية الى تحقيق التفاعل الإيجابي مع البيئة الحضرية المحيطة إضافة الى تعزيز

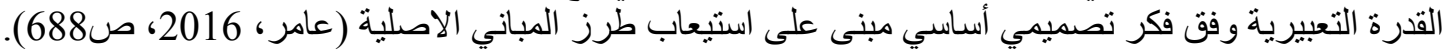

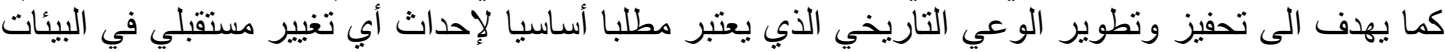

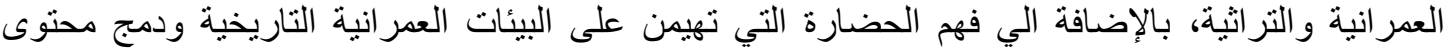

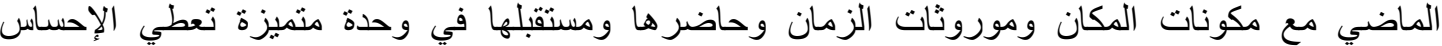

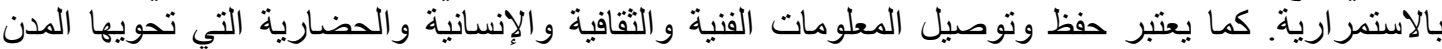

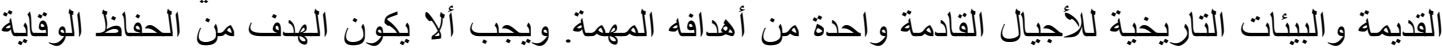

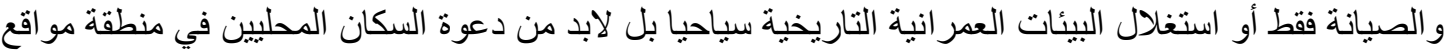

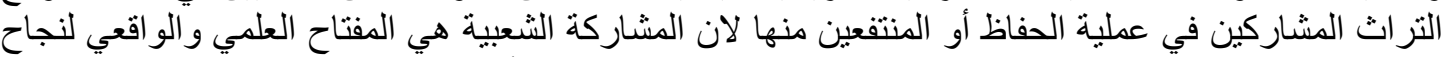

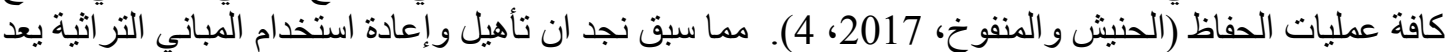

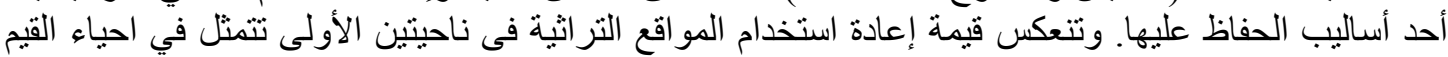

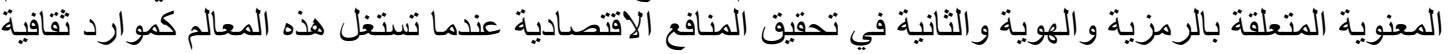

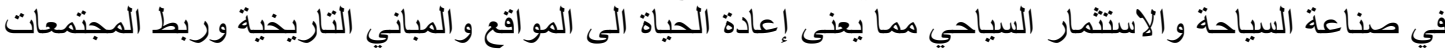

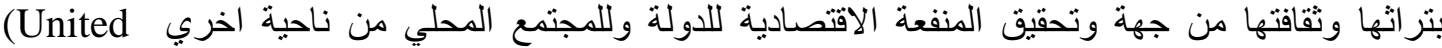
.Nation Program, 1997)

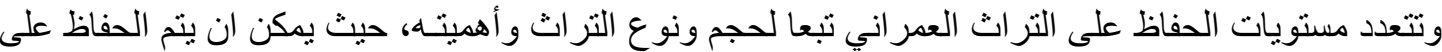

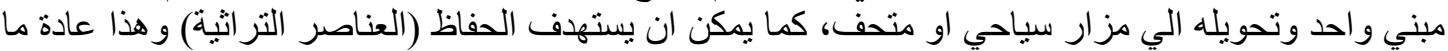

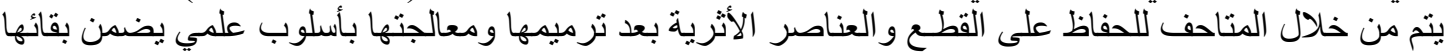

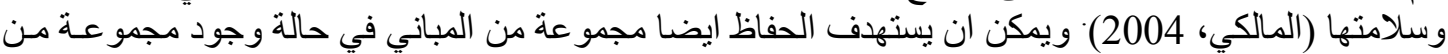

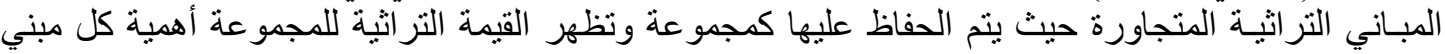

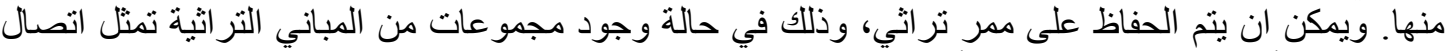

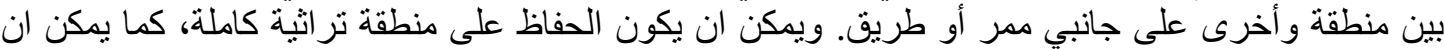

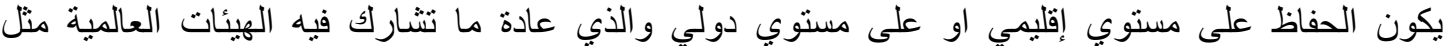

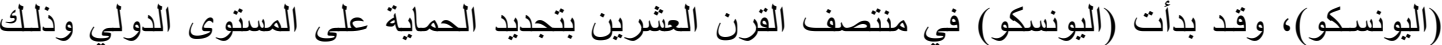

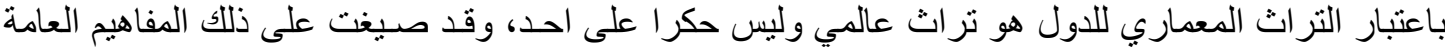

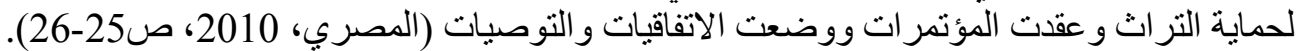

\section{أساليب الحفاظ على المباني التاريخية والتراثية:}

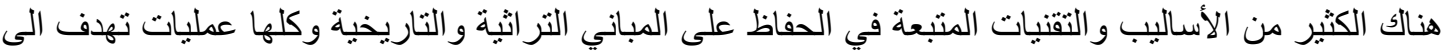

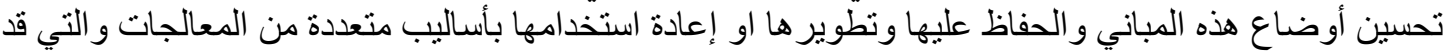

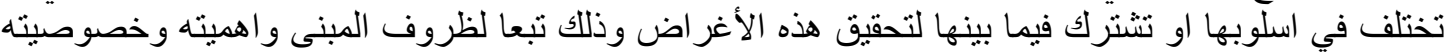
التاريخية والتر اثية ومن أبرز هذه الاساليب:

\section{(1) (1) (Restoration) (الترميم: (2)}

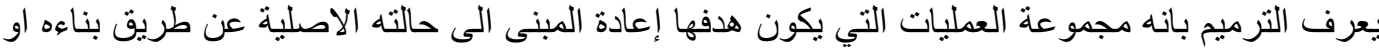

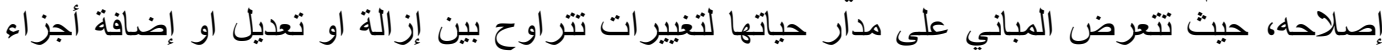

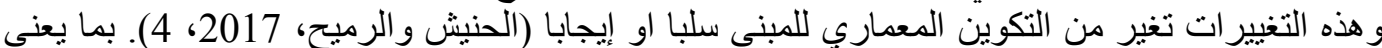

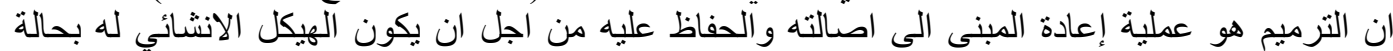

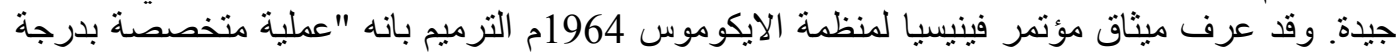

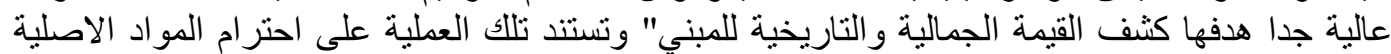




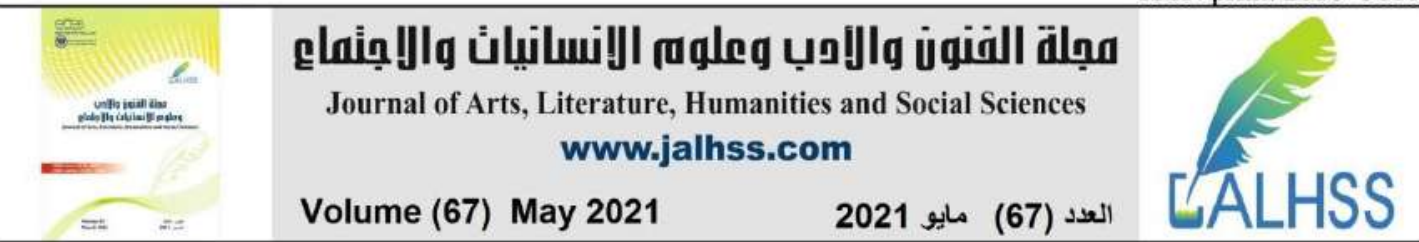

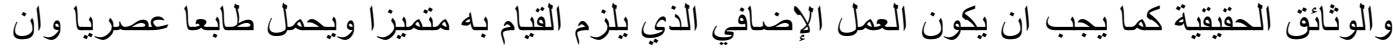

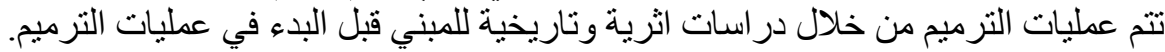

(2) الصيانة: (Maintenance)

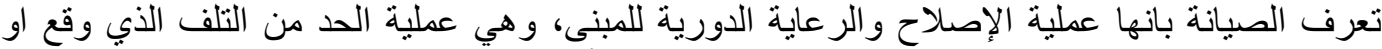

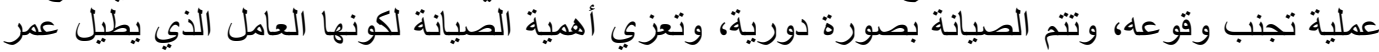

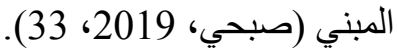

(3) (3) إعادة البناء: (Reconstruction)

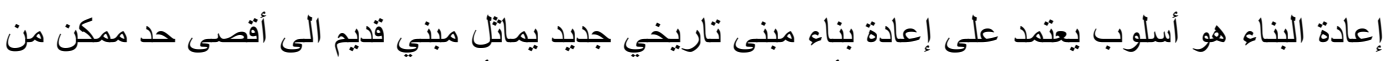

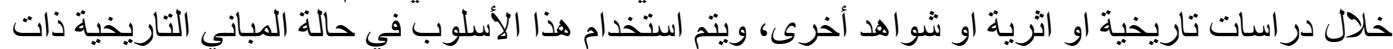

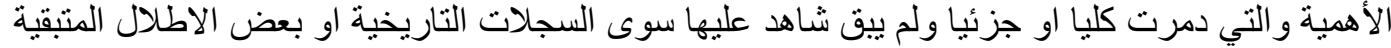

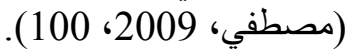

(4) التأهيل: (Rehabilitation):

يقصد بالتأهيل وضع جملة من المحددات لإعادة المبنى بصورته الحالية لأداء وظائفه القديمة أو أي وظيفة

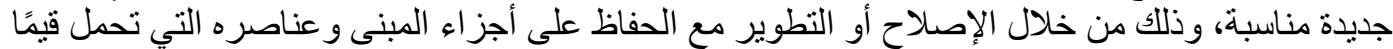

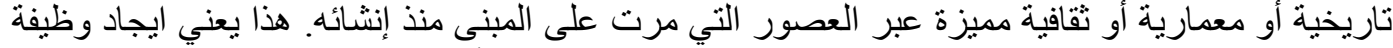

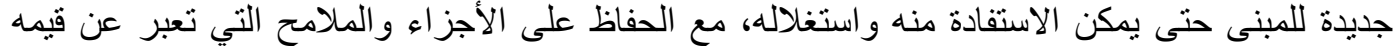

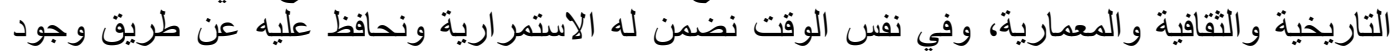

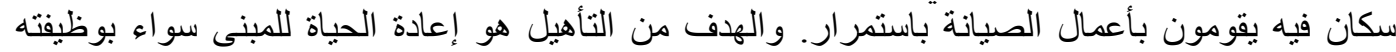

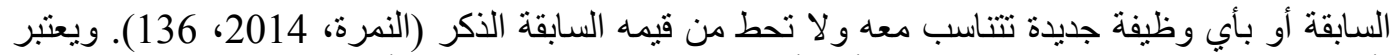

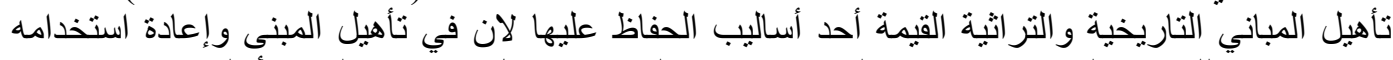

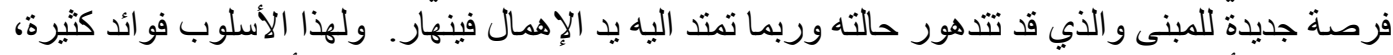

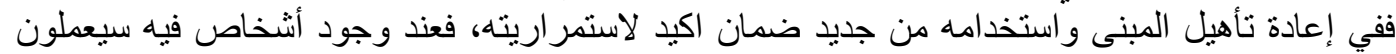

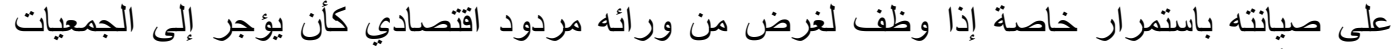
الثقافية، أو يستخدم كنزل او متحف او ائ شكل اخر من الاستخدامات.

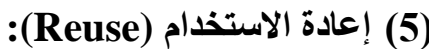

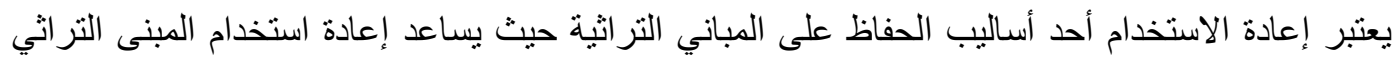

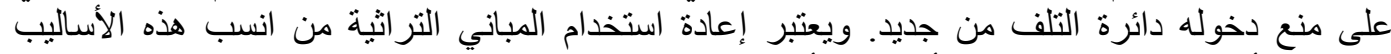

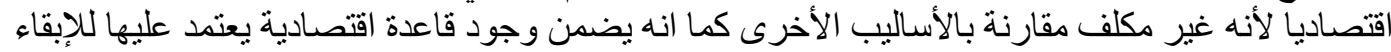

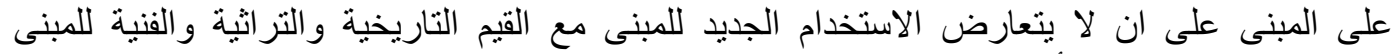

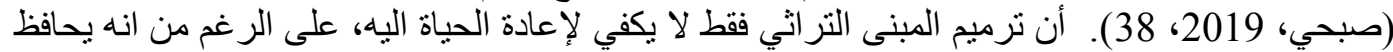

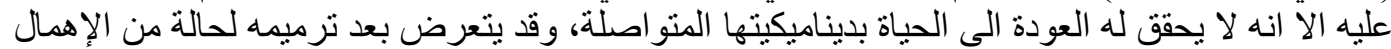

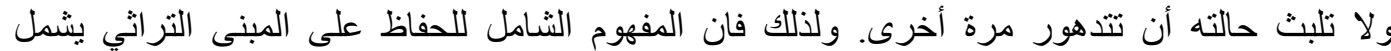

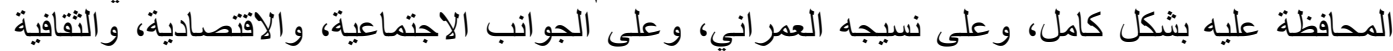

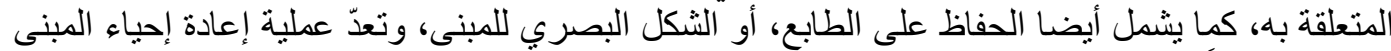

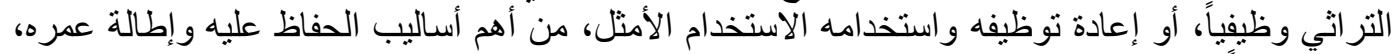

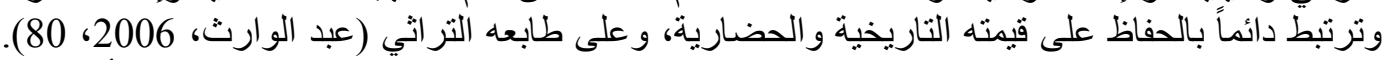

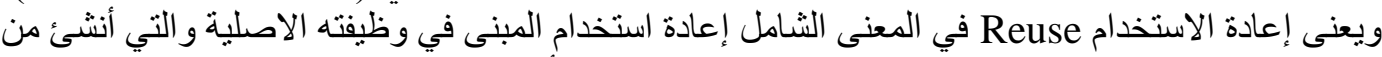

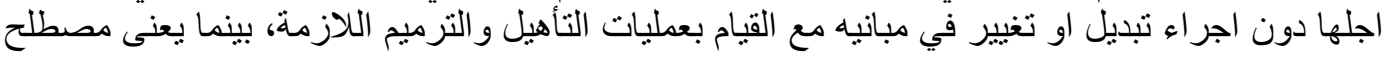




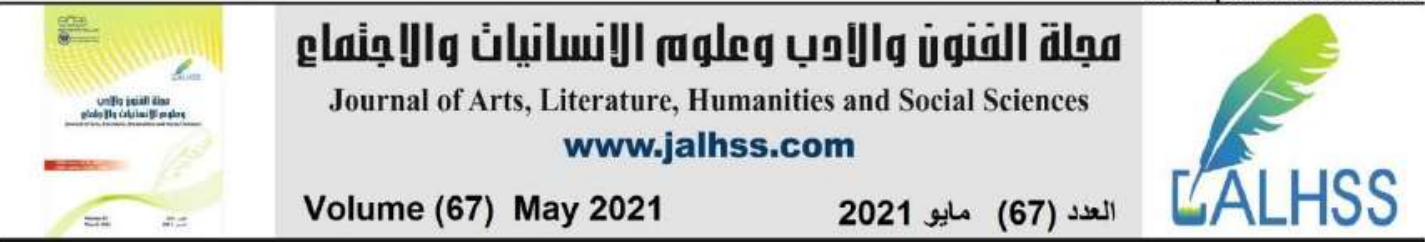

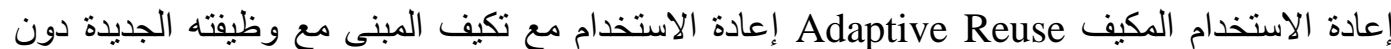

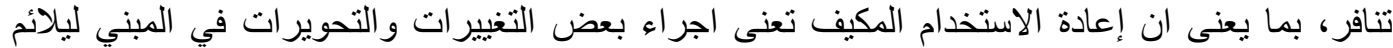

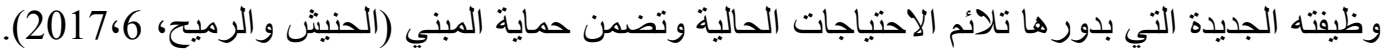

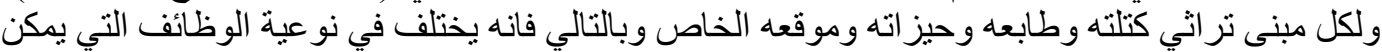

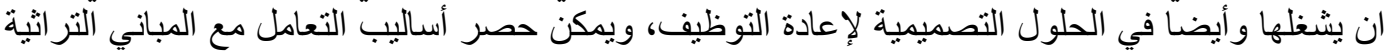

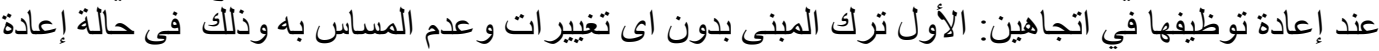

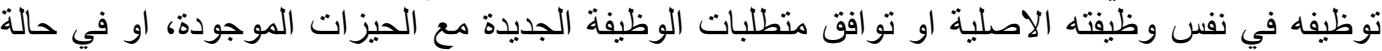

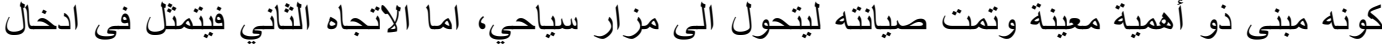

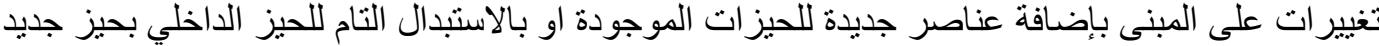

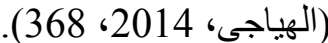

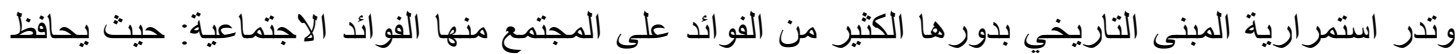

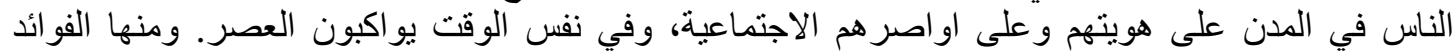

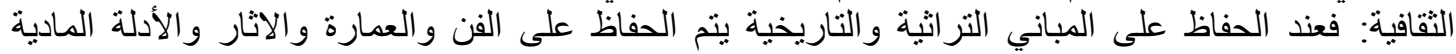

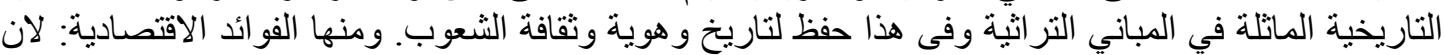

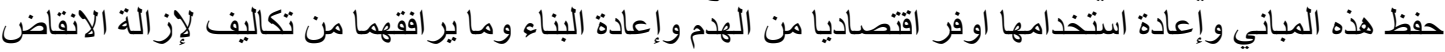

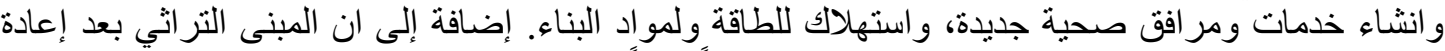

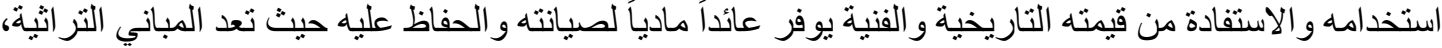

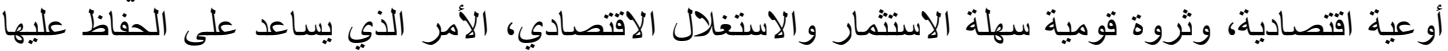

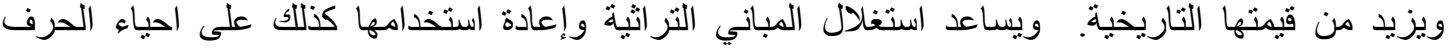

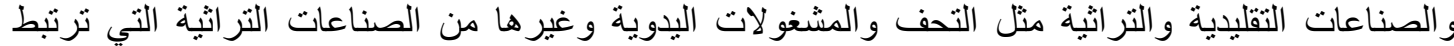

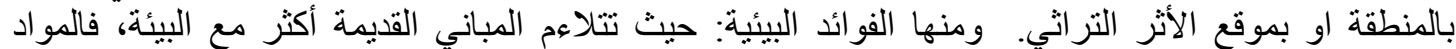

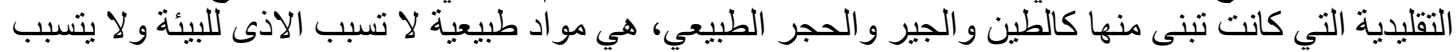

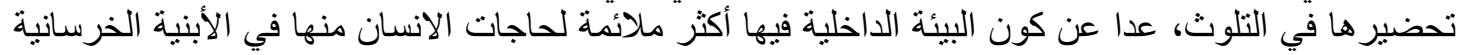

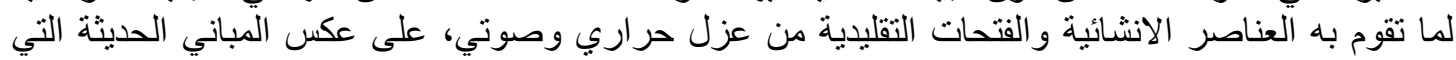

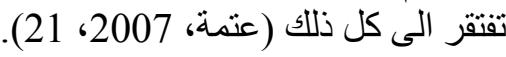

\section{مراحل إعادة تأهيل المباني التاريخية والتراثية:}

تمر عملية إعادة تأهيل المباني التاريخية و التراثية بعدة مر احل رئيسية بدءا بالدر اسة وجمع المعلومات و انتهاء بوضع المخططات و التنفيذ ويمكن تلخيص هذه المر احل كما يلي:

جمع المعلومات والوثائق التاريخية والمعمارية عن المبنى: تجمع هذه المعلومات من كتب

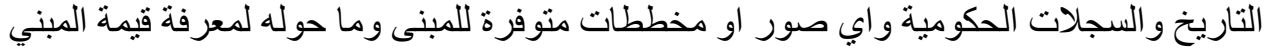

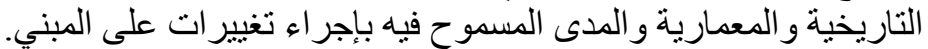

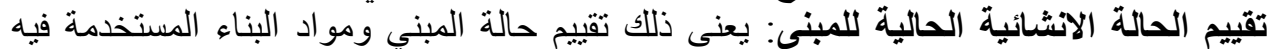
ومدى التلف في عناصره مع وصف دقيق لنقاط الضعف في مواد البناء من شقوق تصدعات

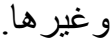

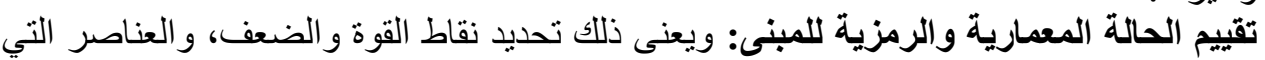

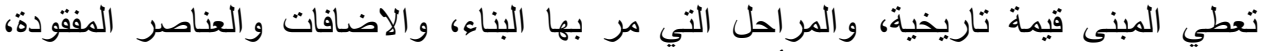

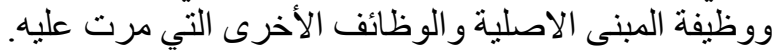

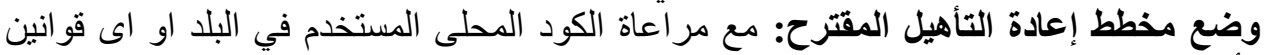

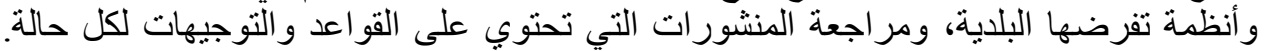

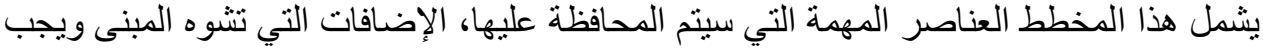

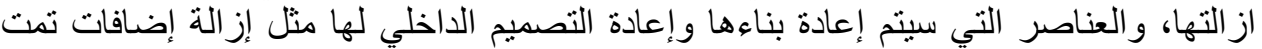




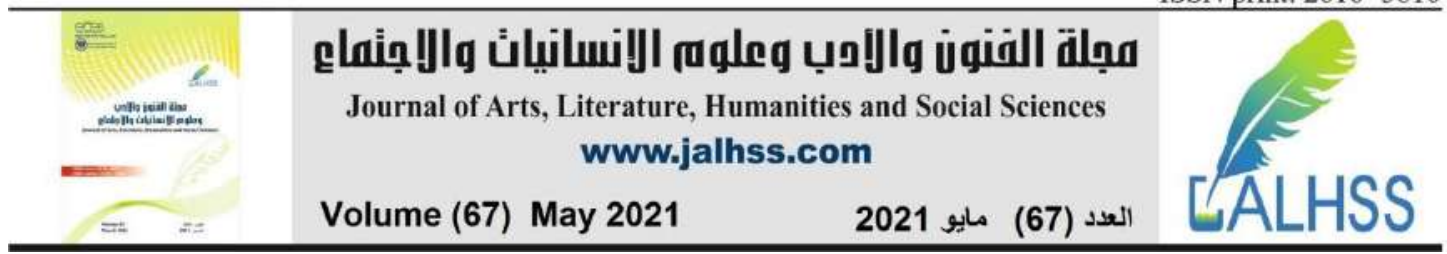

اضافتها في أوقات سابقة، او إعادة عناصر تمت ازالتها في أوقات سابقة، وتوفير الفراغات

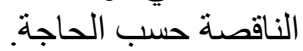

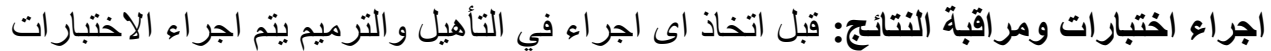

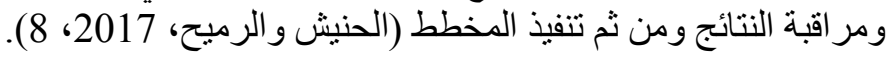

وتتوقف درجة التدخل المطلوب في أي مبنى تراثي او تاريخي والطرق المستخدمة في ذلك على العديد من ونان

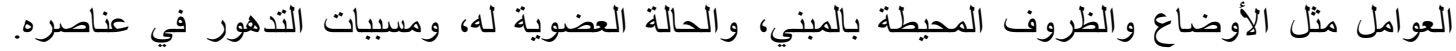

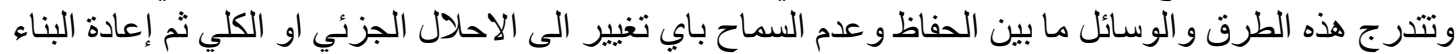

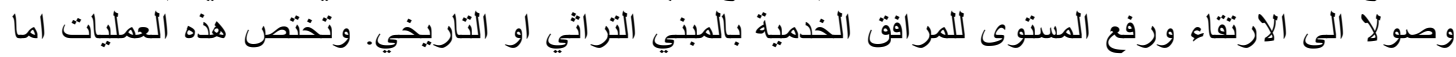

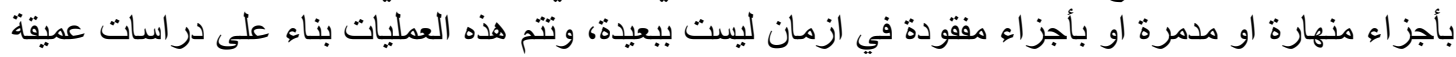

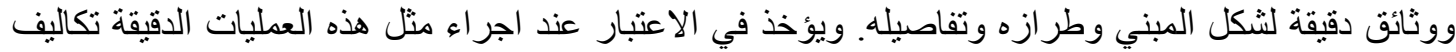

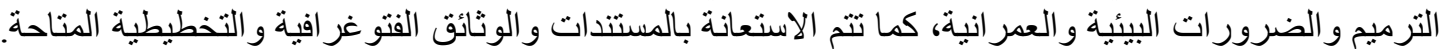

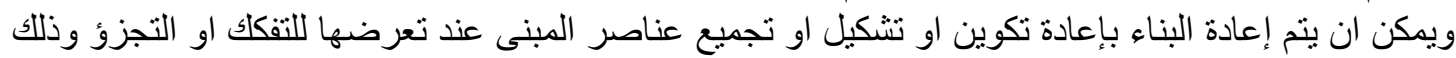
باستخدام عناصر المبني القديم دون إضافة جديدة الا في اضيق الحدود (مصطفي، 2009، 104-105).

\section{حي (الاحو): الموقع والطراز المعماري:}

يقع حي (الدحو) في الجهة الجنوبية من وسط مدينة الرياض القديمة، ضمن منطقة (قصر الحكم) في المنطقة

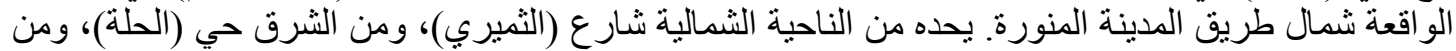

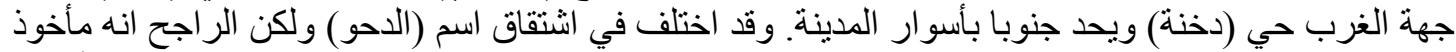

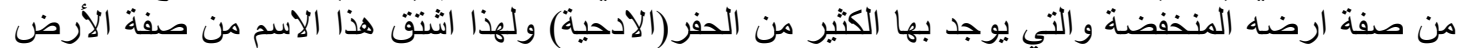

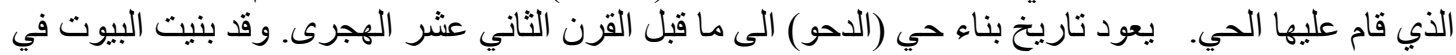

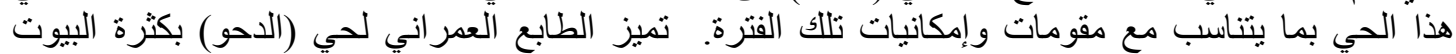

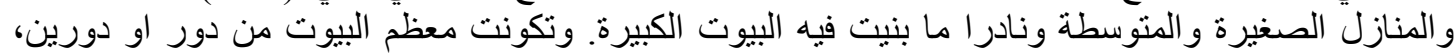

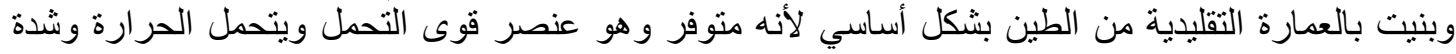

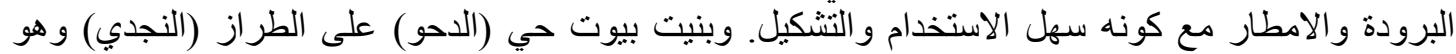

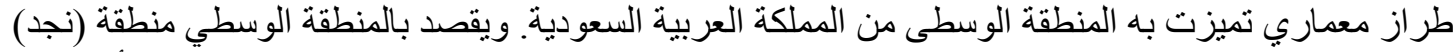

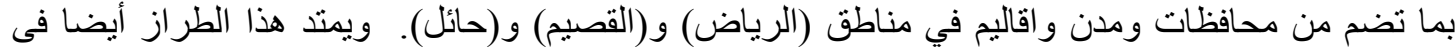

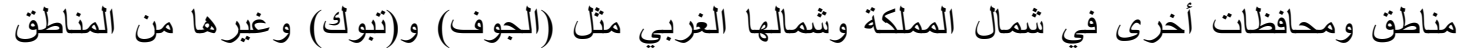

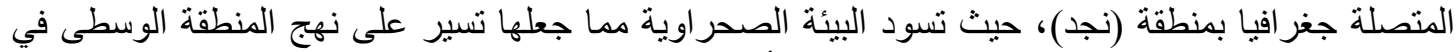

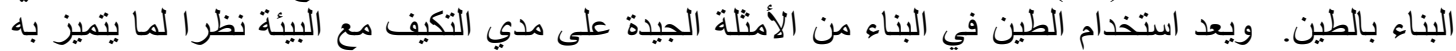

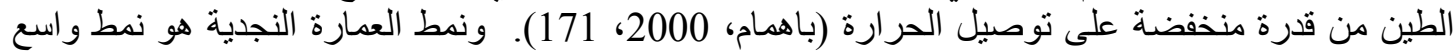

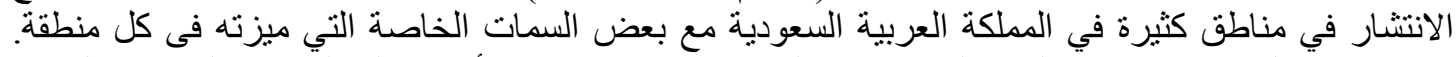

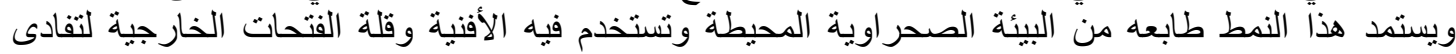

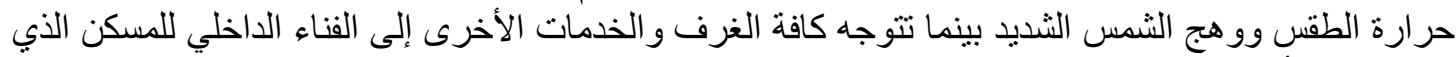

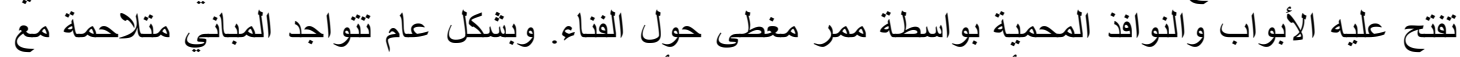

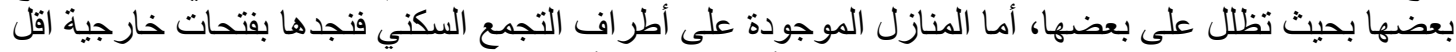

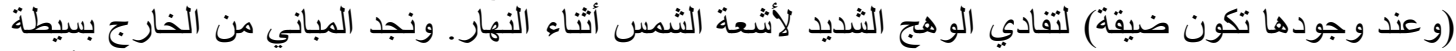

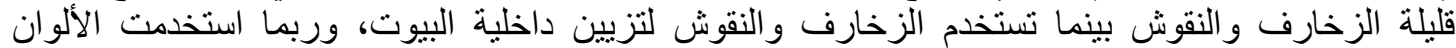

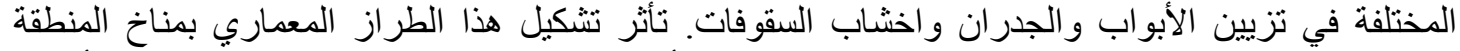

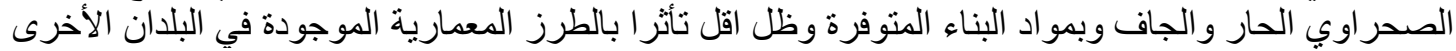

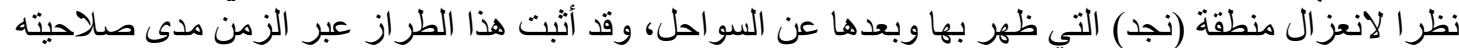

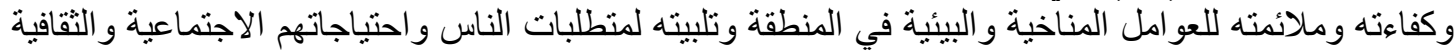




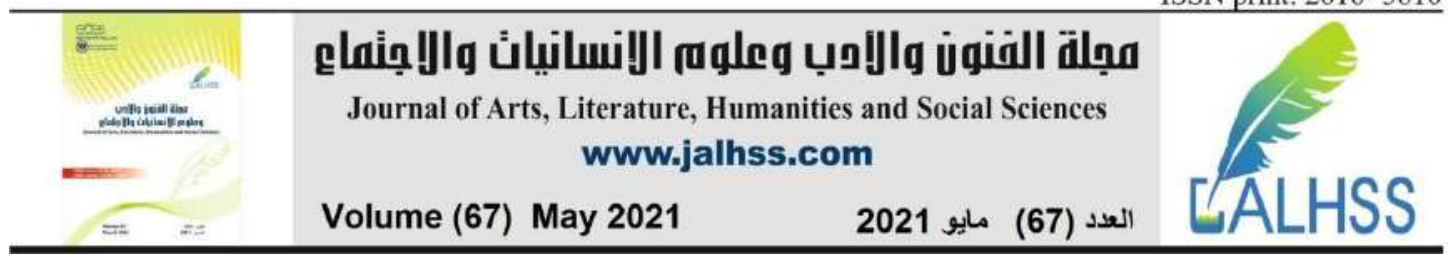

\section{طريقة البناء القديمة في حي (الاحو): العناصر المعمارية والتراثية:}

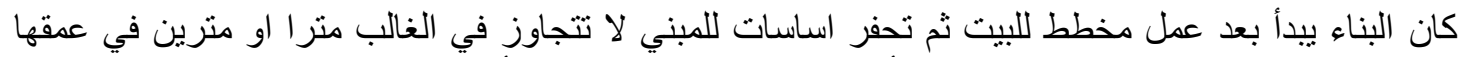

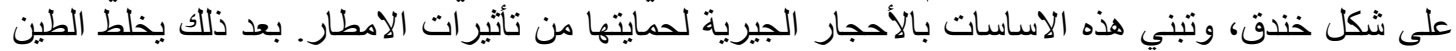

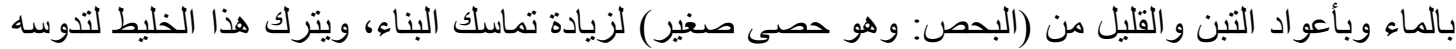

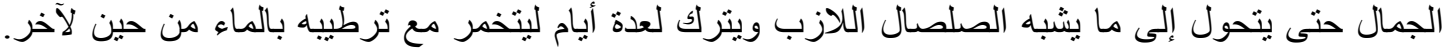

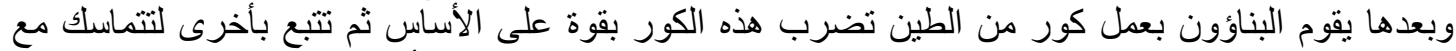

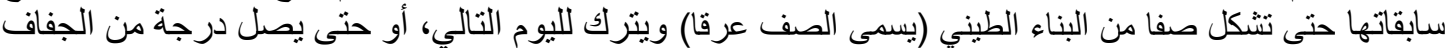

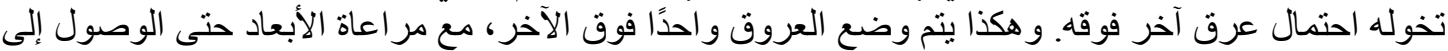

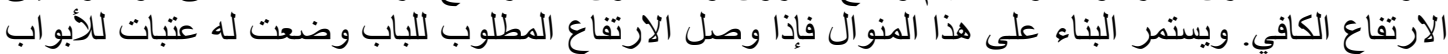

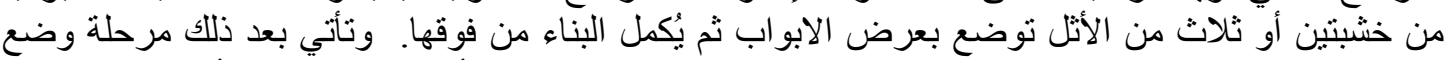

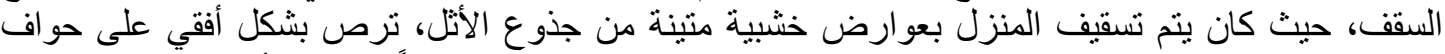

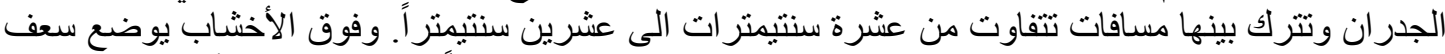

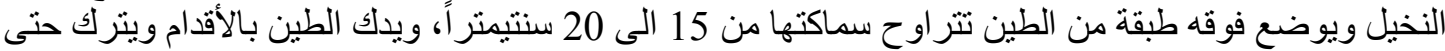

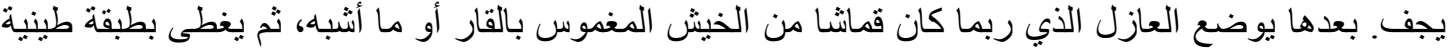

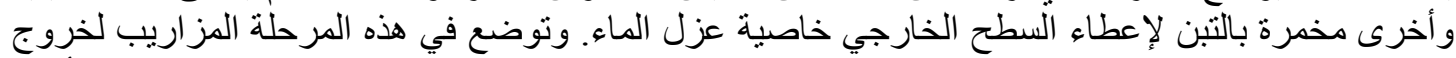

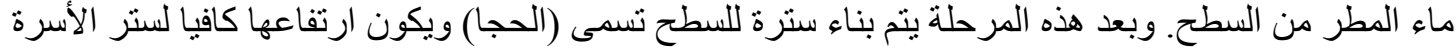

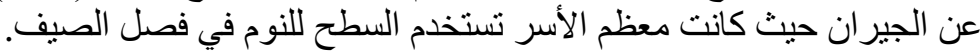

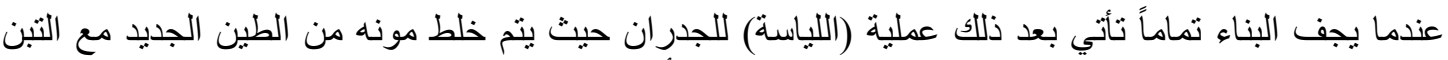

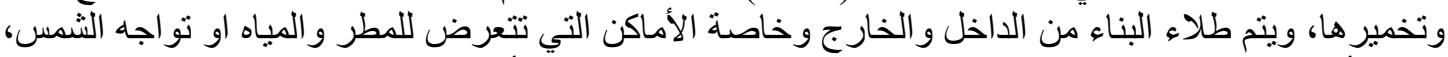

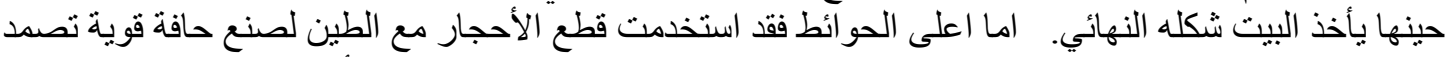
لظروف البيئة الخارجية من شمس ورياح وامطار والئه واستخدمت اخشاب الاتل في الأعمال الهيكلية في السقوف

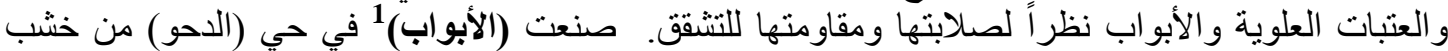

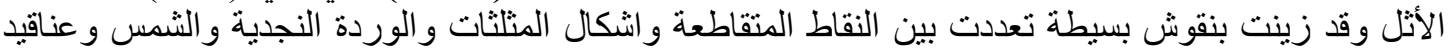

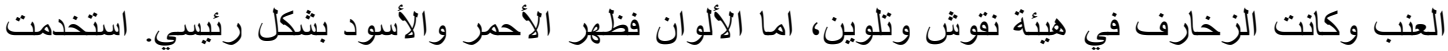

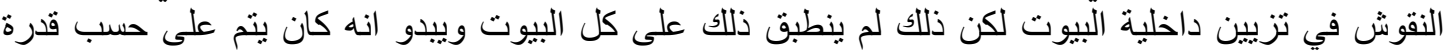

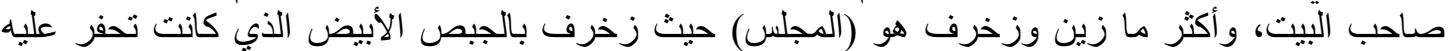

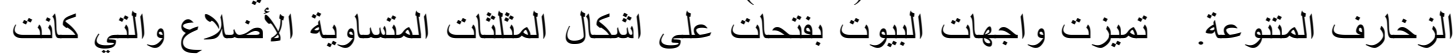

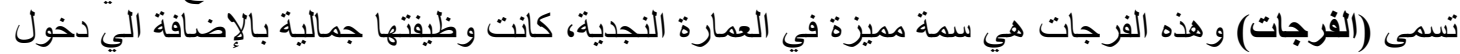

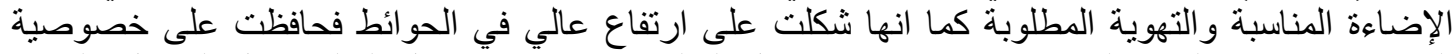

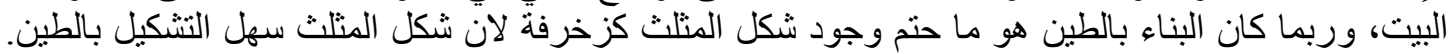

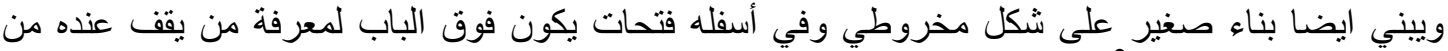

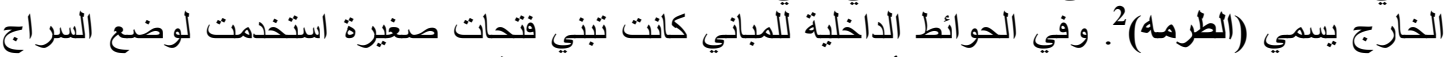

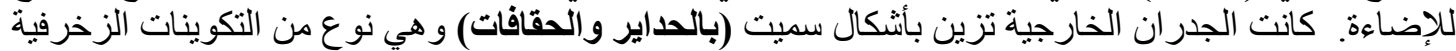

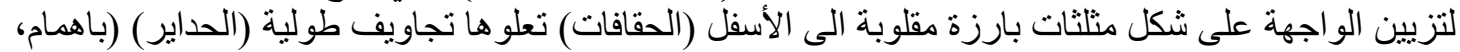

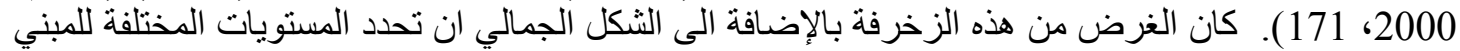

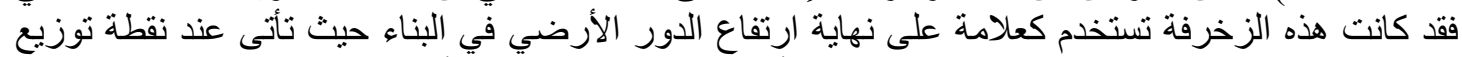

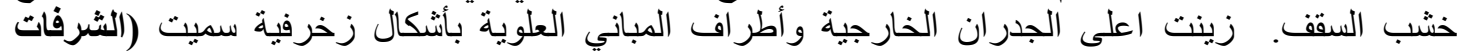

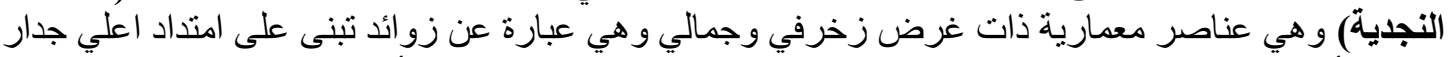

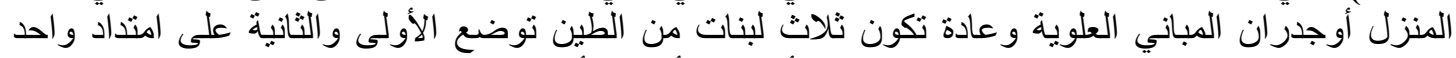

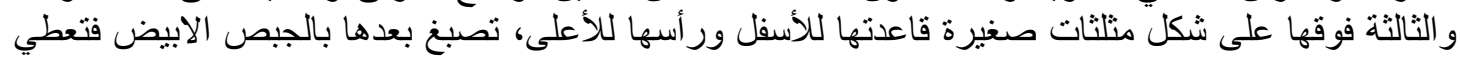

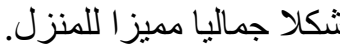




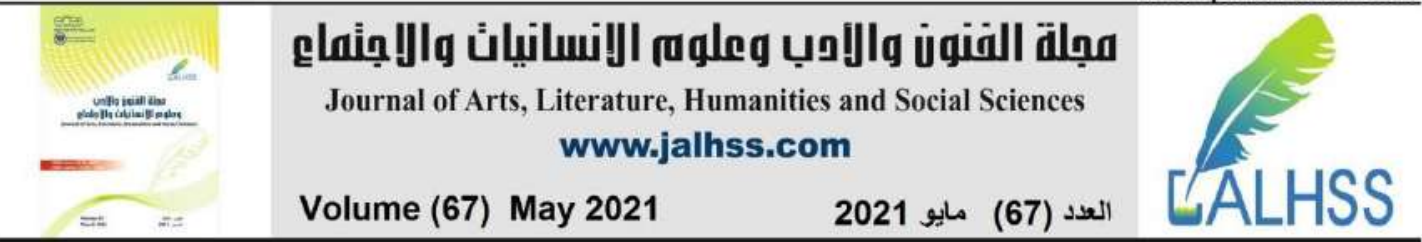

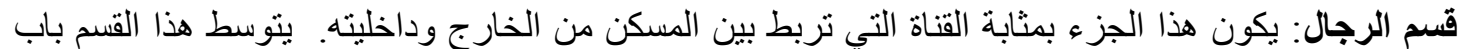

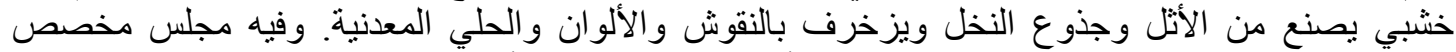

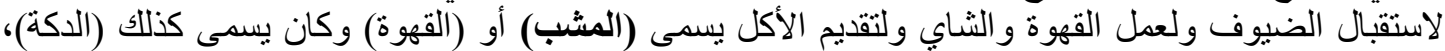

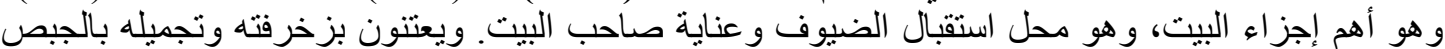

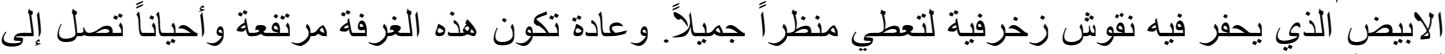

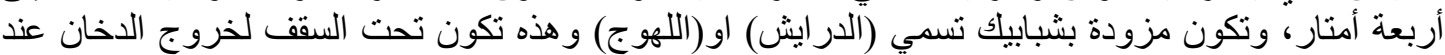

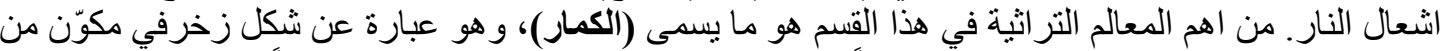

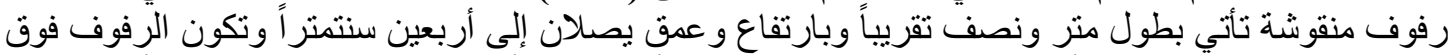

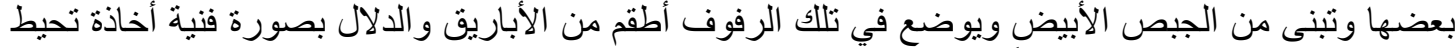

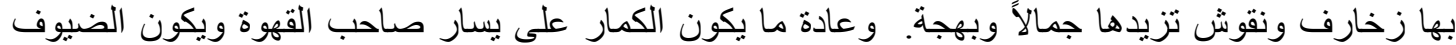

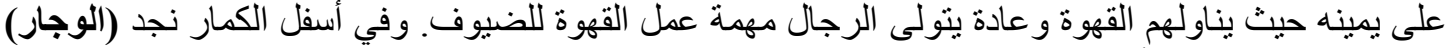

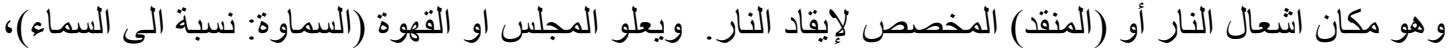

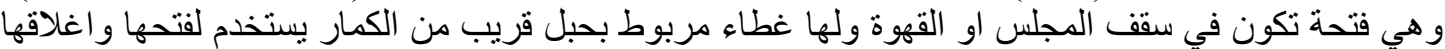

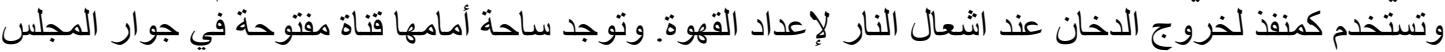

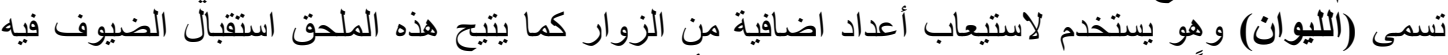

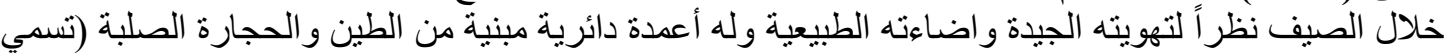

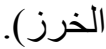

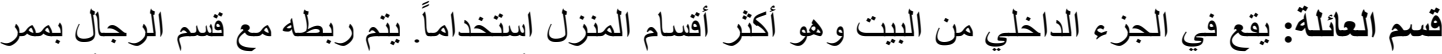

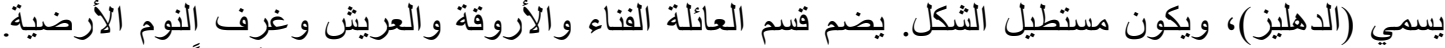

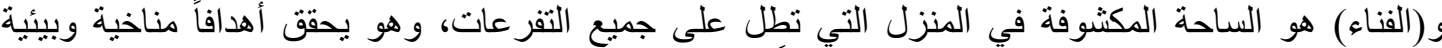

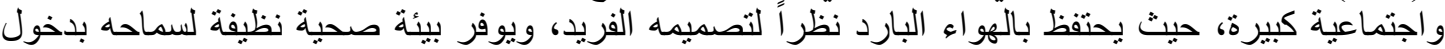

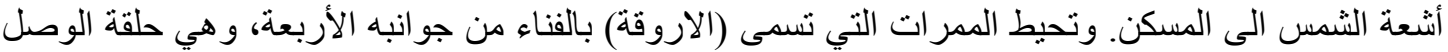

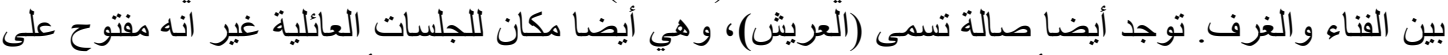

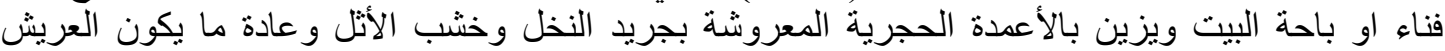

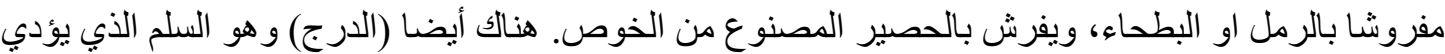

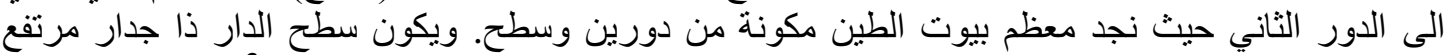

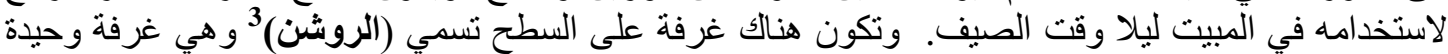

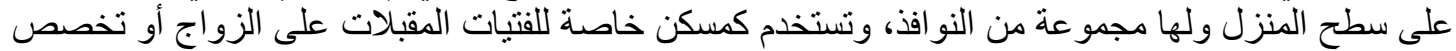

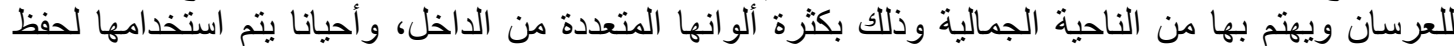
الحبوب أو مفارش النوم، ويوظف فيها البناء بوضع الأوتاد للتعليق و التجويفات و الفو التهن وغ للتخزين. قسم مخصص للخدمات: ويشتمل على مكان طهي الطعام وإعداده ويسمى (الموقد) و غرف التخزين، وتحتوي بعض المنازل على آبار وحظائر للحيو انتات

\section{الوضع العام لحى (الاحو) قبل البدء بأعمال التأهيلج}

يعد حي (الدحو) أحد أهم أحياء مدينة الرياض القديمة لما له من أهمية تاريخية و عمر انية، كونه الأقدم تاريخياً

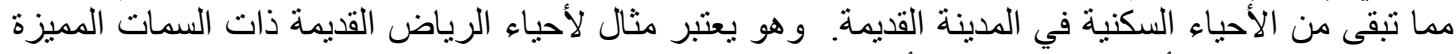

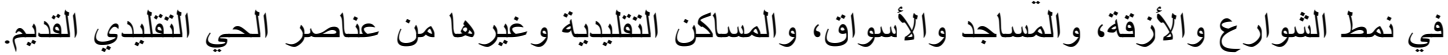

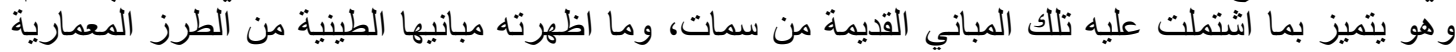

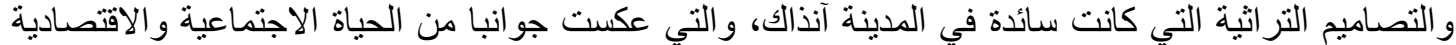

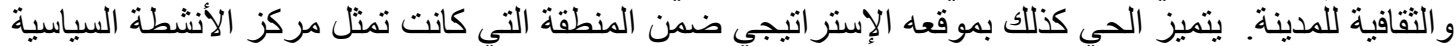

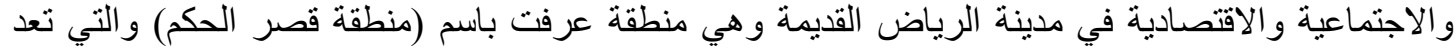
بمثابة النواة التي انطلقت منها مدينة الرياض. 


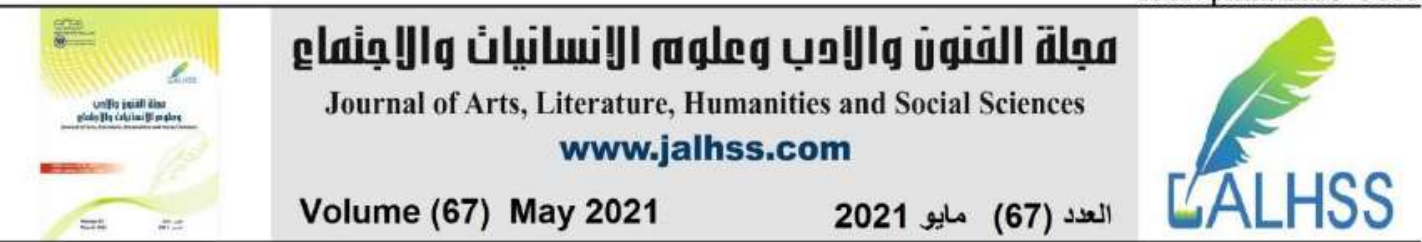

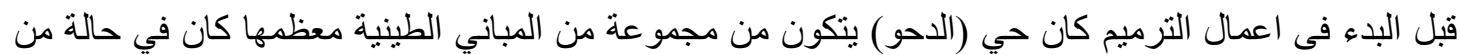

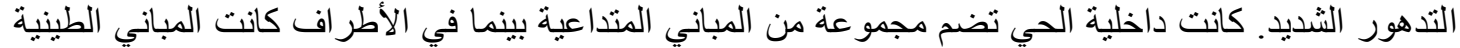

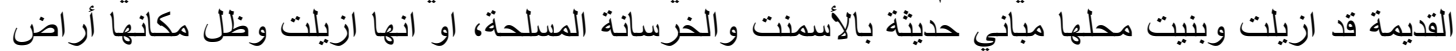

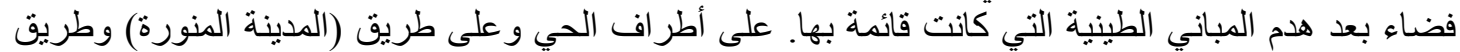

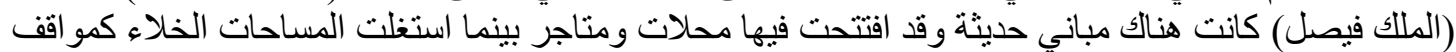

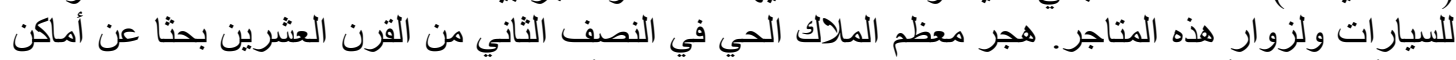

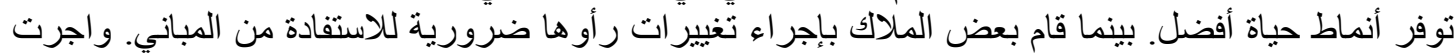

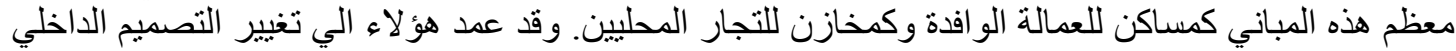

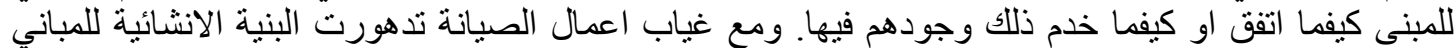

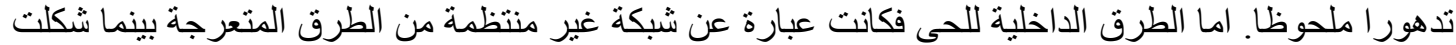

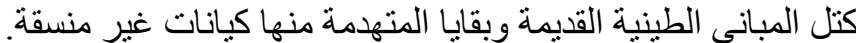

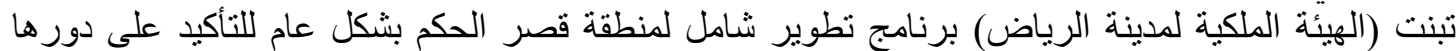

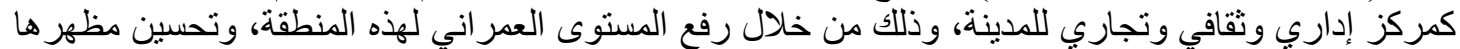

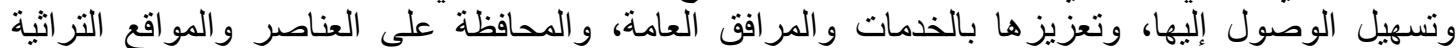

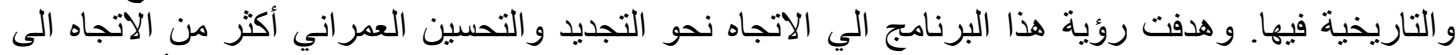

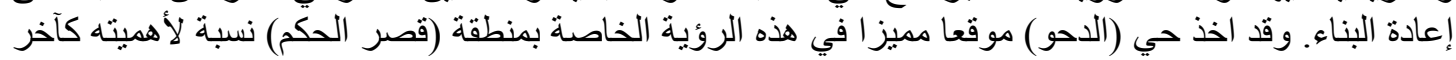

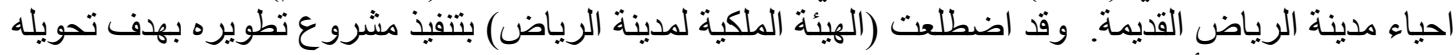

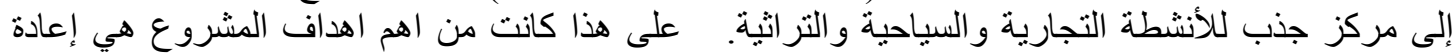

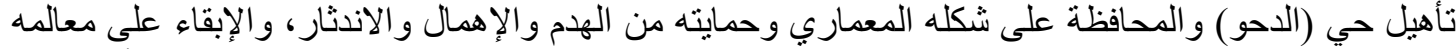

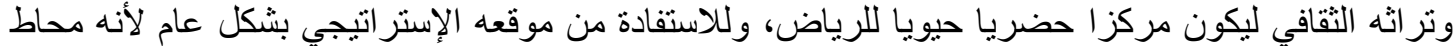

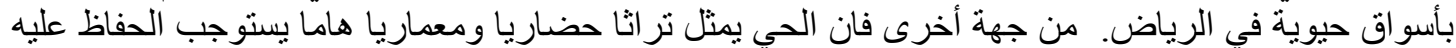

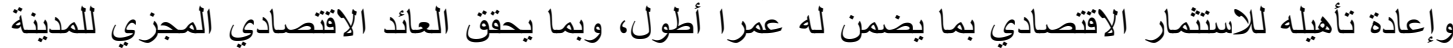
ويعود بالنفع على المجتمع المحلى، وليكون نموذجا حيا لإعادة استخدام العمارة الطينية التقليدية التراثية الثية.

\section{مواد الترميم التي استخدمت في عمليات تأهيل مباني حي (الاحو):}

لقد تمت مر اعاة اصلالة المو اد المستخدمة في الترميم و البناء بما لا يتنافى مع توفير الحد الأدنى الامن من السلامة

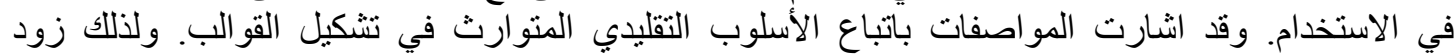

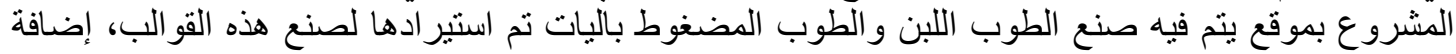

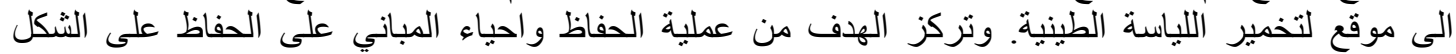

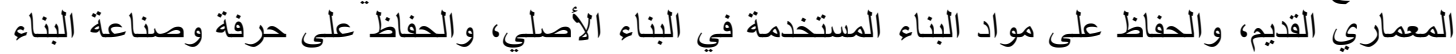
التقليدي القديم واحياءها، والحفاظ على اصلالة المواد المستخدمة بها وتقنياتها المتوارثنة. وقد تم تحقيق ذللك من

استخدام الطوب الطيني كمادة بناء أساسية لترميم المباني القديمة و لإعادة بناء الأجز اء المتهدمة

منها.

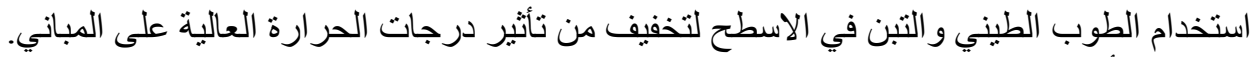

استخدام الأحجار في الارضيات وضات والاساسات و اسافل المباني و الاعمدة.

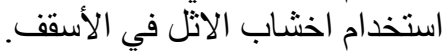

استخدام اللياسة الطينية في الحوائط.

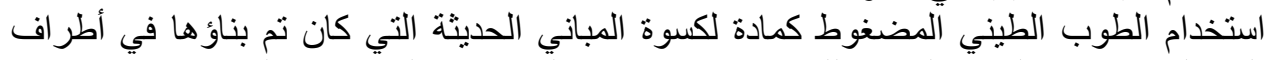

$$
\text { الحي لتتماشى مع الروح التراثية للحي وحتى لا تنتافر التشكيلات الحديثة مع القديمة. }
$$

المنهجيات التي استخدمت في اعمال التأهيل:

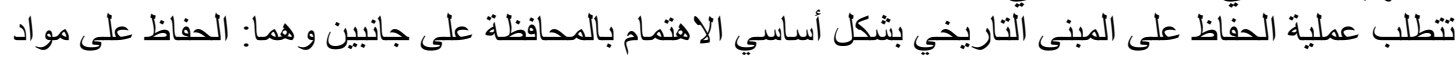

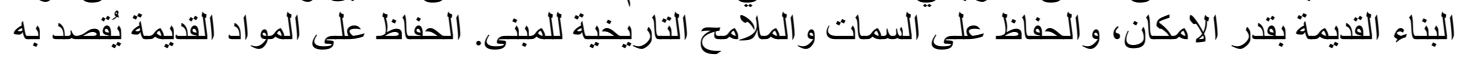




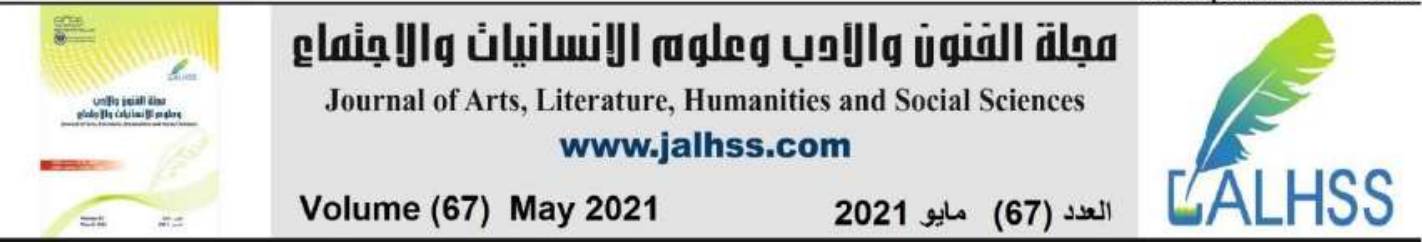

إصلاحها وليس استبدالها ما أمكن ذلك، والاستبدال لا يتم إلا في حال تعذر إصلاحها. و الحفاظ على السمات

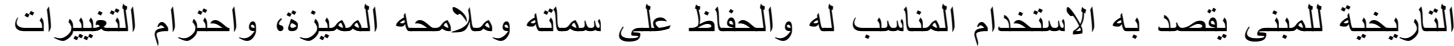

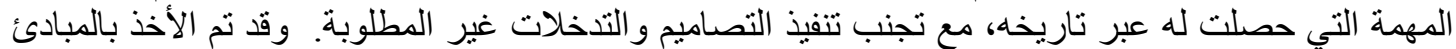

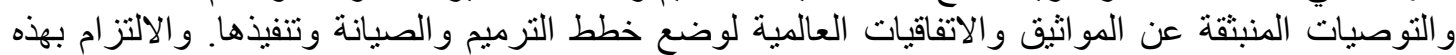

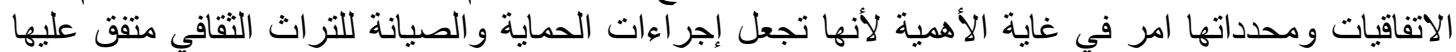

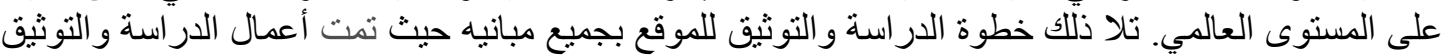

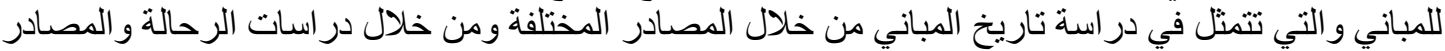

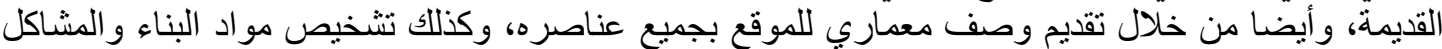

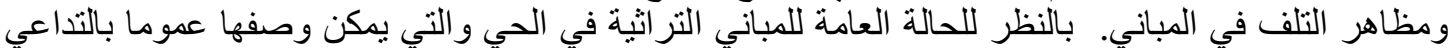

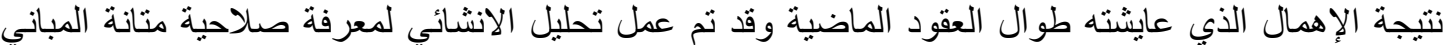

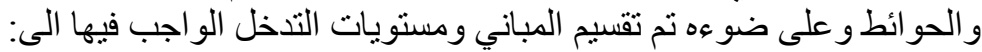

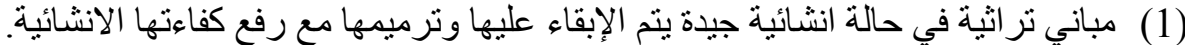

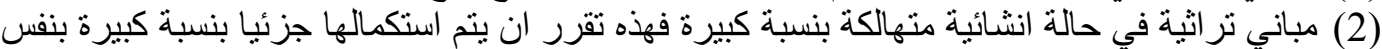

مادة البناء التقليدية (الطين) ولكن بالطوب الطيني اللبن مع ترميم الأجزاء الباقية ورفع الكفاءة الانثائية

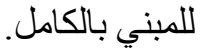

(3) مباني جديدة نم إعادة بناؤها على النسق القديم و على نفس المخطط بنفس النسب ولكن باستخدام وحدات

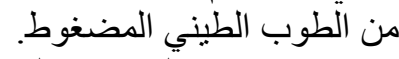

(4) مباني حديثة من الخرسانة المسلحة المكسوة بالطوب الطيني المضغوط تم بناؤها بتصميم جديد متتاسق

$$
\text { مع المباني القديمة ولكن بصيغة حديثة التئة محايدة. }
$$

الخطوات والأساليب التي استخدمت في تأهيل المباني التراثية في حي (الدحو):

توثيث حالة المباني ونظافة الأبساب الموقع:

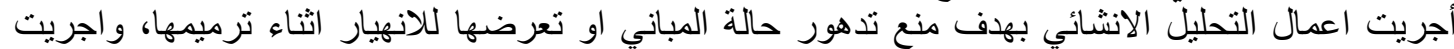

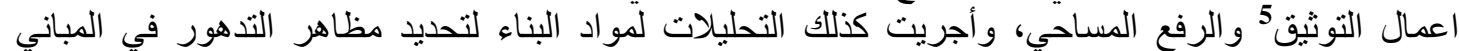

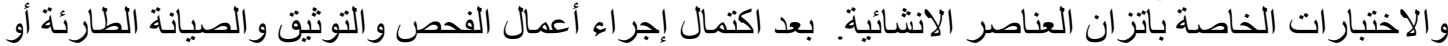

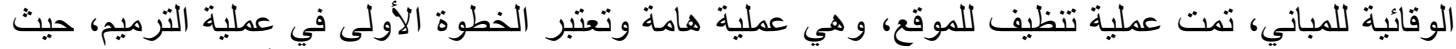

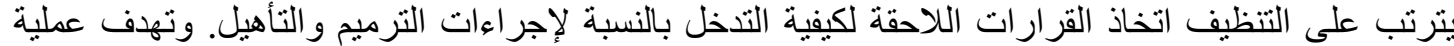

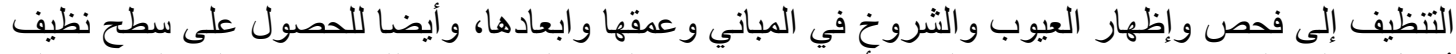

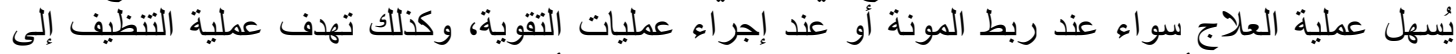

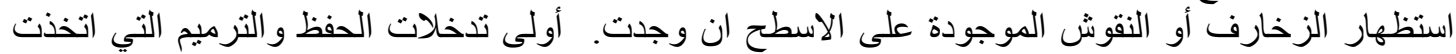

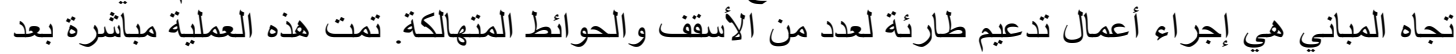

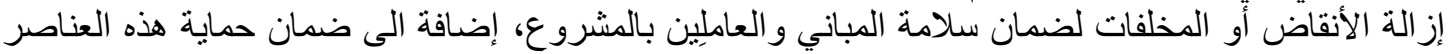

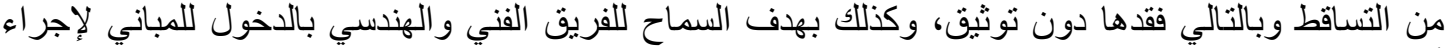

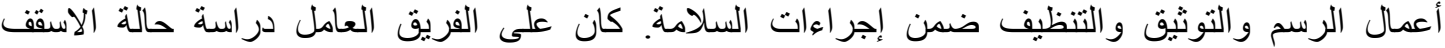

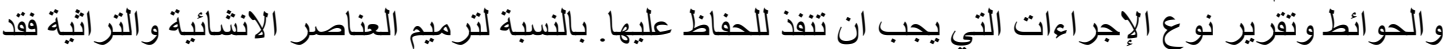

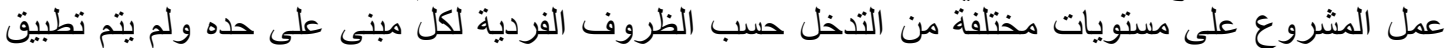

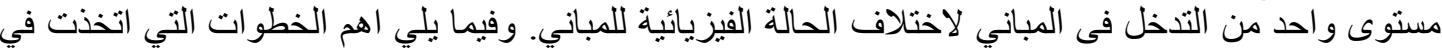

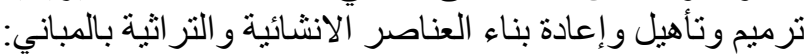

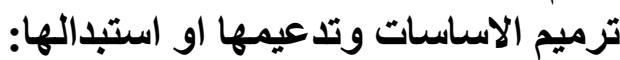

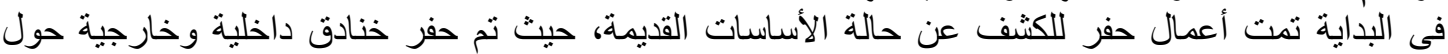

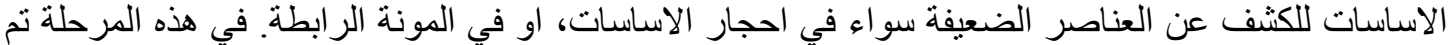

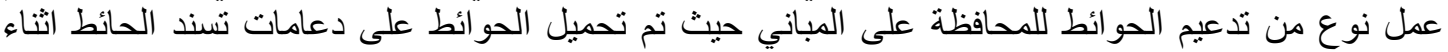

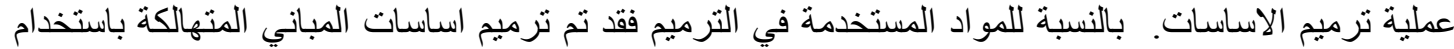

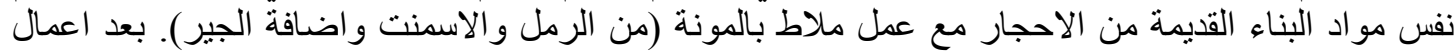
الحفر والاستكثاف يتم تحديد اماكن التلف في الخلطة الرابطة أو في أحجار الأساسات، فتتم إزالة الإلة المونة 


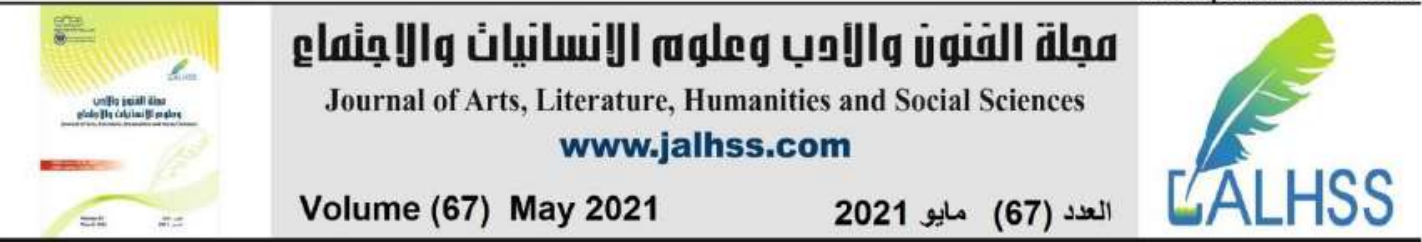

و الأحجار التالفة وينم وضع خلطة المونة الجديدة في مكان الترميم ثم تحشر الأحجار الكبيرة بقوة داخل الخلطة،

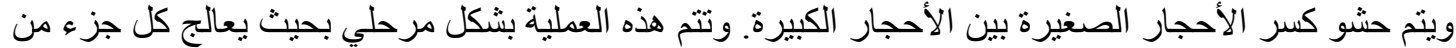

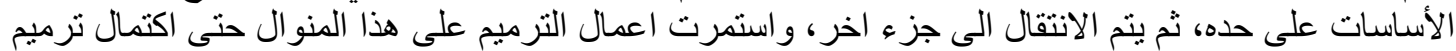

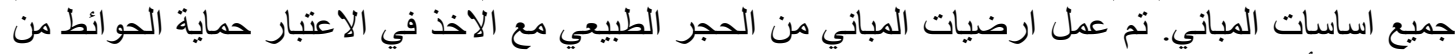

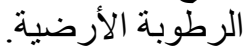

\section{ترميم حوائط المباني جزئيا او اعادة بناءها:}

بناء على اعمال التحليل الانثائي للمباني يتم تحديد ما إذا كان المبنى امن ام غير امن لتحمله للأحمال التشغيلية

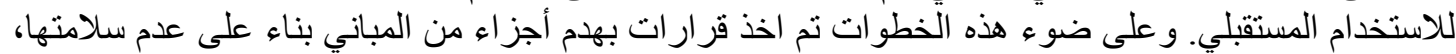

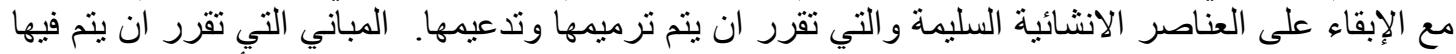

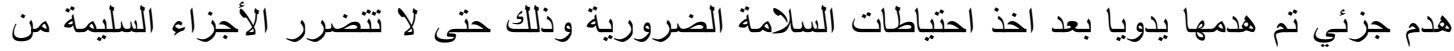

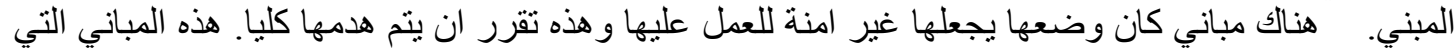

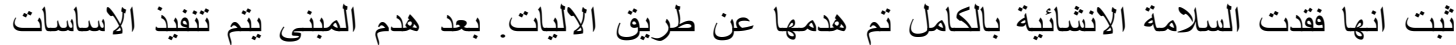

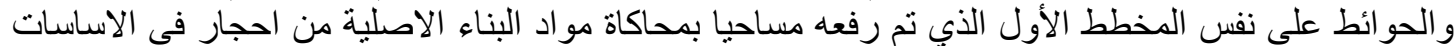

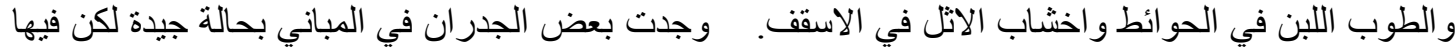

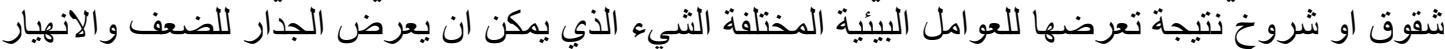

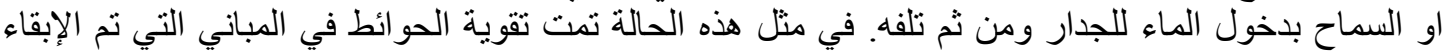

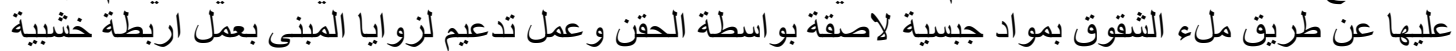

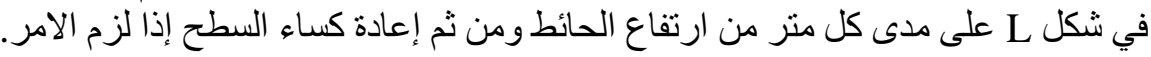

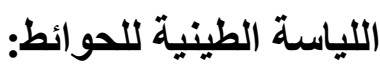

تلعب طبقة اللياسة دورا هاما في سلامة الجدران الداخلية و الخارجية للمباني. حيث تعمل هذه الطبقة على تلى توفير

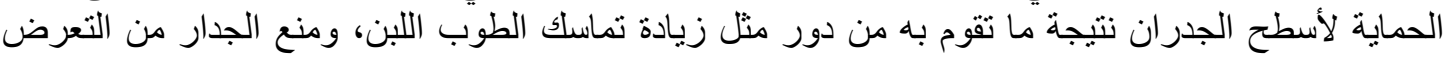

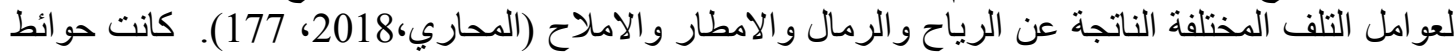

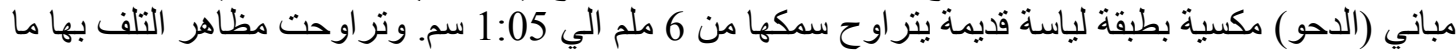

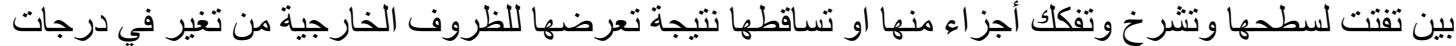

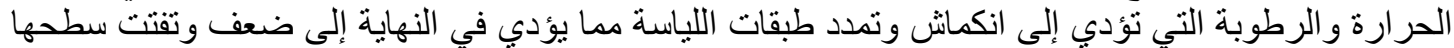

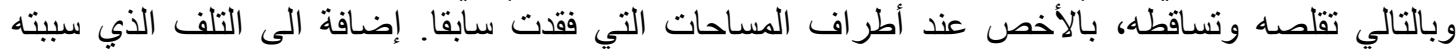

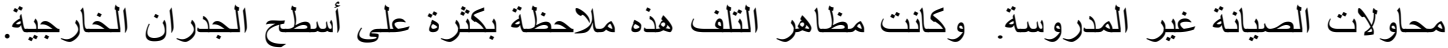

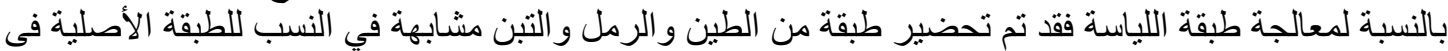

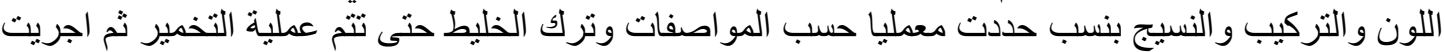

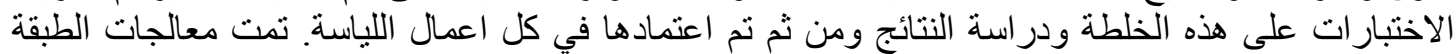

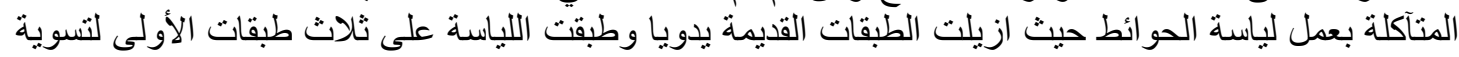

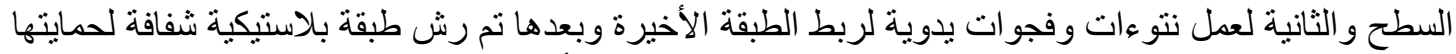

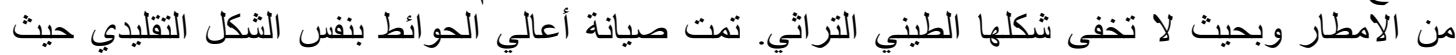

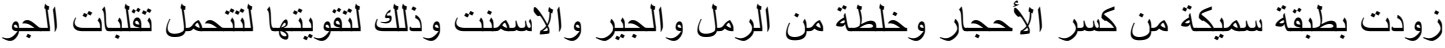
من شمس ورياح و امطار وحماية سطح الحو ائط من تسرب المن المياه الى داخلها.

\section{كسوة بعض المباني بالطوب الطيني المضغوط:}

بنيت ضمن اعمال المشروع مباني حديثة للخدمات مثل مو اقف السيارات والمسجد إضافة الي بعض المبال المال

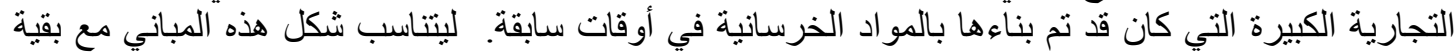

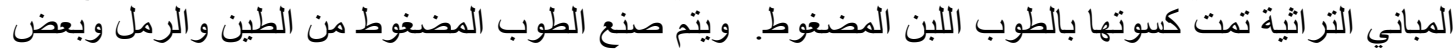




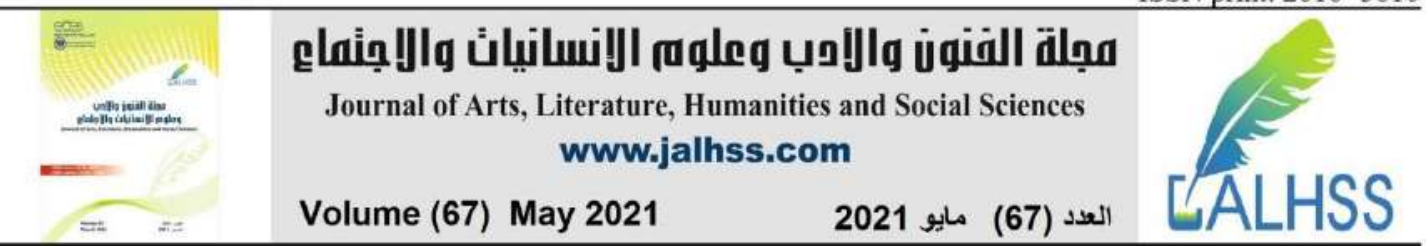

المو اد الترابية بالإضافة الى القليل من الجبص والاسمنت وتككن الطوبة ذات منانة جيدة وقليلة الامتصاص إضافة الى انها تعطى الثكل التراني التي للمباني. ترميم وإعادة بناء الاعمدة الحجرية:

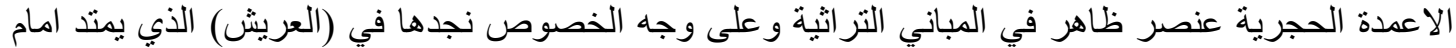

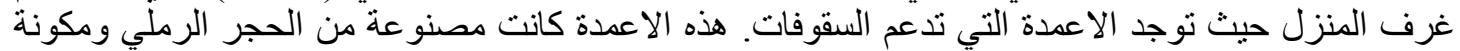

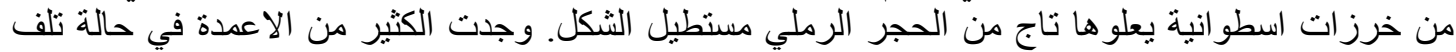

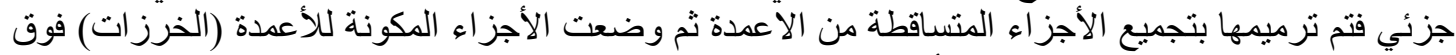

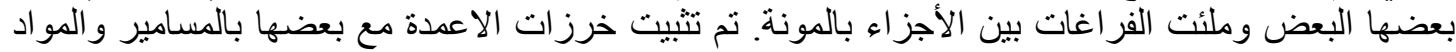

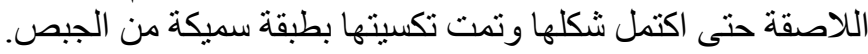

\section{ترميم اواستبدال السقوفات او الإبقاء على القديمة:}

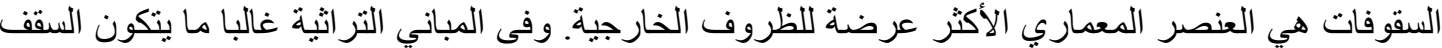

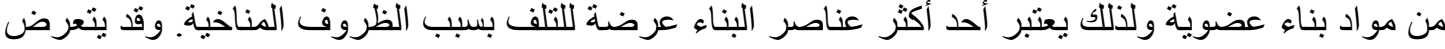

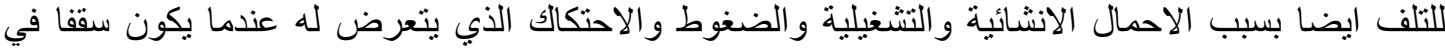

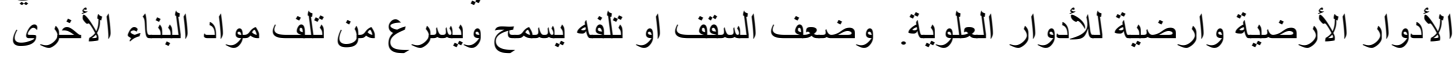

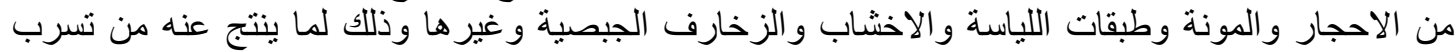

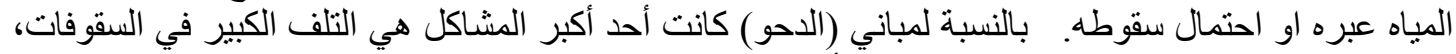

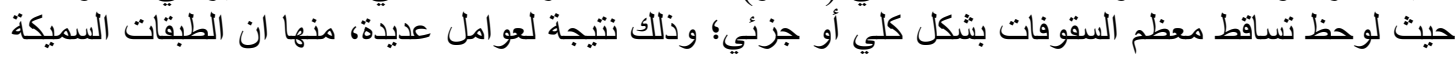

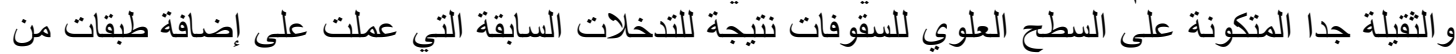

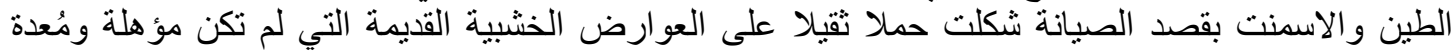

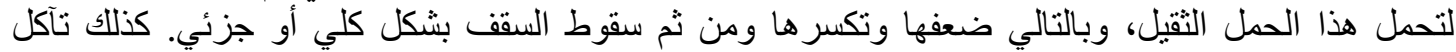

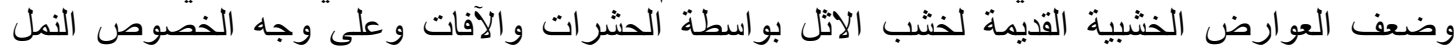

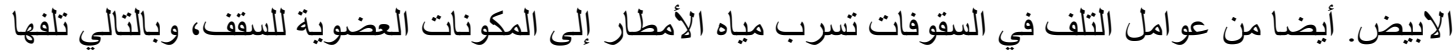

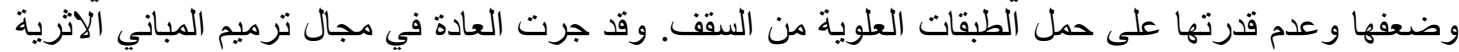

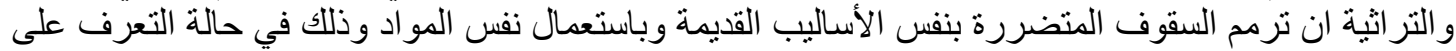

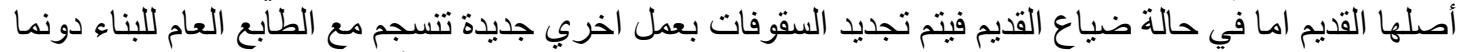

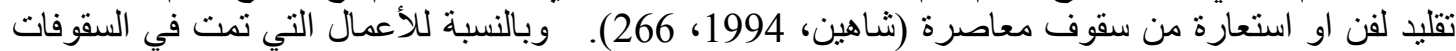

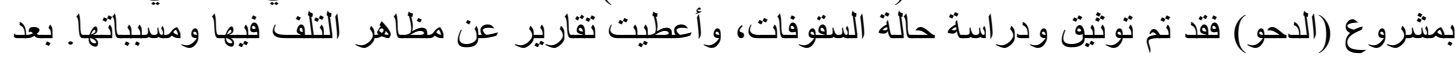

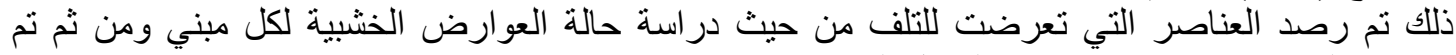
تصنيف السقوفات من حيث مسنوى التدخل إلى:

(1) سقوفات يتم الإبقاء والحفاظ عليها مع صيانتها ومعالجة الأخشاب التالفة جزئيا منها، أو استبدال

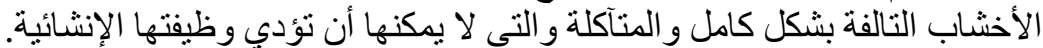

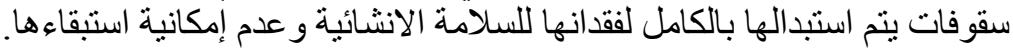

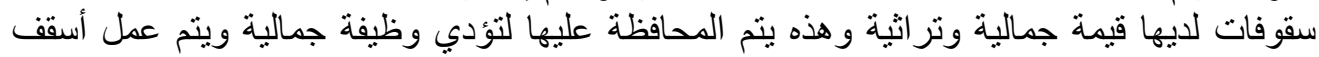

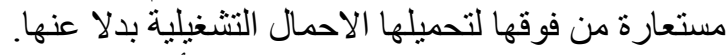

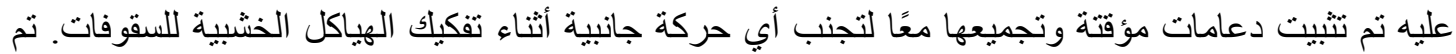

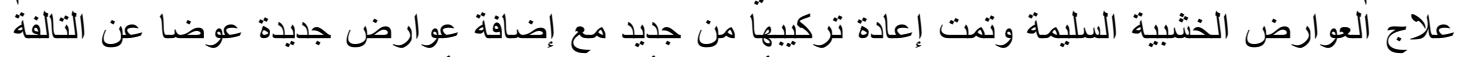

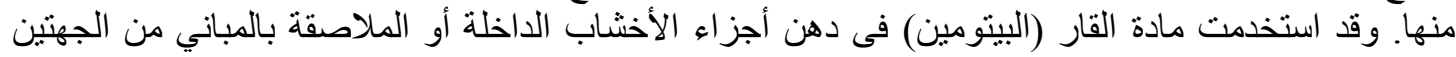

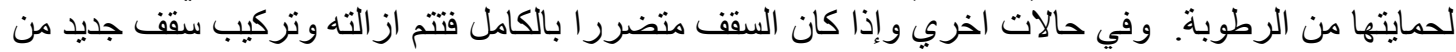
اخشاب الاثل وجريد النخيل و الحصير بمو اد شبيهة بالمو اد الاصلية، على ان هذه العملية تمت في اضيق الحدود التئ 


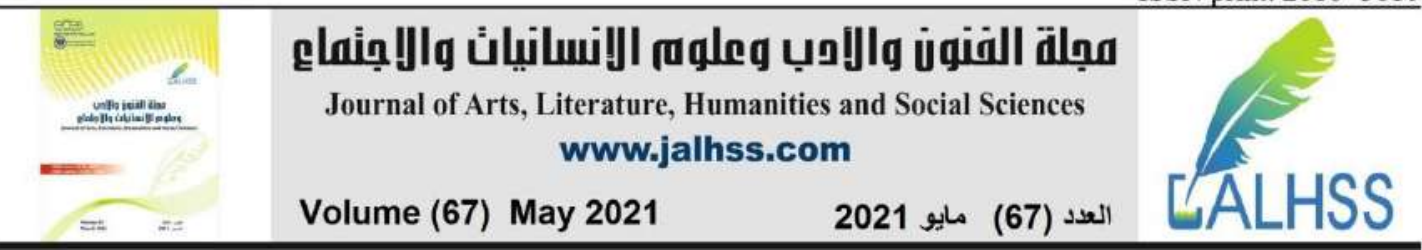

حيث كانت الأولوية للإبقاء على العناصر الاصلية ومعالجتها. كما تم عمل معالجات كيميائية للأخشاب القديمة للقضاء على الحشرات و النمل الأبيض. لأليض.

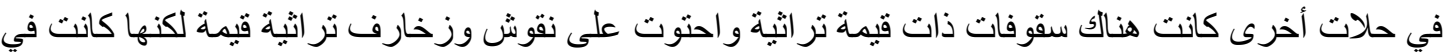

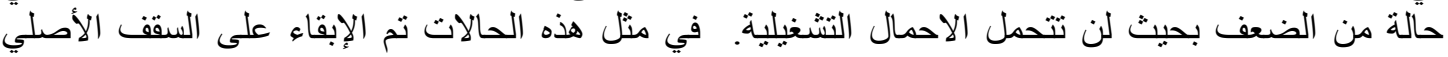

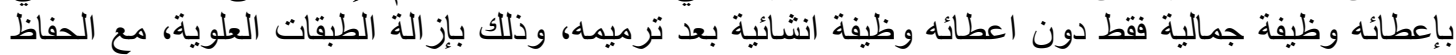

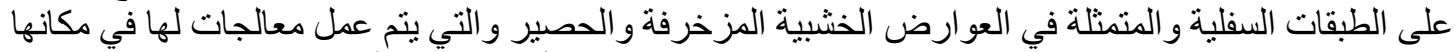

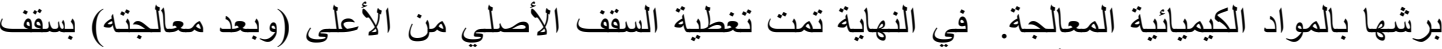

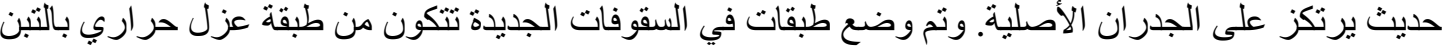

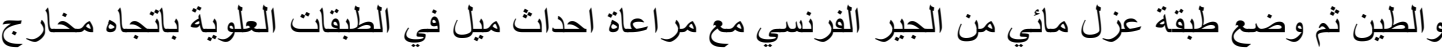
تصريف مياه الأمطار مع عمل المز اريب الخثبية.

\section{صيانة اواستبدال الأبواب الخشبية:}

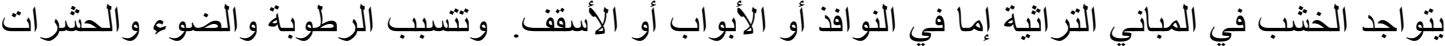

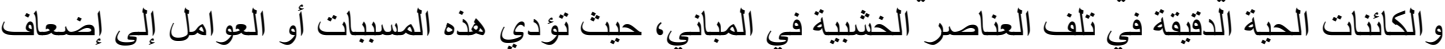

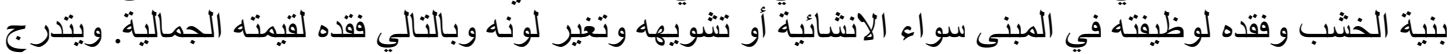

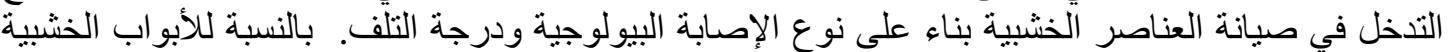

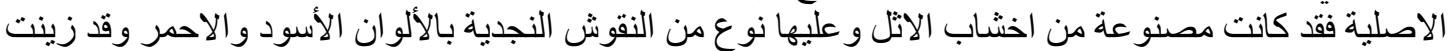

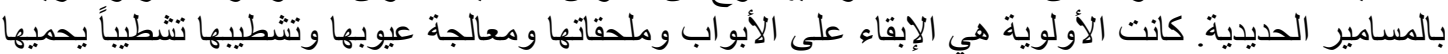

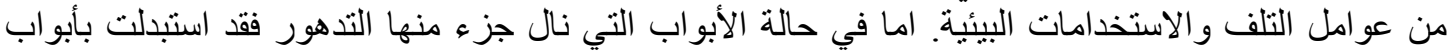
جديدة مصنو عة من نفس نوع الأخشاب المصنوع منها الباب الأصلي. صيانة وترميم العناصر التراثية:

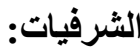

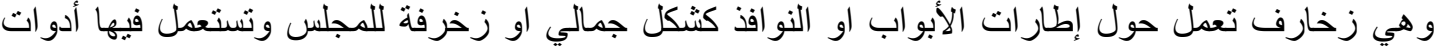

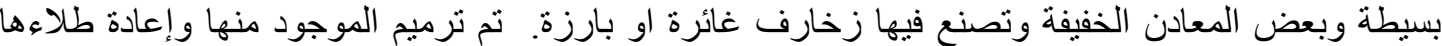
بالجبص كما تم اكمال النو اقص منها حسب النفي النسق القديم.

$$
\text { المجببات (مفردها مجبب)6 }
$$

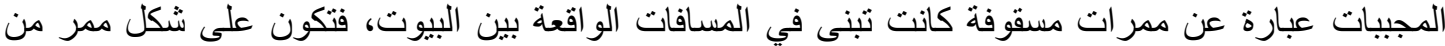

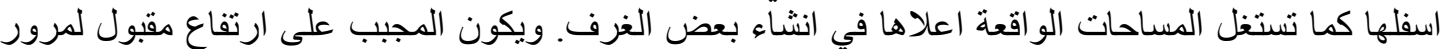

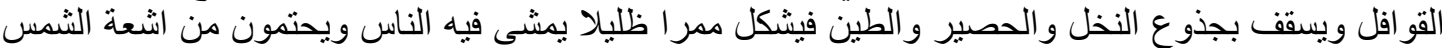

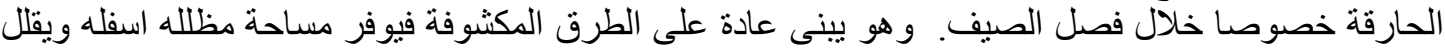

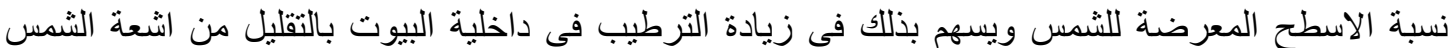

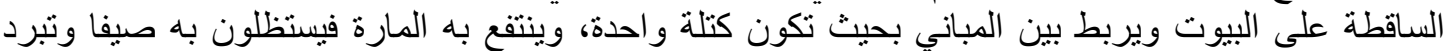

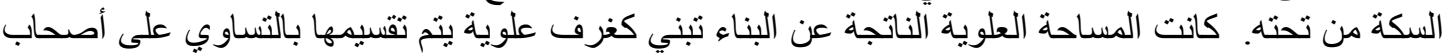

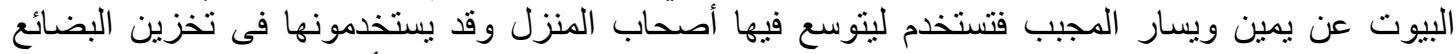

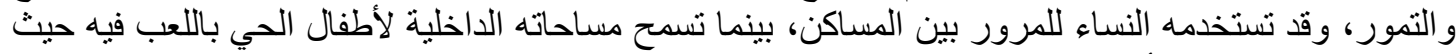

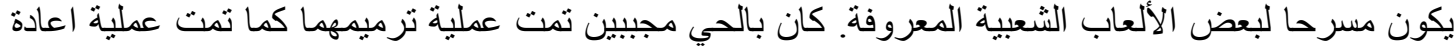
بناء لمجبيين اثثين اخرين كانا في حالة تهدم كامل على نفس النسف النس القديم. 


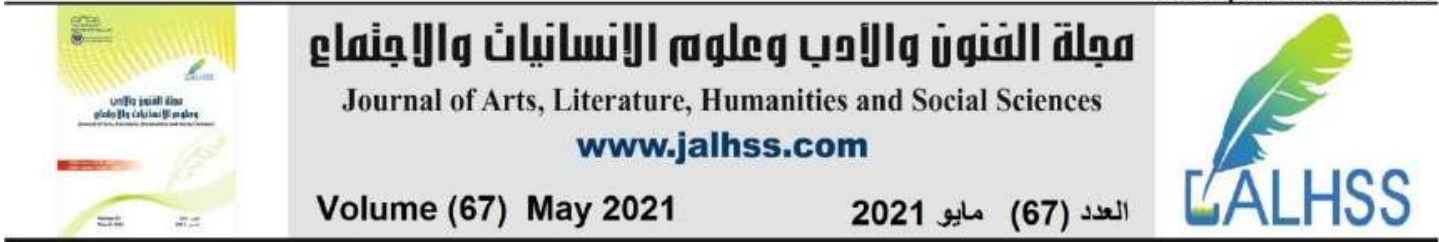

استخدمت الزخارف النجدية في تزيين الجدران الداخلية للمجالس في بعض البيوت حيث كان يعنى بمنطقة

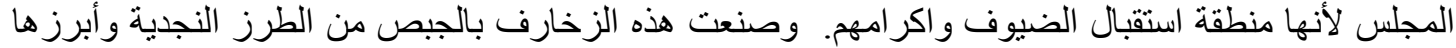

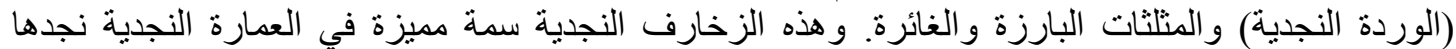

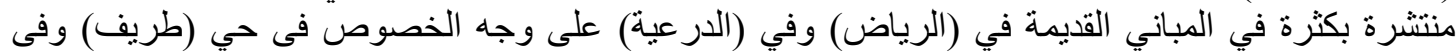

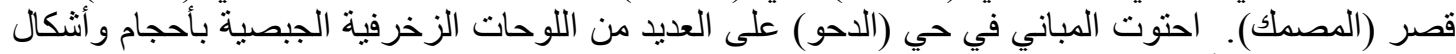

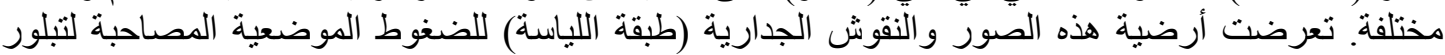

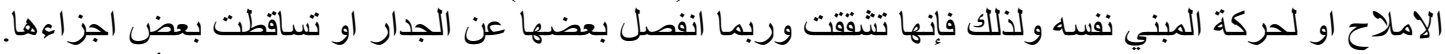

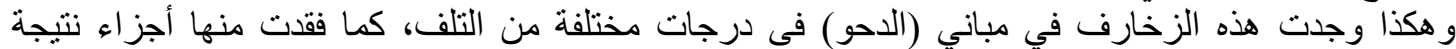

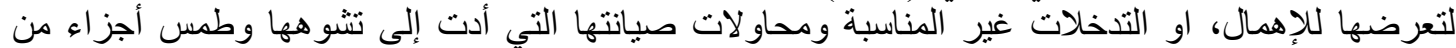

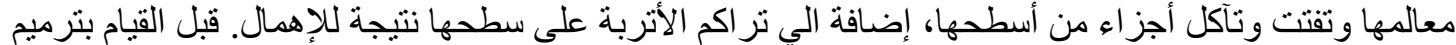

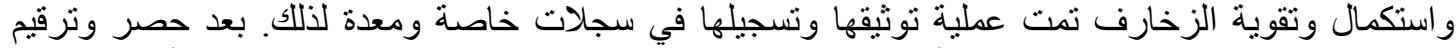

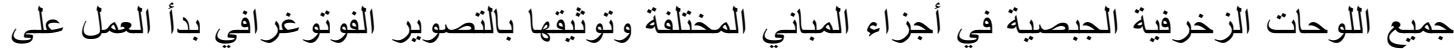

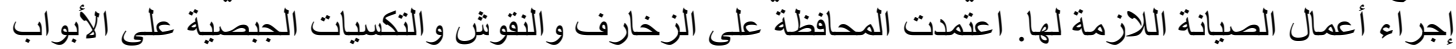

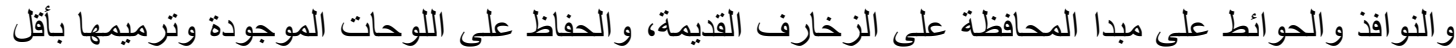

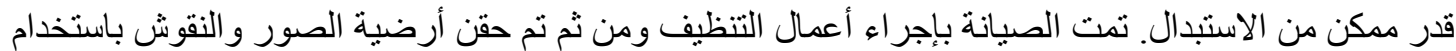

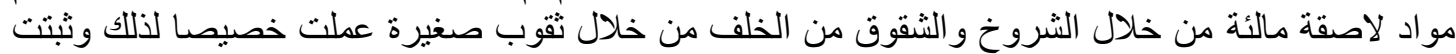

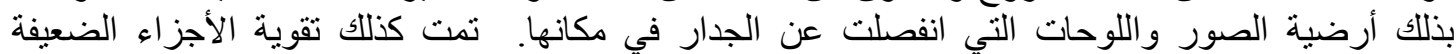

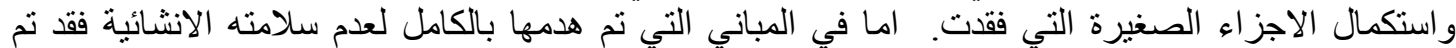

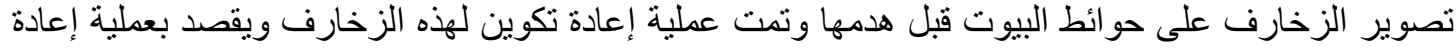

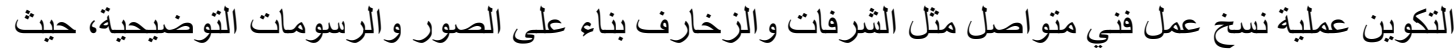

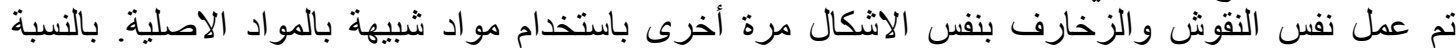

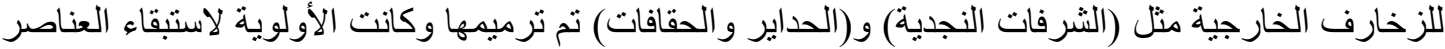

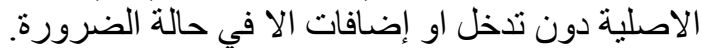

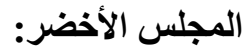

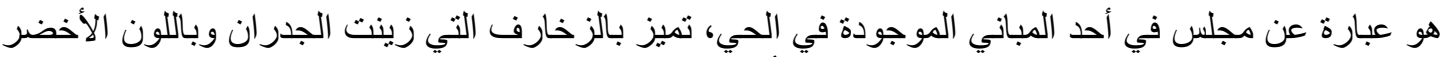

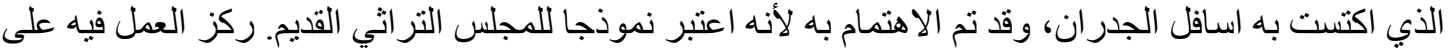

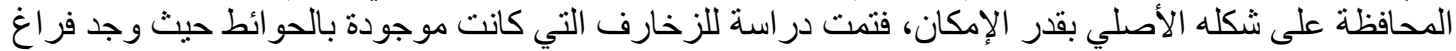

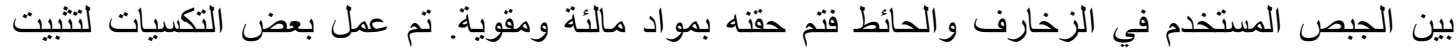

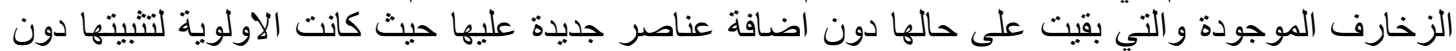

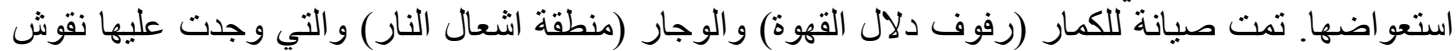

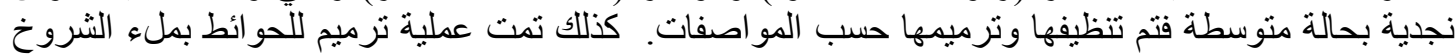
التي كانت موجودة بالحو ائط، كما تمت صيانة السقف باستبدال بعض الاخشاب التي فقدت السلامة الانشائية.

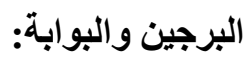

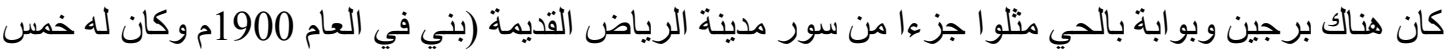

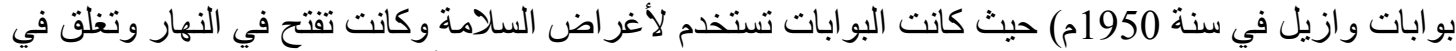

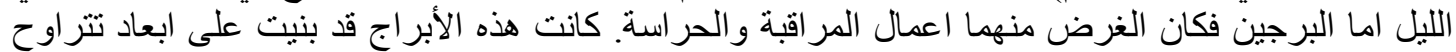

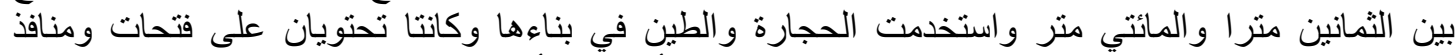

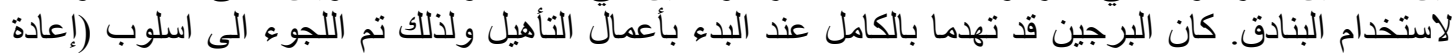

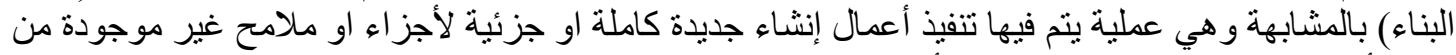

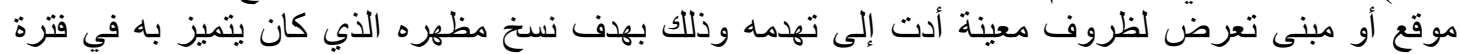

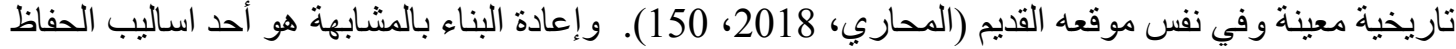

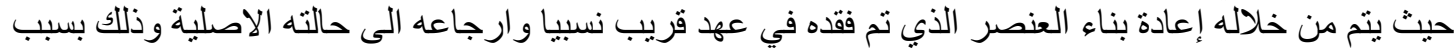




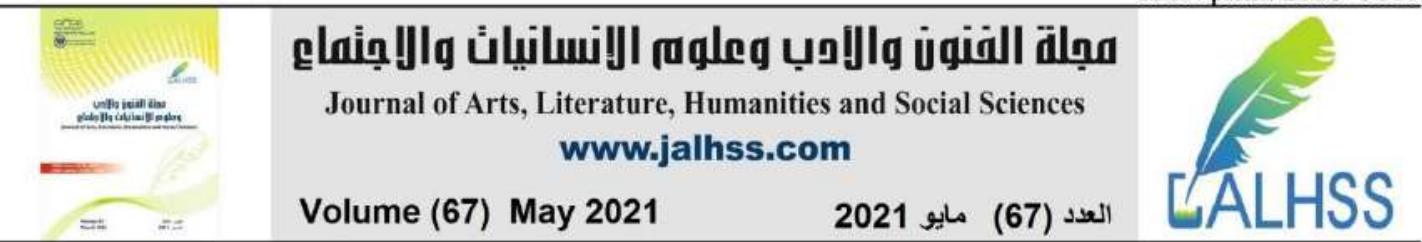

أهميته او ندرته ويعتمد هذا النوع على المقارنة والاقتباس والتقلبد لعناصر المبنى الأثري مع بعض المباني المشابهة له و التي تنتمي إلى نفس العصر وفنرة الإنشاء، مع توفر الأدلة المادية والوثائقية التي تدعم هذه العملية

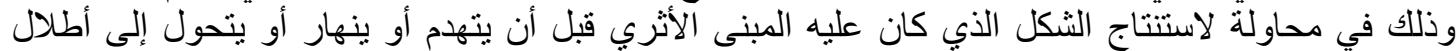
(مصطفي، 2009، 116). وبناء على هذا تم انشاء البرجين على نفس النسق القديم وقد استعين في هذه المئ المهية

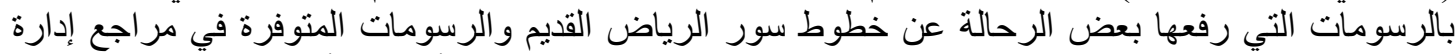

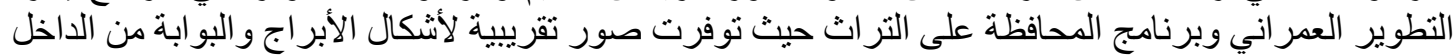
و الخارج فتم إعادة بناء البرجين بناء على هذه الوثائق باستخدام المواد التقليدية، بحيث تكون قادرة على التى اعطاء

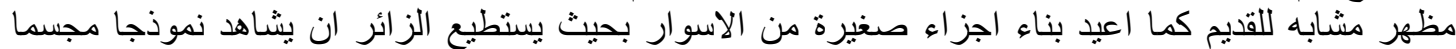

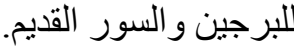

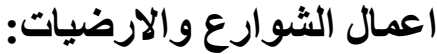

لقد صمدت طرقات حي (الدحو) منذ زمن بعيد وقبل انتشار استعمال السيارات وغيرها من المركبات، وكانت

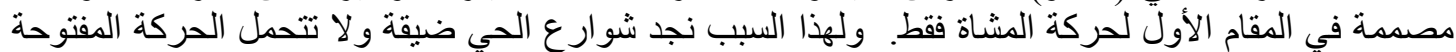

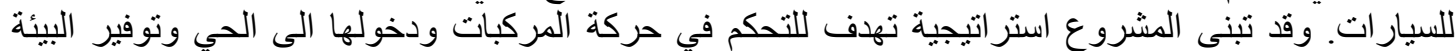

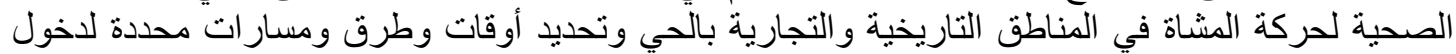

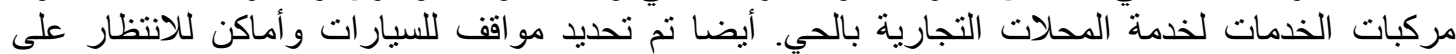

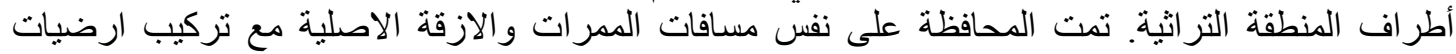

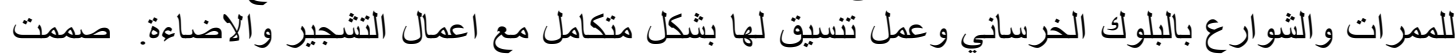

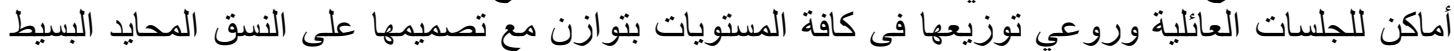

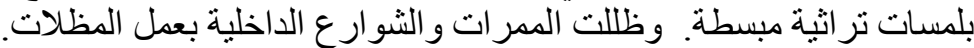

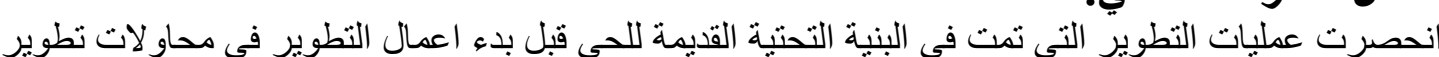

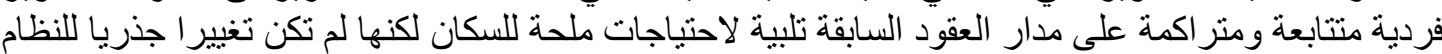

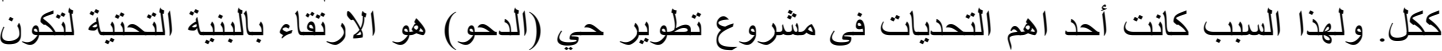

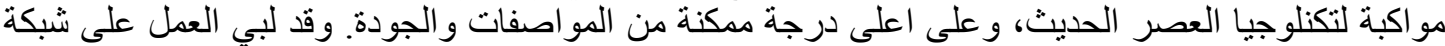

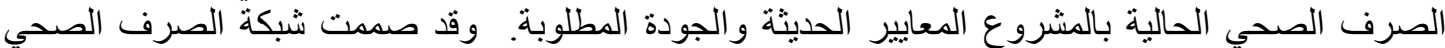

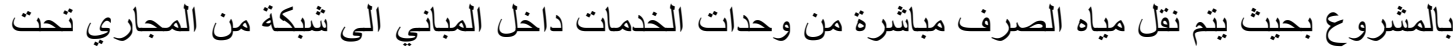

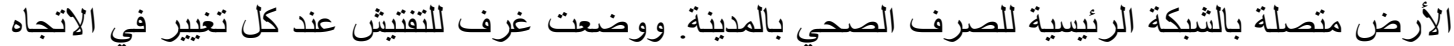

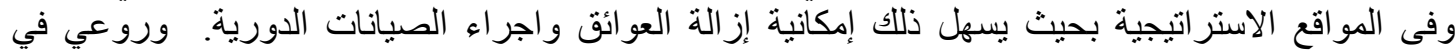

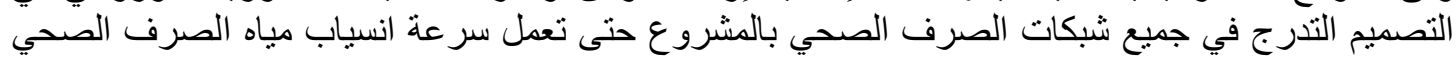
على التقليل من حدوث الانسدادات ومنع نشكل الروائح الكريهة.

شبكة تصريف مياه الامطار:

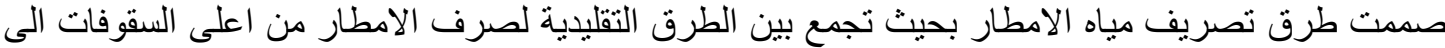

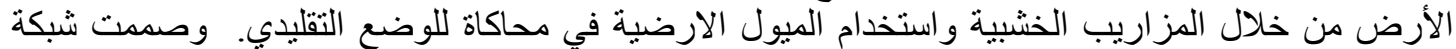

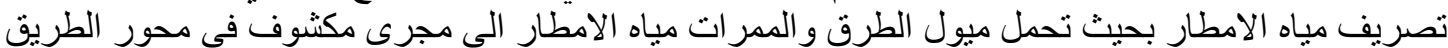

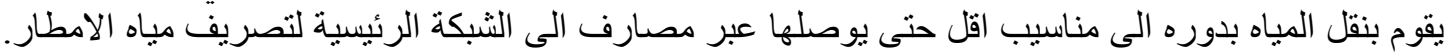

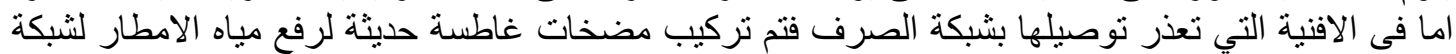
تصريف مياه الامطار و هي مضخات صغيرة سهلة الصيانة. 


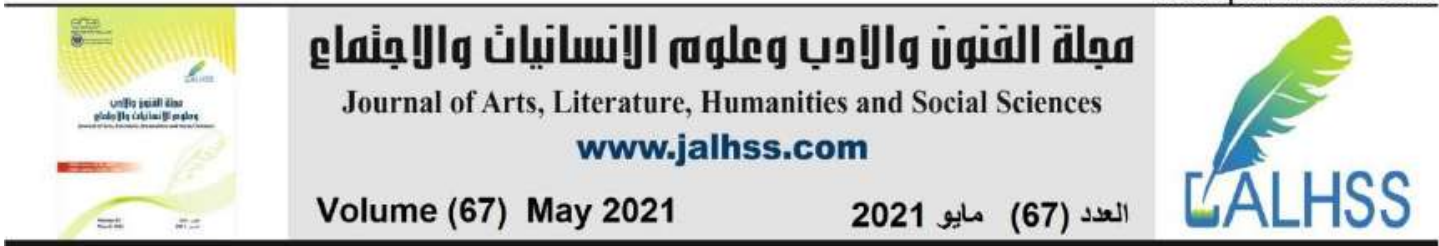

توفير مياه الثرب والري ومياه مكافحة الحريق:

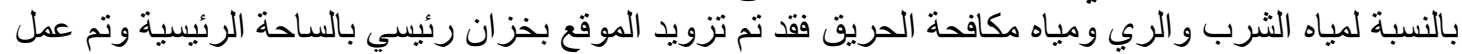

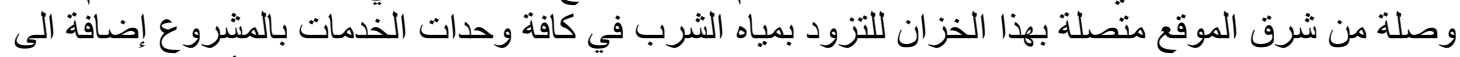

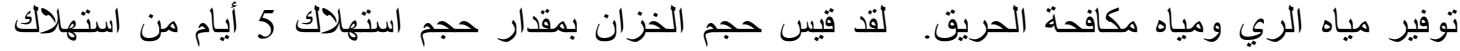

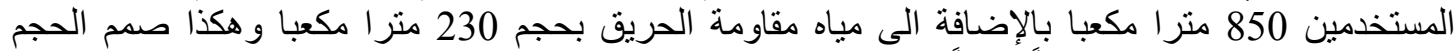

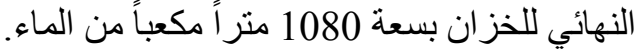

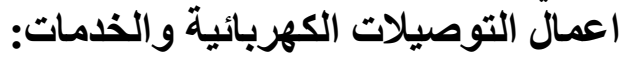

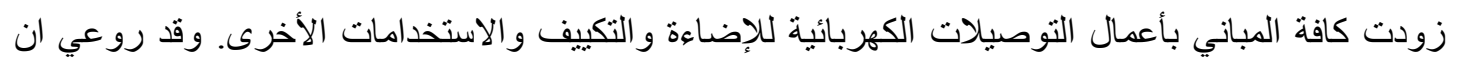

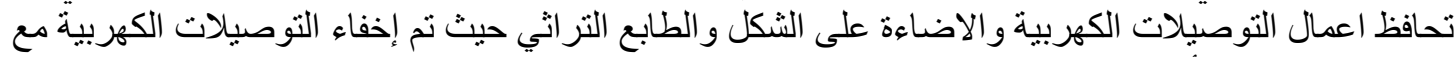

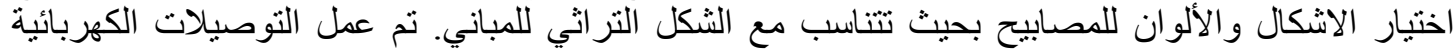

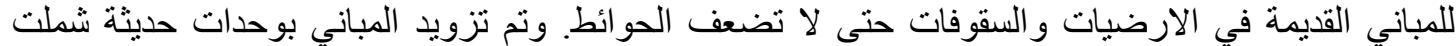

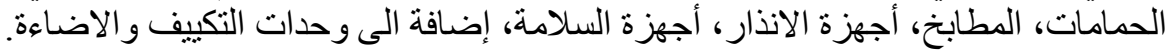

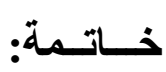

نفذت أعمال المشروع على مساحة إجمالية تبلغ 40 ألف متر مربع. و هدفت اعماله في المجمل الى تأهيل

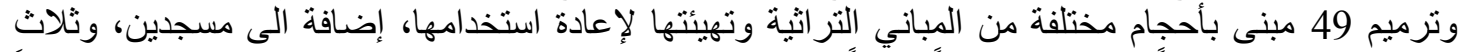

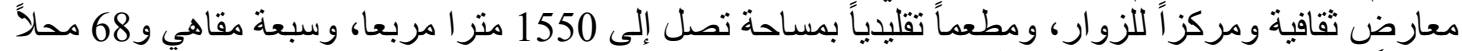

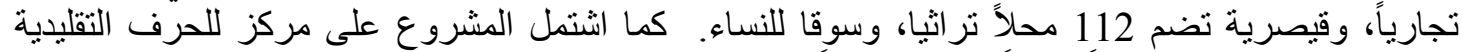

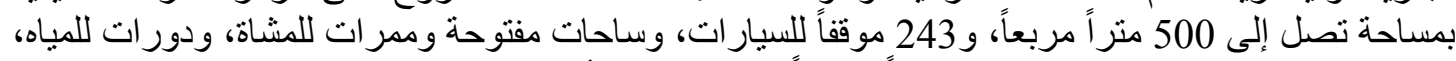

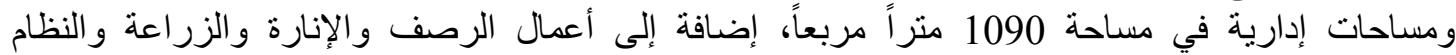
الإرشادي وشبكات الخدمات.

ركزت الرؤية العامة والمتكاملة للمشروع على الحفاظ على النسيج العمر اني التراثي، وترميم المباني الطينية،

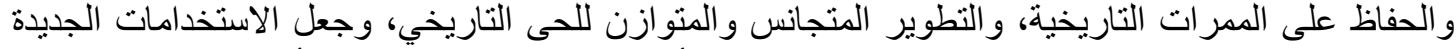

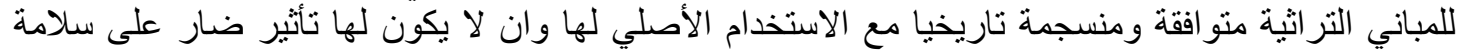

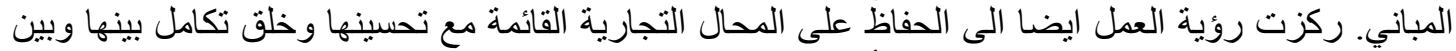

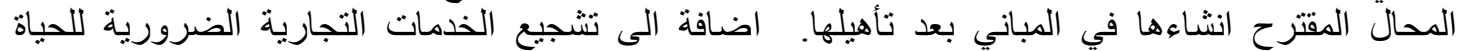

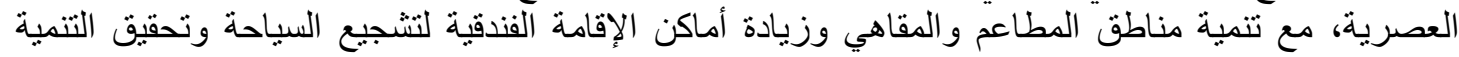

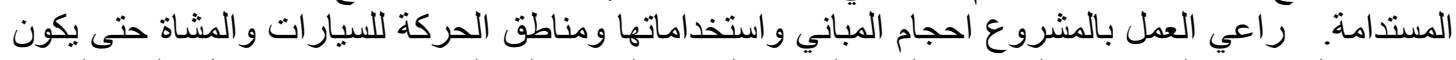

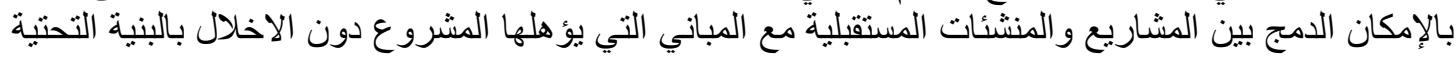

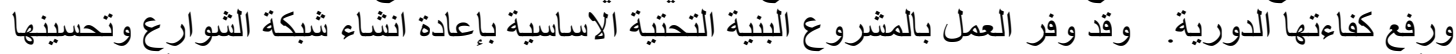

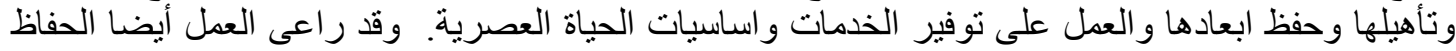

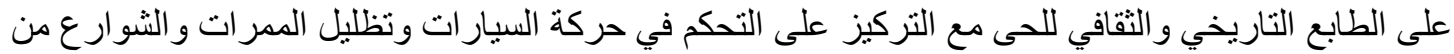
اجل توفير بيئة مريحة للمشاة وتشجيع الزو الزيع التركيل على الشي داخل الحي.

حقق العمل في مشروع نطوير حي (الاحو) القدر الأكبر من الحفاظ على الموروث الثقافي للحي القديم سواء

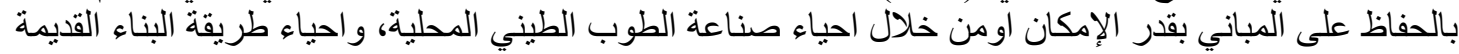

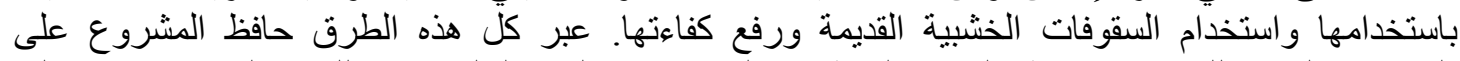

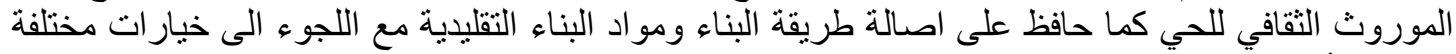

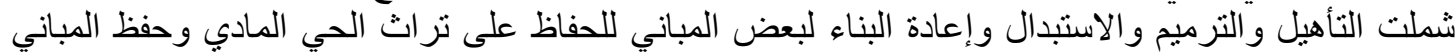

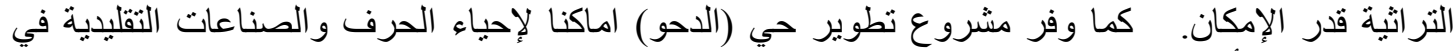

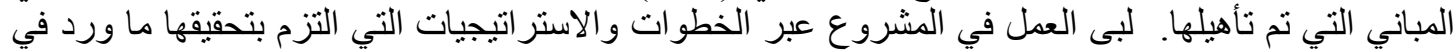

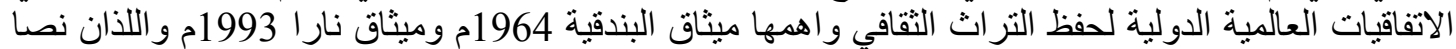
على ضرورة الحفاظ على الموروث العمر اني الثقافي مع اقل تدخل مدكن مع مر اعاة رفع الكفاءة البنائية للمباني 


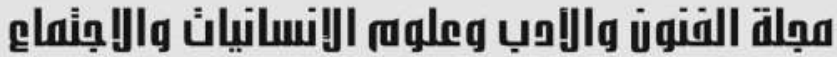

vithieat tim

Journal of Arts, Literature, Humanities and Social Sciences

www.jalhss.com

\section{Volume (67) May 2021}

العدد (67) مايو 2021

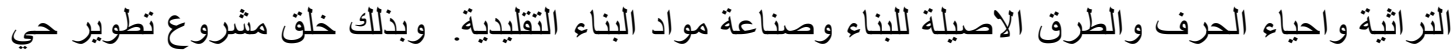

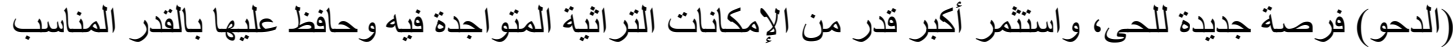

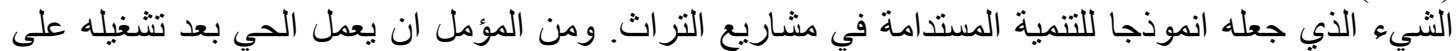

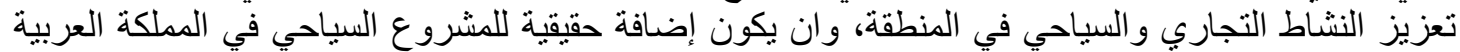

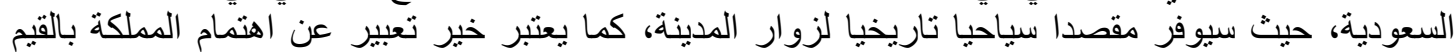

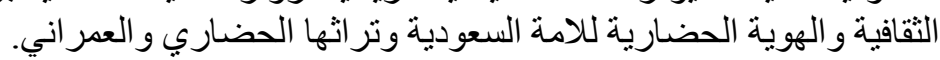

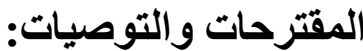

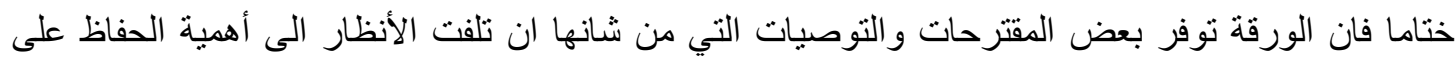

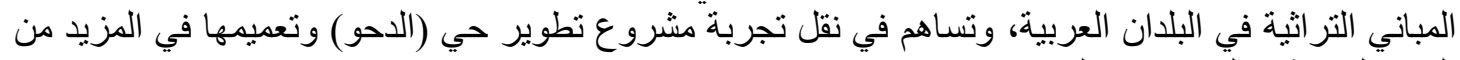

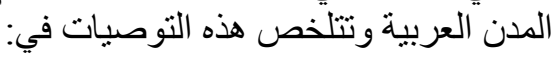

1. إحياء التراث القديم بكل صوره للحفاظ عليه من الاندثار والضياع، وتحسين البنية التحتية للمباني التر اثية و التاريخية و إعادة تأهيلها وتجديدها.

2. اتخاذ اعادة الاستخدام كأحد اهم استر اتيجيات وأساليب الحفاظ على التراث المعماري و التراثي للمدينة

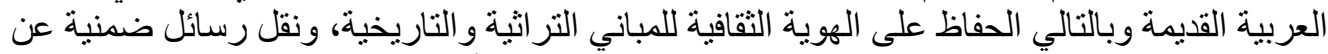

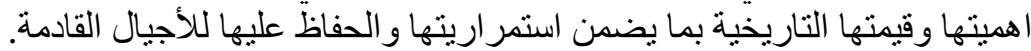

3. التأكيد على مشاركة الهيئات و المؤسسات الحكومية وغير الحكومية في توعية المواطنين بأهية التراث

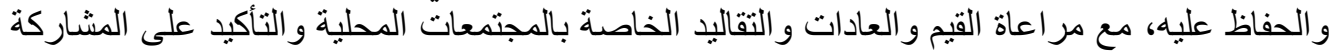
المجتمعية في الإعداد و التنفيذ لأعمال إعادة تأهيل المباني التر اثنة.

4. نشر و وعي الاستثمار فى المباني التاريخية و التراثية لدى القطاعين الحكومي و الخاص، وتثجيع السياحة التراثية والاستثمار السياحي لتحقيق التنمية المستدامة.

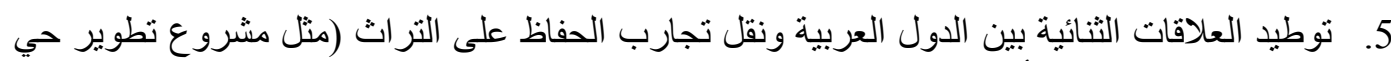

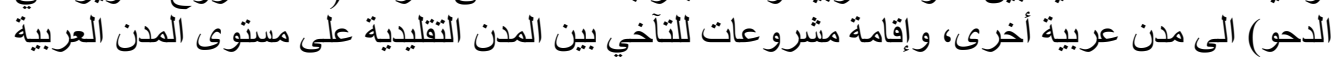
مما يساهم في تنشيط الدور الثقافي و التنموي للطرفين. 


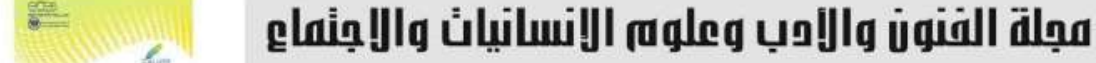

Journal of Arts, Literature, Humanities and Social Sciences
www.jalhss.com
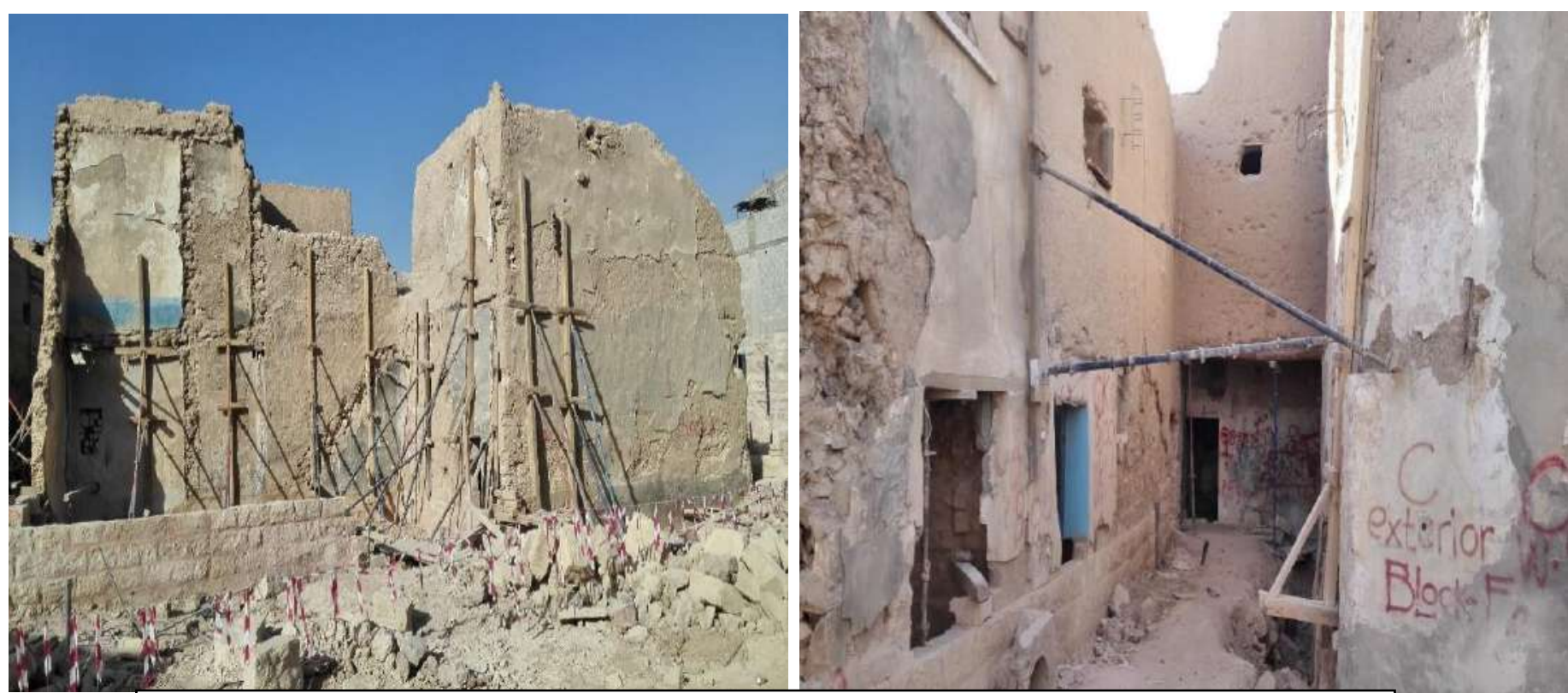

الصورة على البمين تظهر حالة المباني قبل بدء اعمال الترميم ويظهر مدى التلف والضرر الذي كانت عليه الجدران،

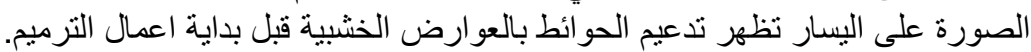
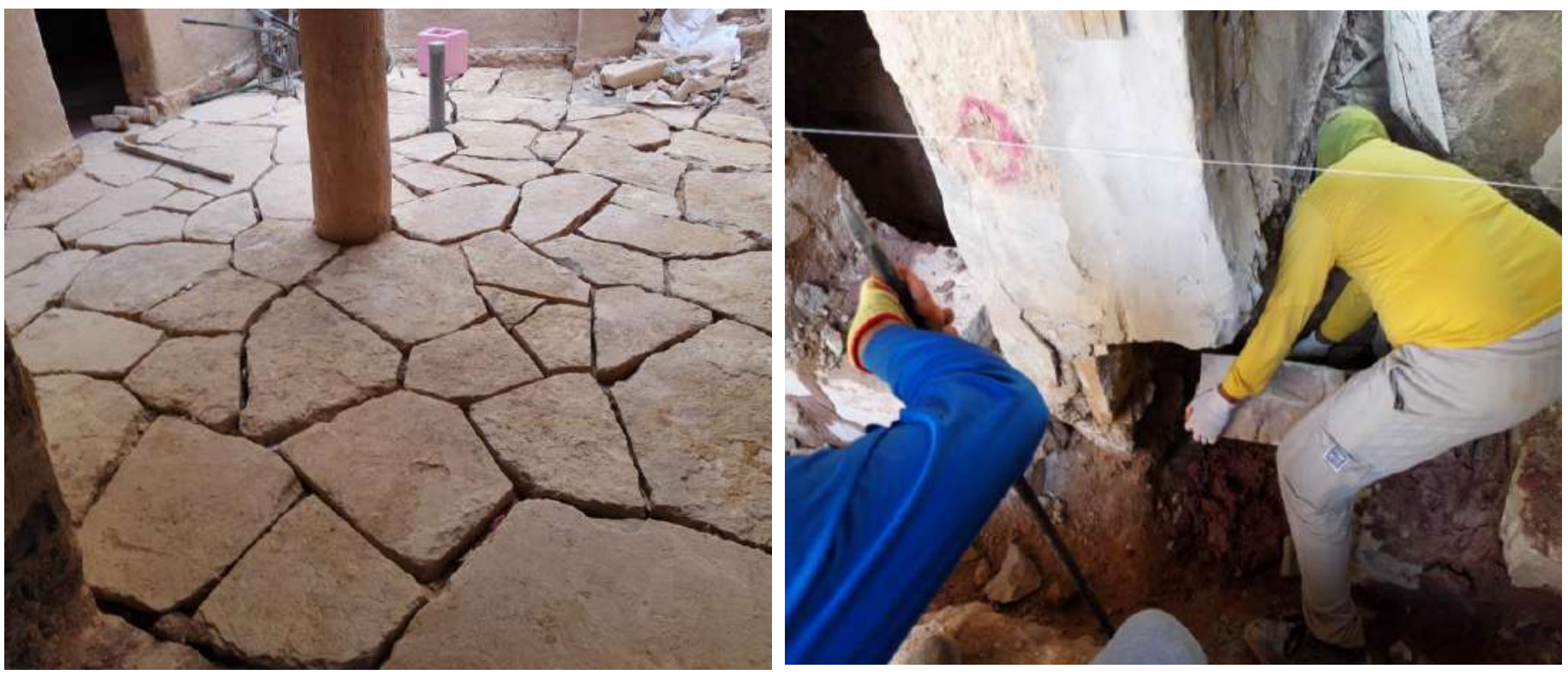

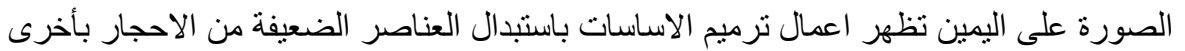
سليمة، والصورة على اليمين تظهر اعمال الحجر الطبيعي في الارضيات. 


\begin{tabular}{|c|c|c|c|}
\hline 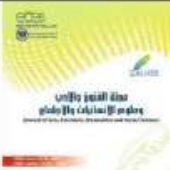 & 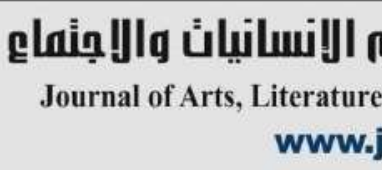 & 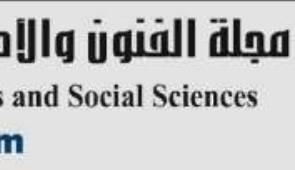 & \\
\hline$=\Rightarrow$ & Volume (67) May 2021 & العدد (67) مايو 2021 & \\
\hline
\end{tabular}
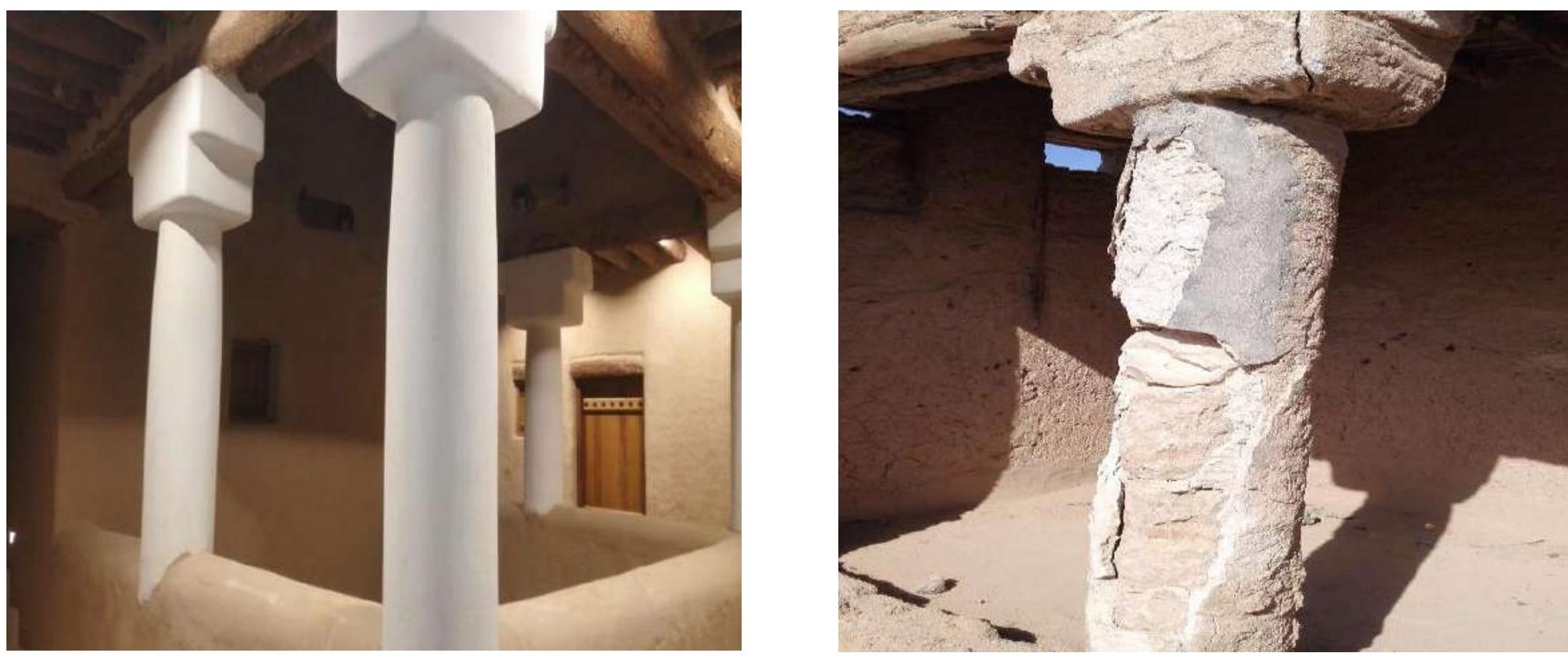

الصورة على اليمين تظهر حالة الاعمدة الحجرية قبل الترميم والصورة على اليسار تظهر حالتها بعد اكتمال اعمال الترميم.
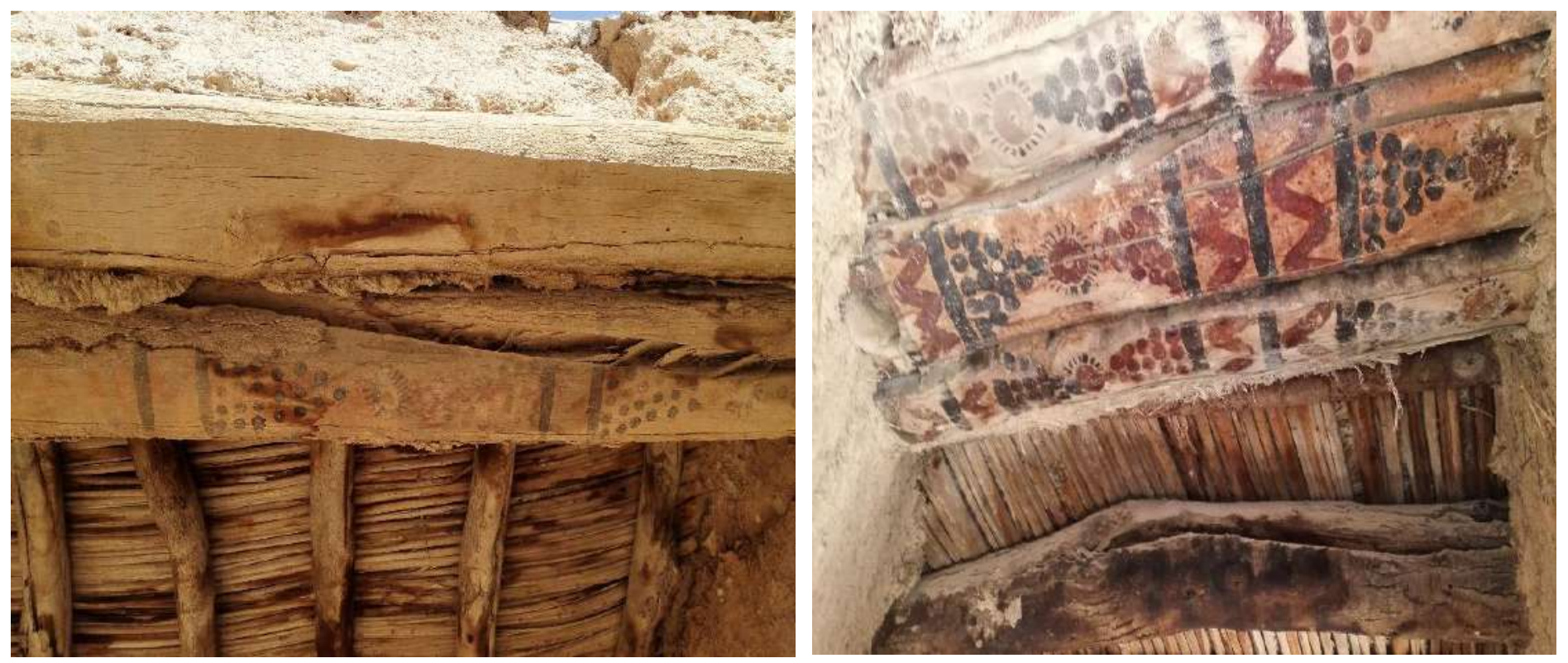

تظهر الصورتان هنا نوعا من النقوش التراثية التي وجدت على اخثاب السقف. 


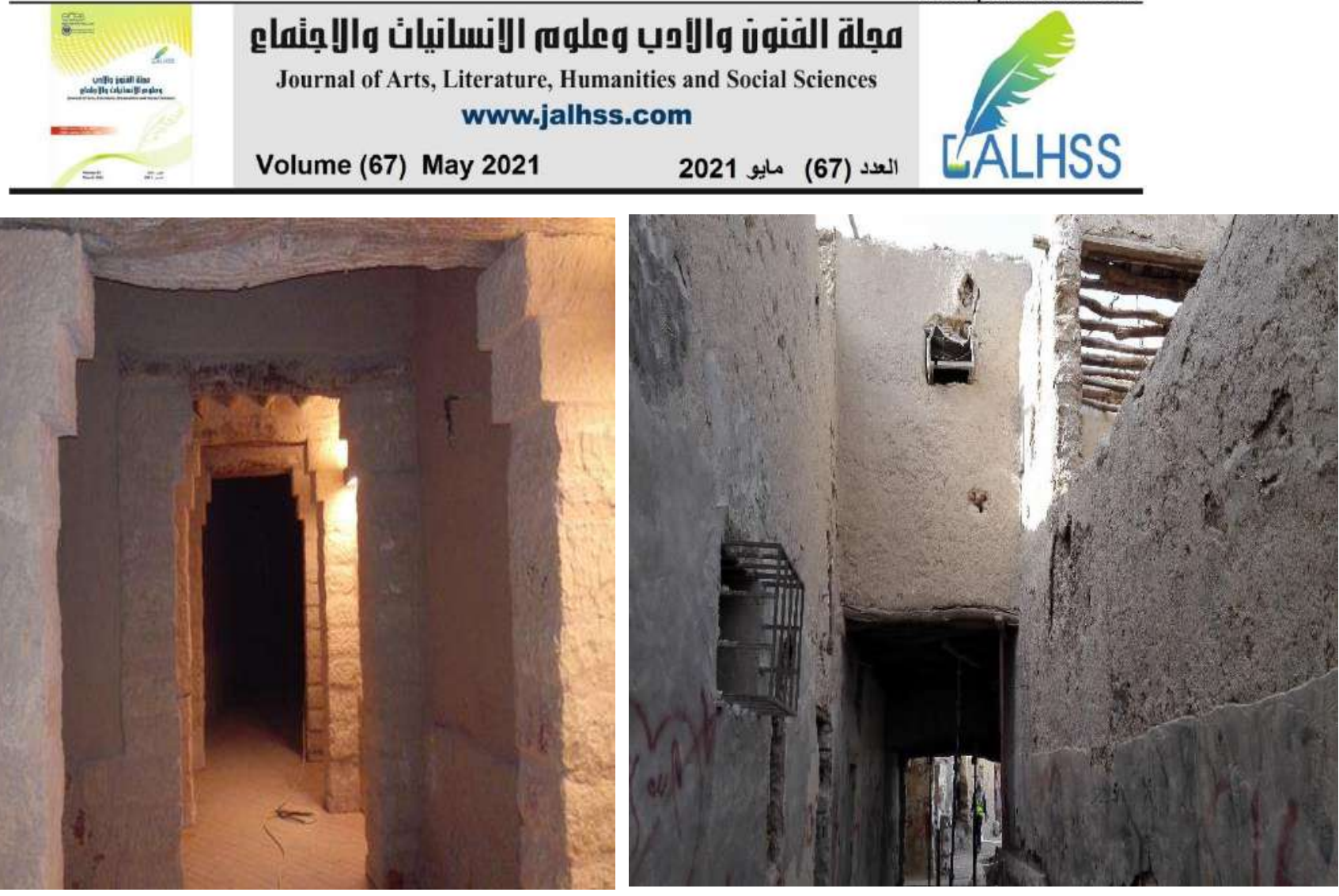

الصورة على اليمين تظهر أحد الجببات قبل البدء بأعمال الترميم وفي الصورة على اليسار يظهر أحد المجبيات بعد ترميمه.
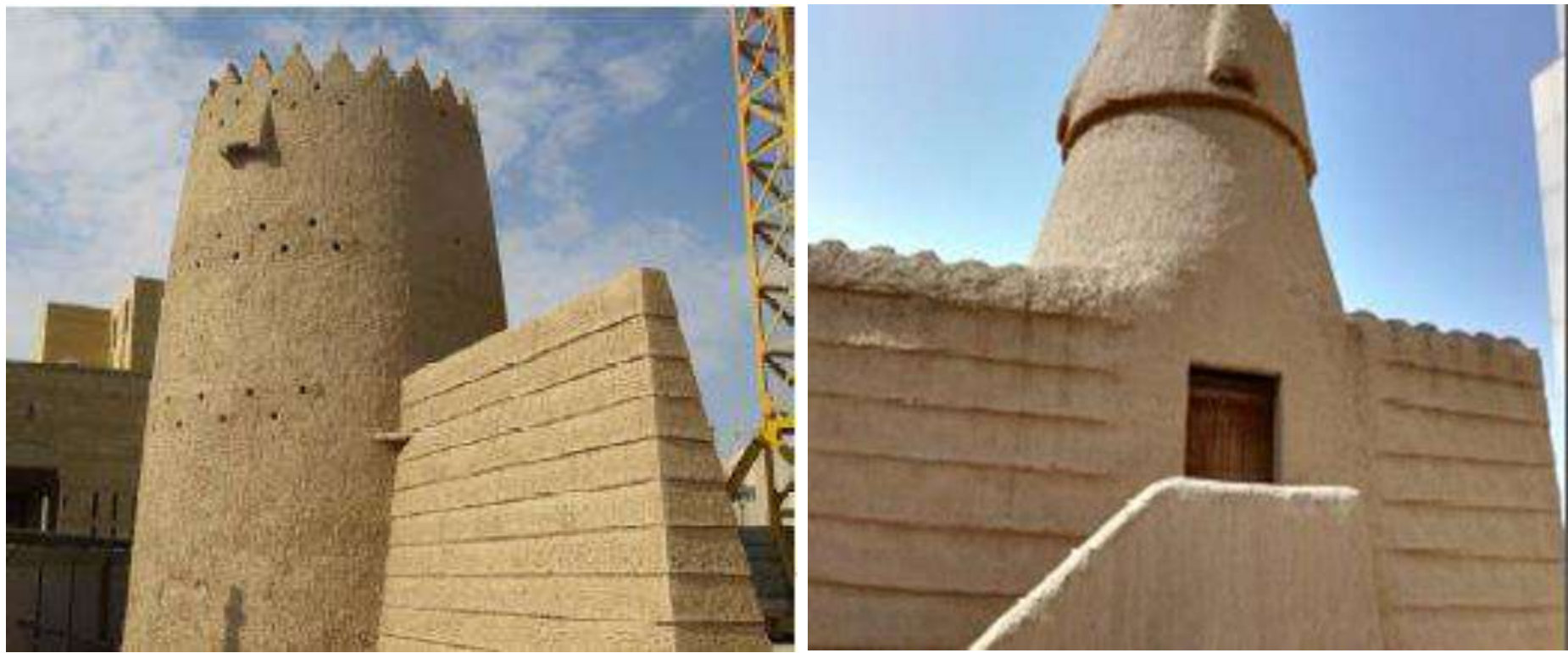

الصورتان تظهران البرجين بعد اكتمال إعادة بناءهما وتظهر في الصورة الثانية الفتحات التي كانت تستخدم للإطلاق بينما

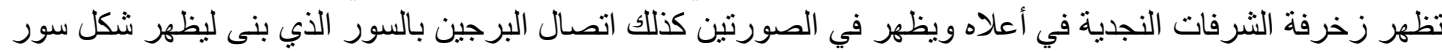
الرياض القديم. 


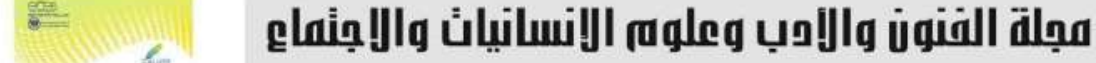

Journal of Arts, Literature, Humanities and Social Sciences www.jalhss.com

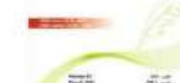

\section{Volume (67) May 2021}

العدد (67) مايو 2021
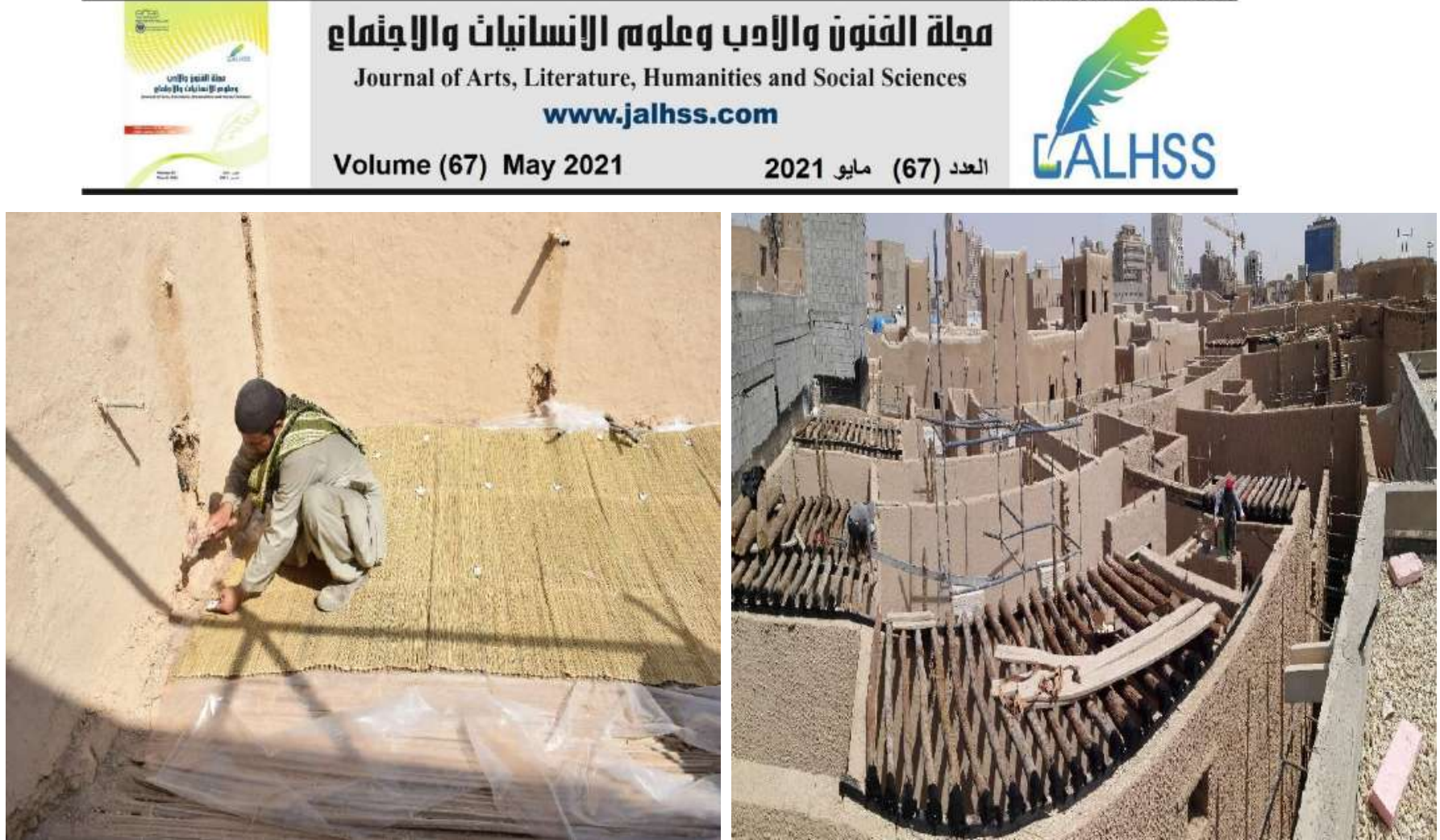

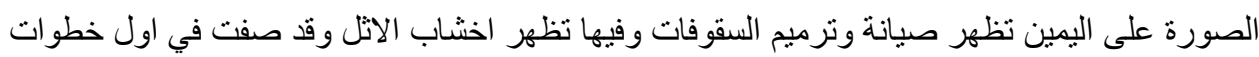

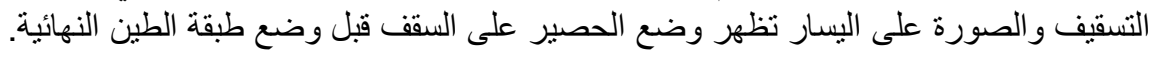
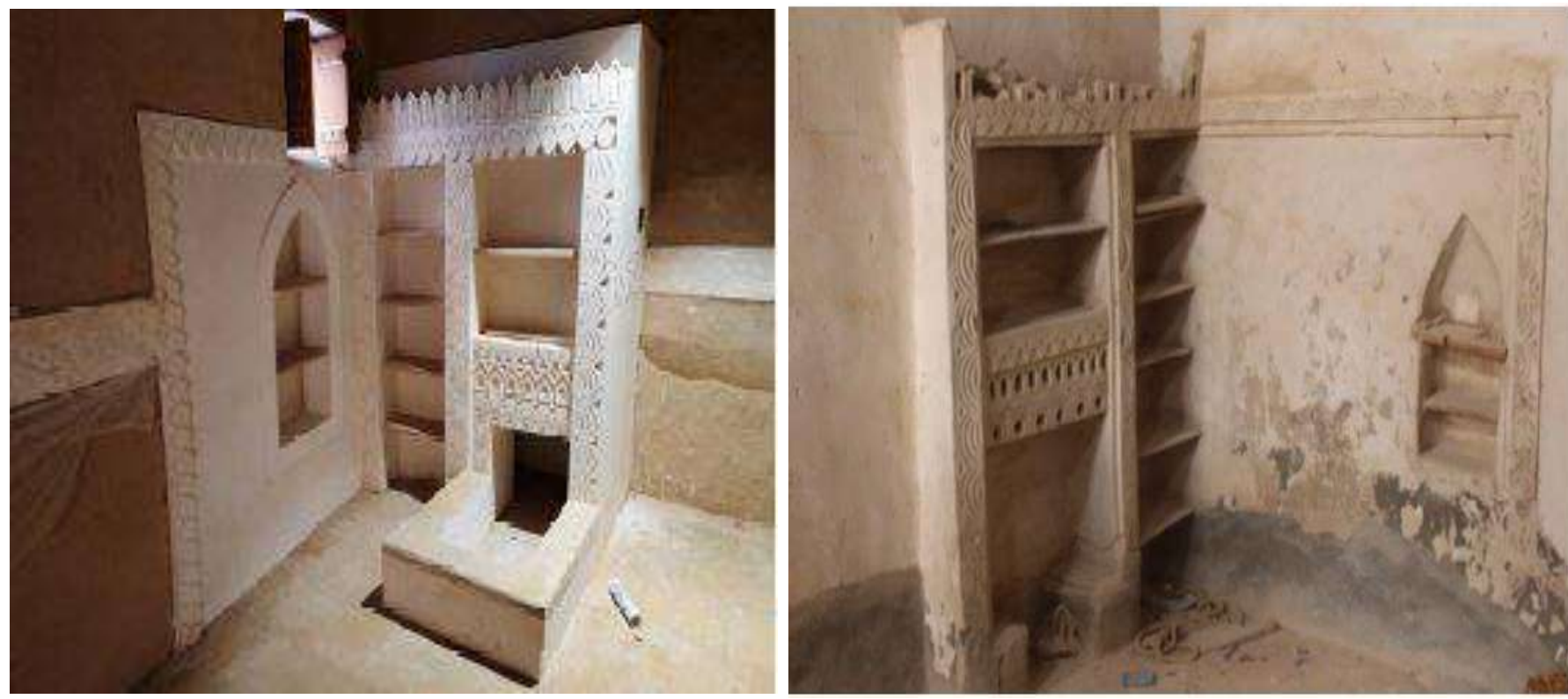

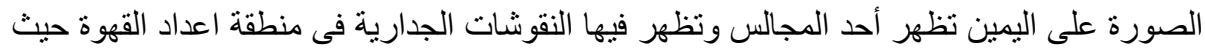

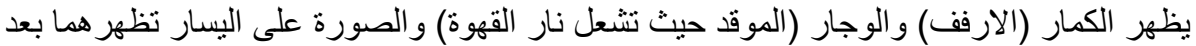

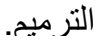




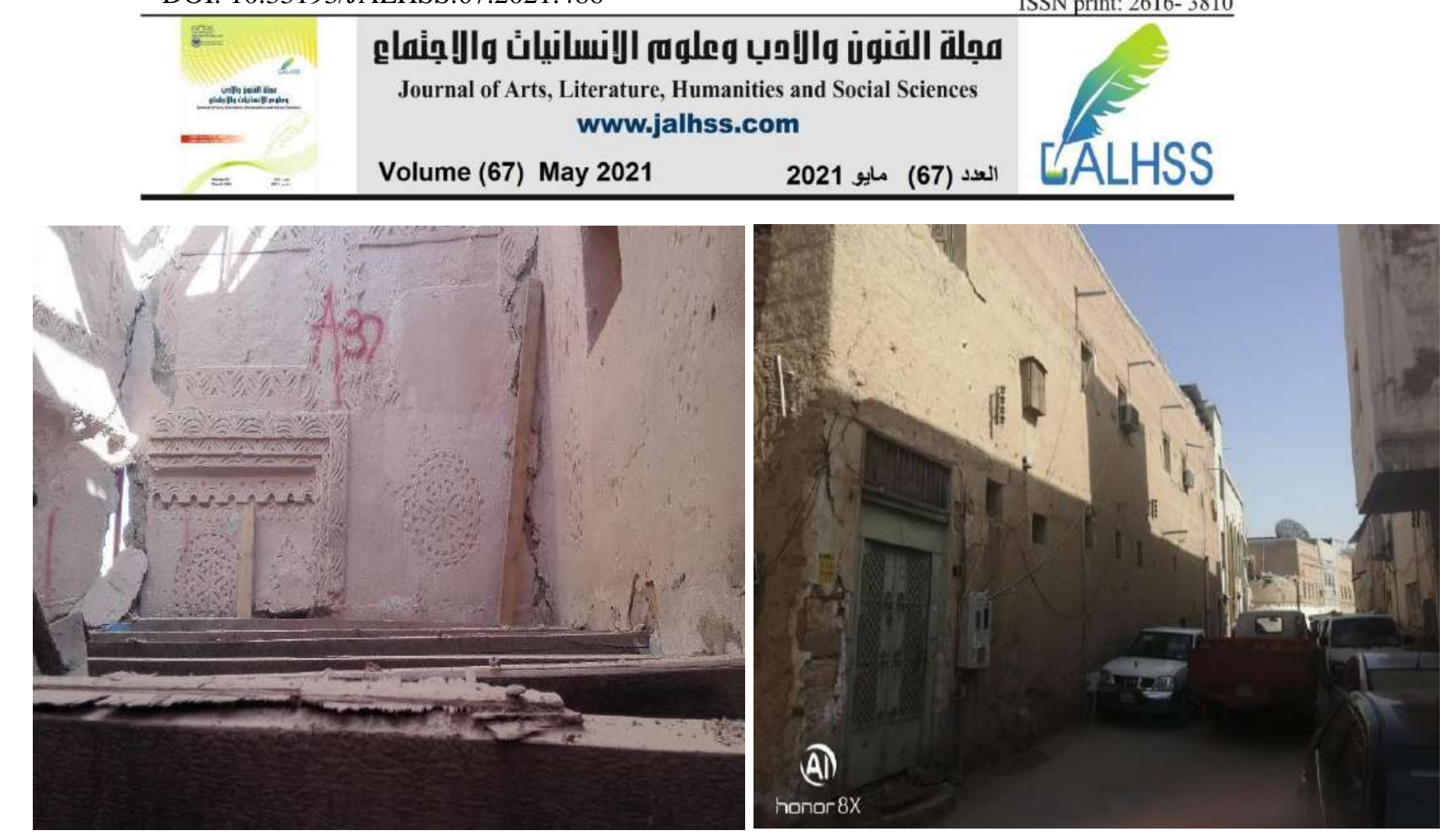

int: $2616-3810$

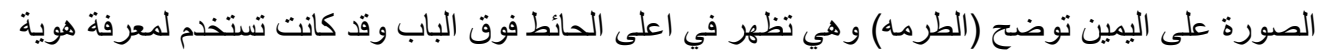
الزوار و الصورة على اليسار تظهر الزخارف التراثية التي وجدت في بعض الثي المباني وتظهر فيها الوردة النجدية.
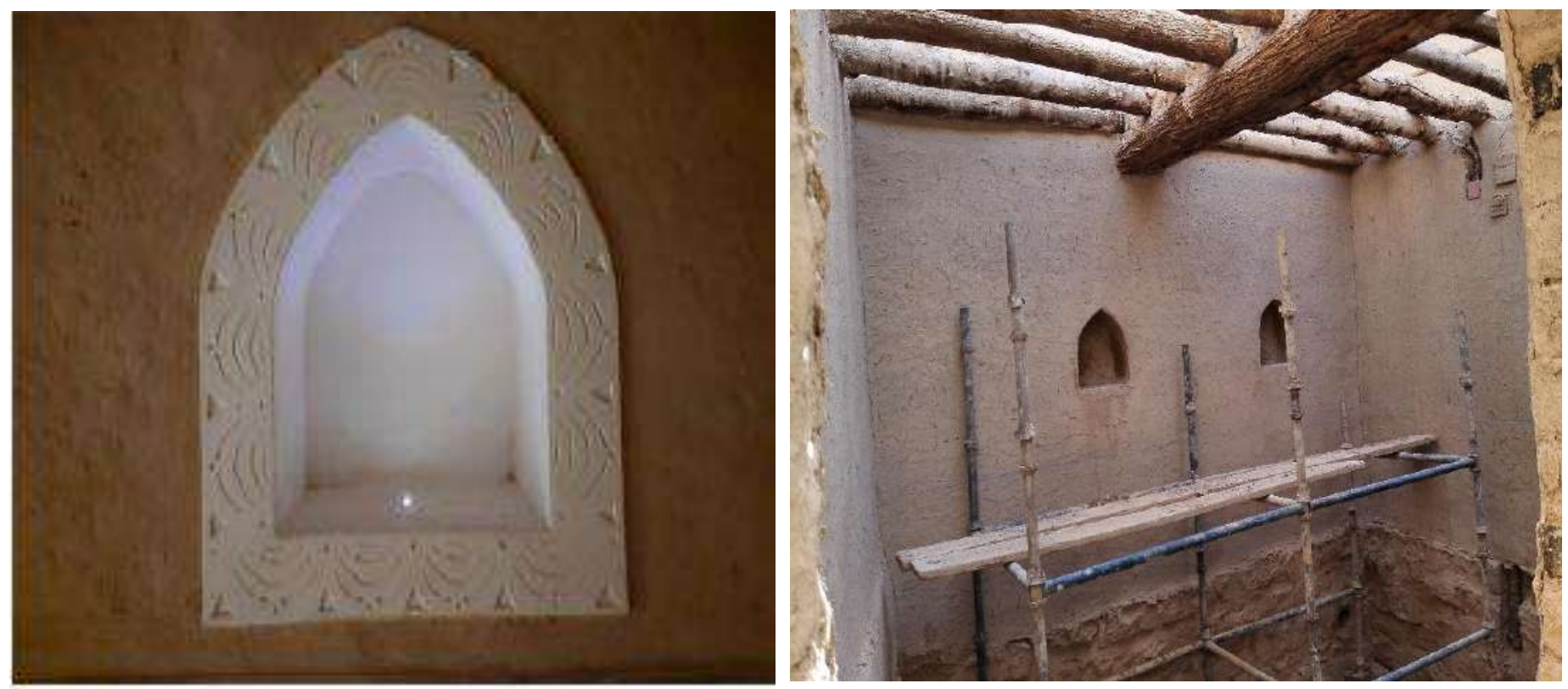

الصورة على اليمين تظهر فتحات كانت تستخدم في وضع السر اج او فو انيس الإضاءة عليها والصورة على تئ اليسار تظهر ها بعد ترميمها. 


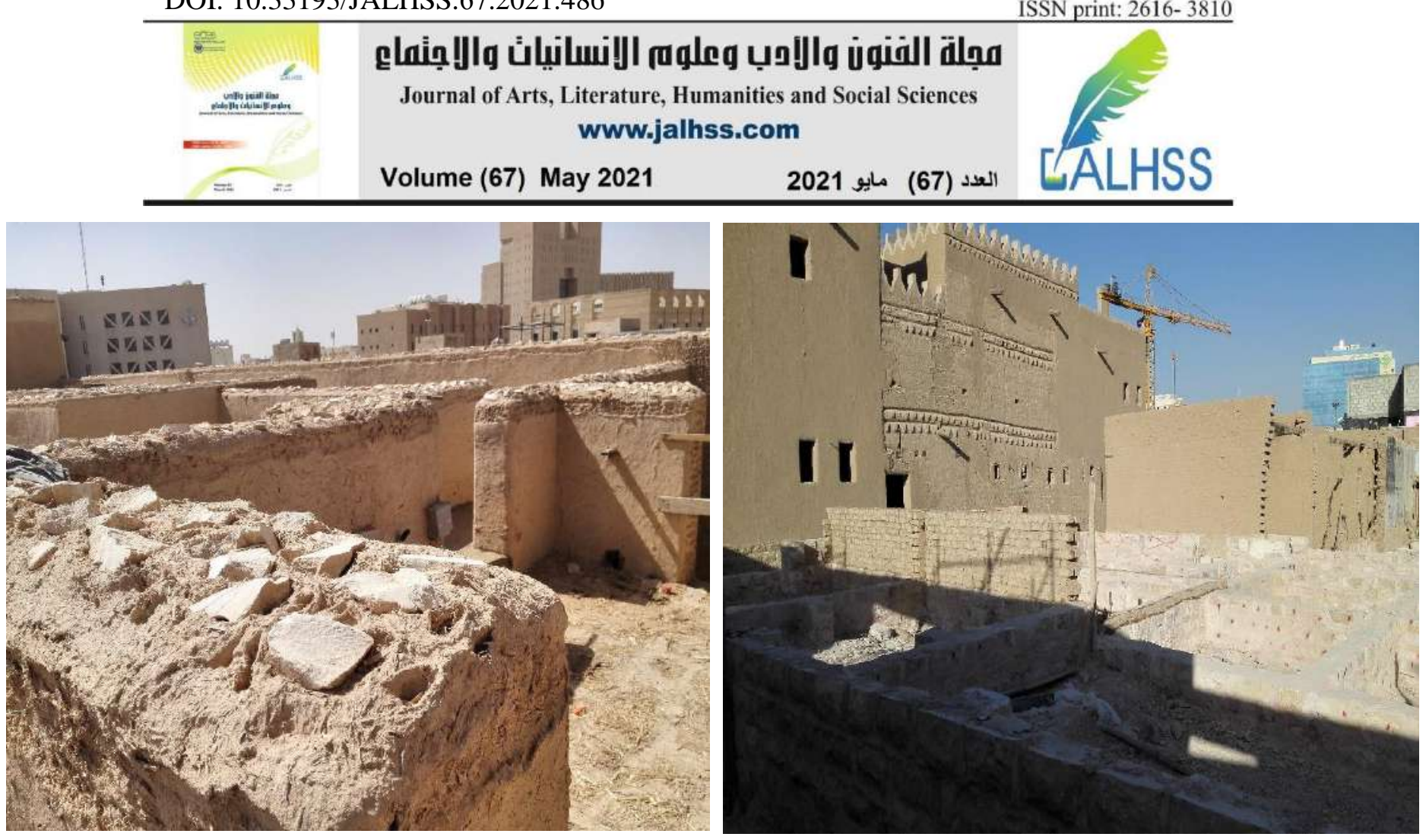

الصورة على اليمين تظهر النقوش الجدارية الخارجية وتسمى (الحداير) و(الحقافات) وكانت تستخدم لمعرفة نهاية الدور

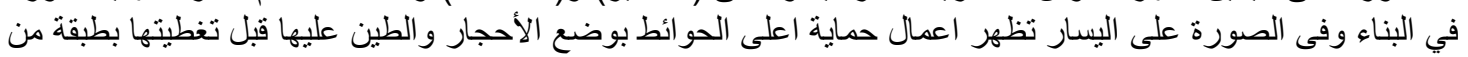

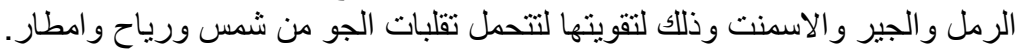
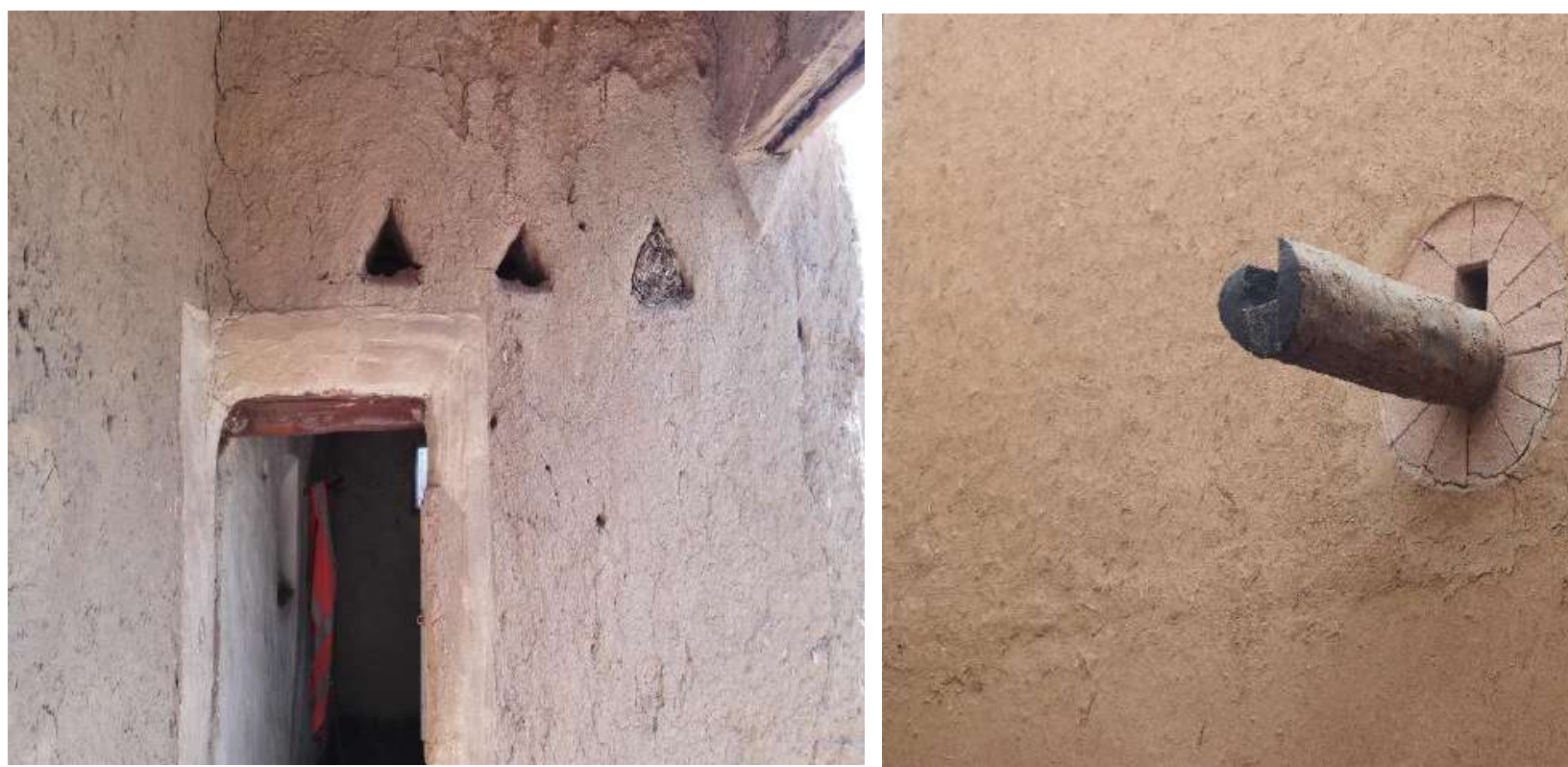

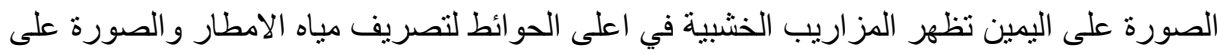

$$
\begin{aligned}
& \text { اليسار تظهر فرجات التهوية في اعلي الحو ائط. }
\end{aligned}
$$




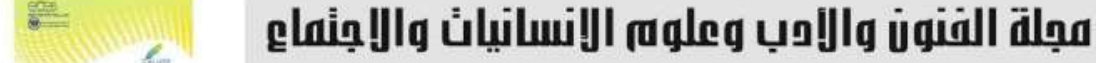

Journal of Arts, Literature, Humanities and Social Sciences www.jalhss.com

$=\quad x=$

\section{Volume (67) May 2021}

العدد (67) مايو 2021
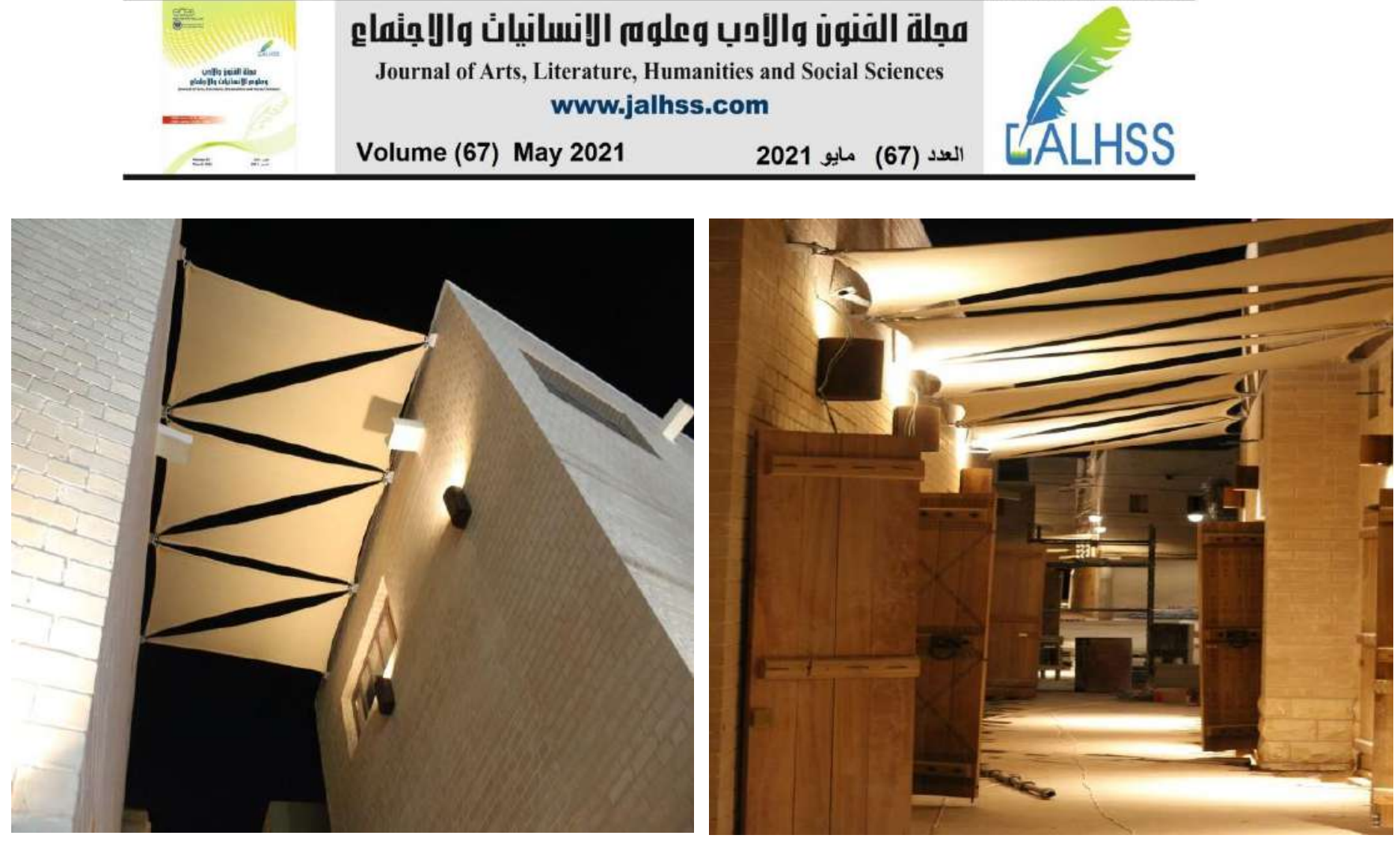

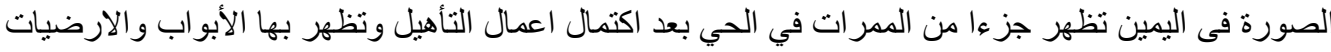
وجزء من المظلات التي استخدت لتظليل الممرات والصورة على اليسار تظهر المظلات بشكل اوضح.
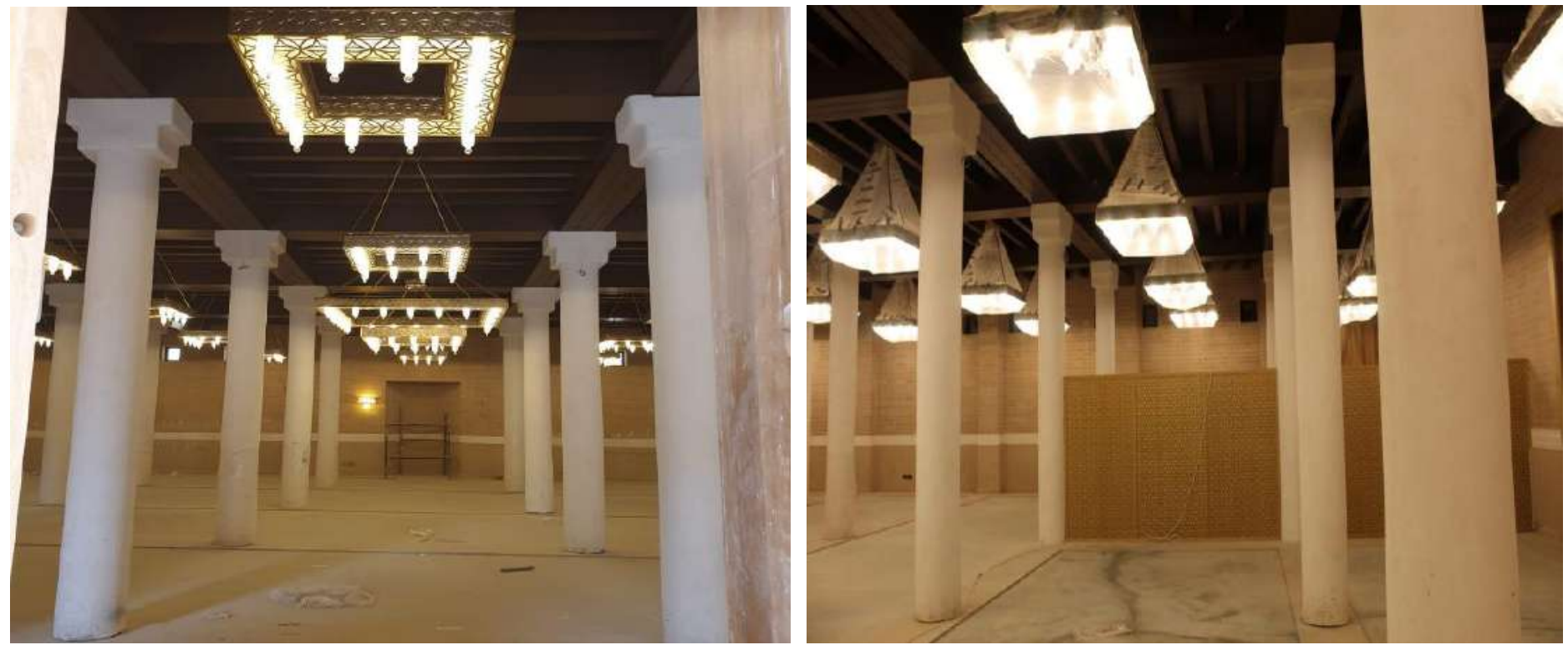

الصورتان من المسجد وتظهر اعمال الإضـاءة والتي استخدمت فيها مصابيح حافظت على الثكل التراثي ل اللمكان وتظهر الاعمدة الحجرية. 


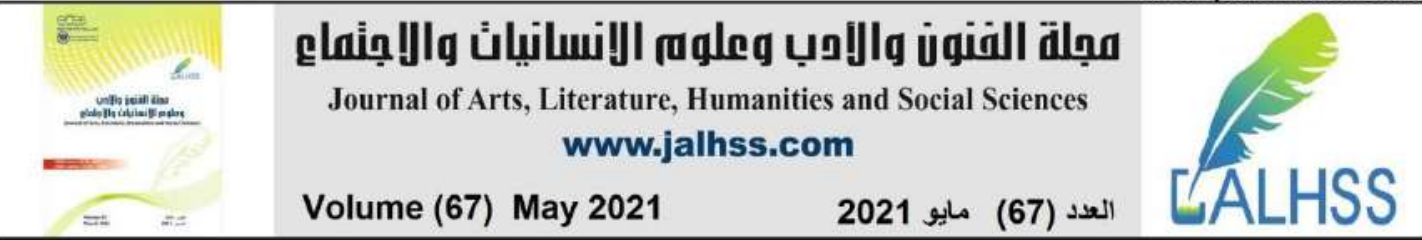
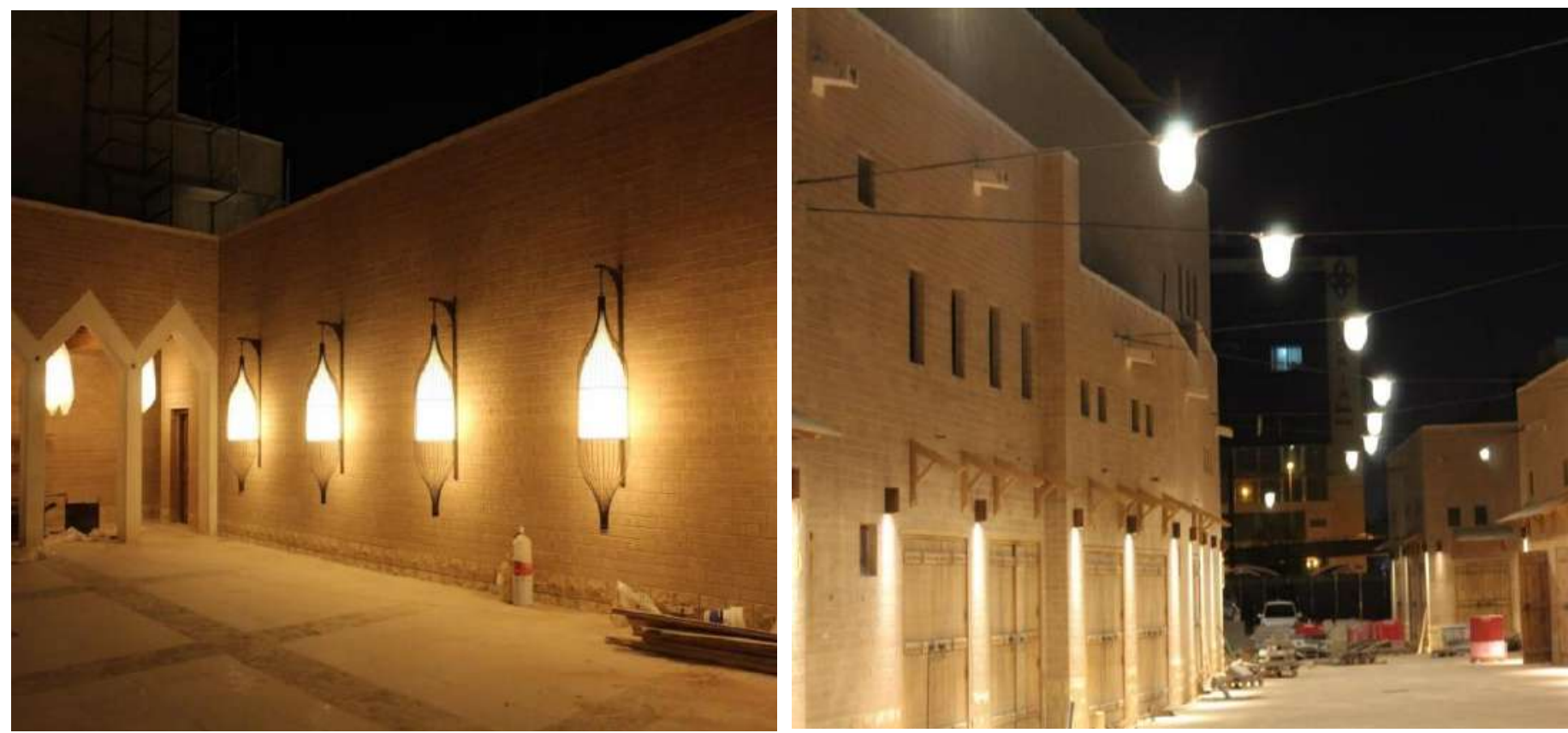

الصورة على اليمين تظهر الساحات الخارجية في الحي والصورة على اليسار نظهر صدن المسجد وتظهر فيهما الارضيات واعمال الإضاءة الجدارية والمعلقة.
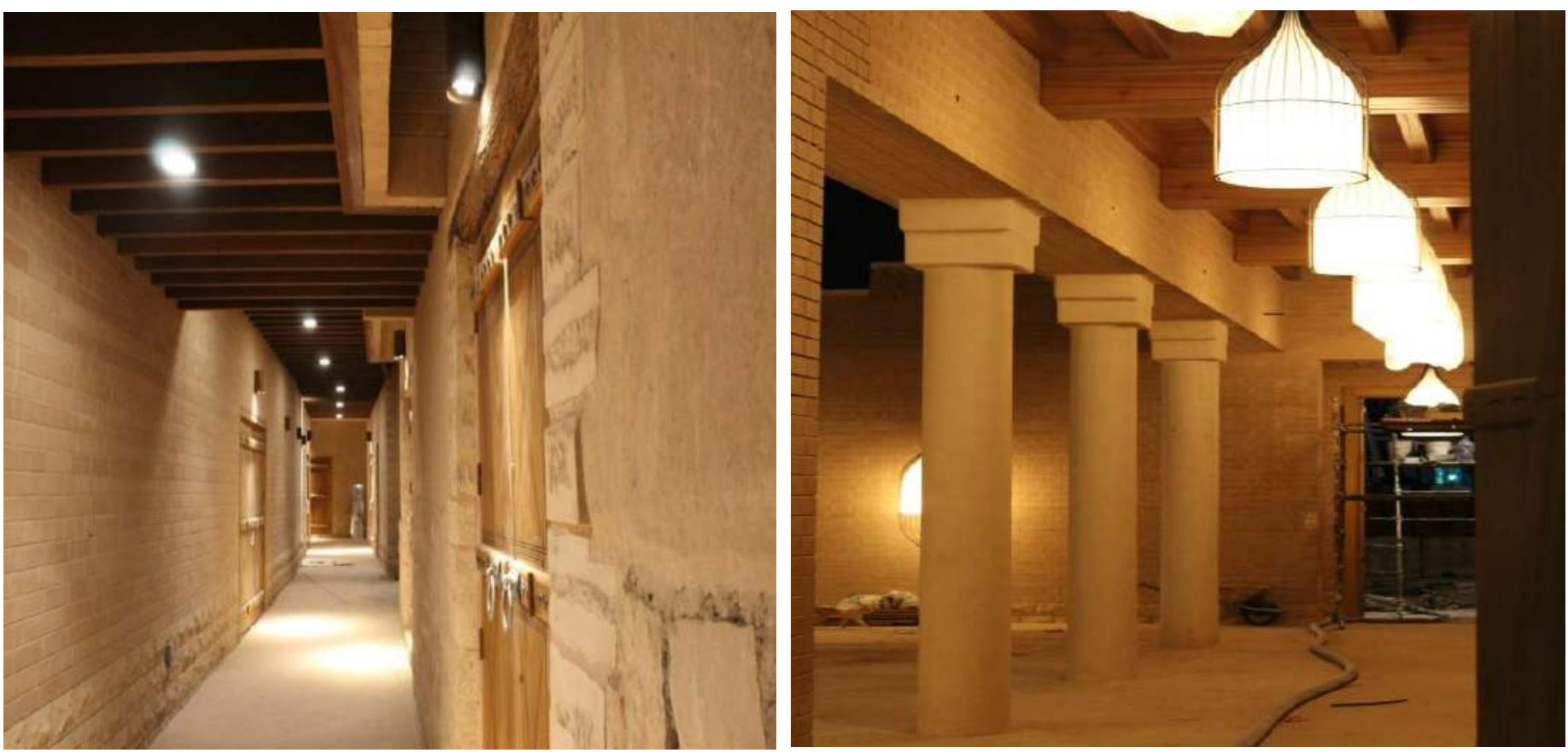

الصورة على اليمين تظهر مدخل المسجد وقد ازدان بالمصابيح التراثية والاعمدة الحجرية والصورة على اليسار تظهر بعض المحال التجارية فى الحي. 


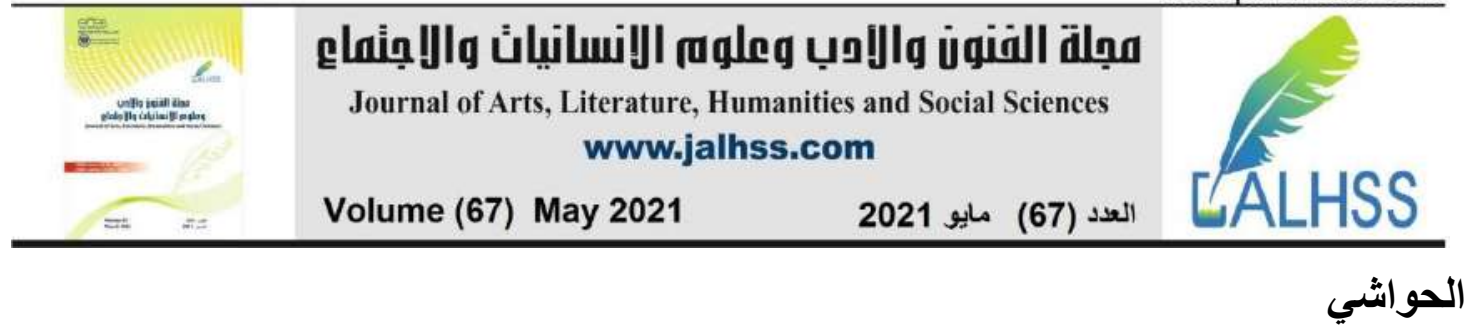

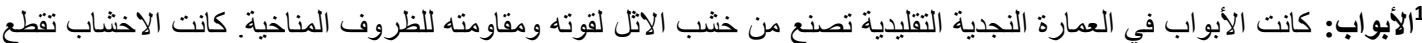

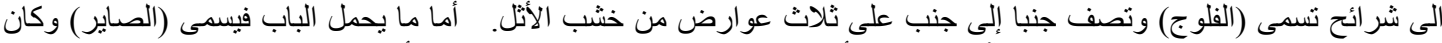

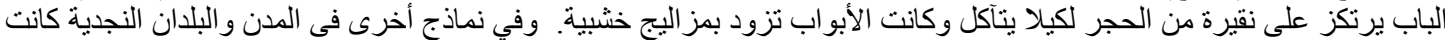

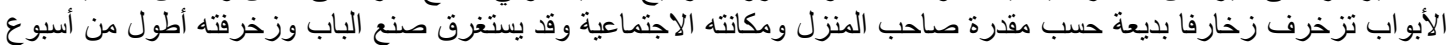

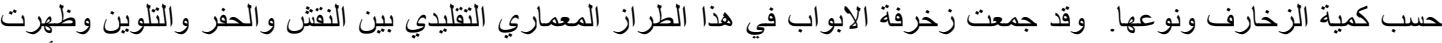

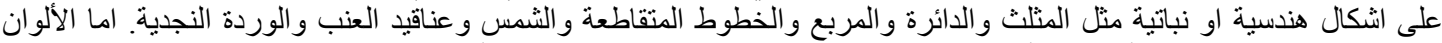

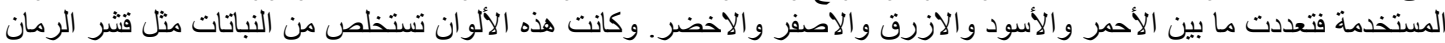

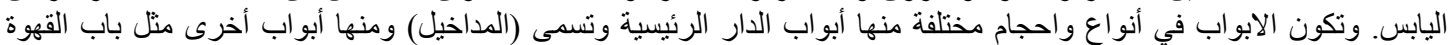

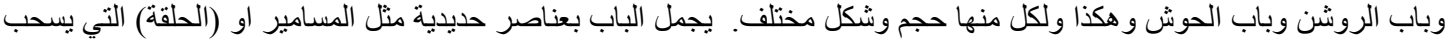

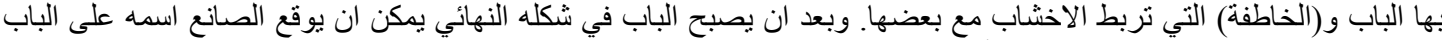

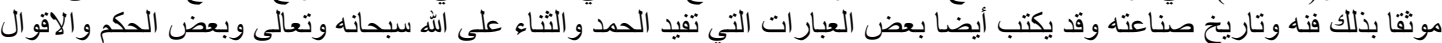
المأثورة ذات الصيغ المختصرة.

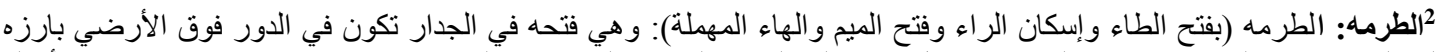

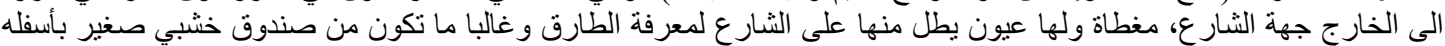

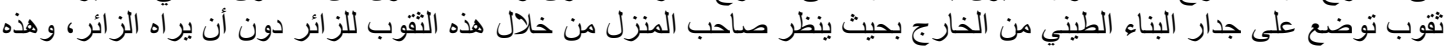

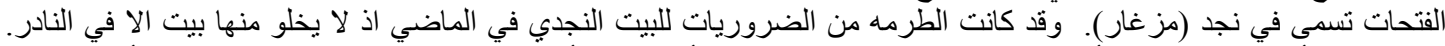

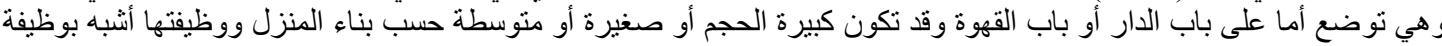

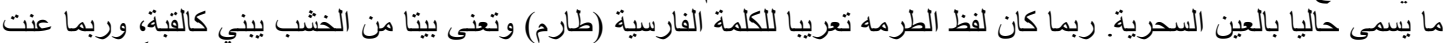

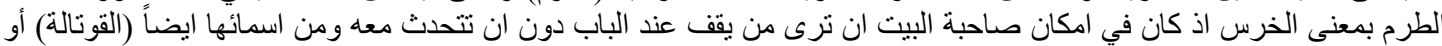
(المشربية) وتزين أحيانا بالجص من في الخدان الخارج.

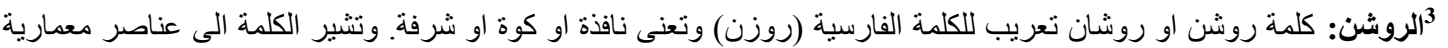

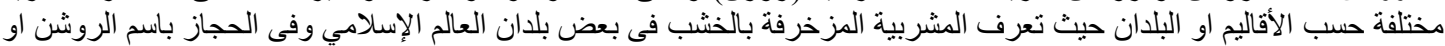

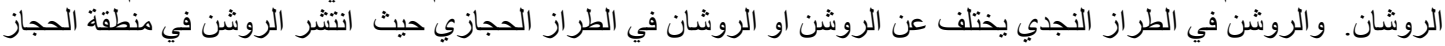

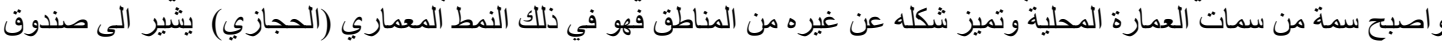

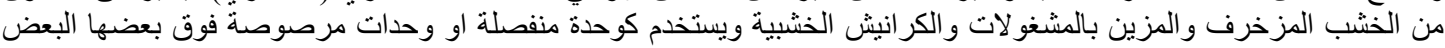

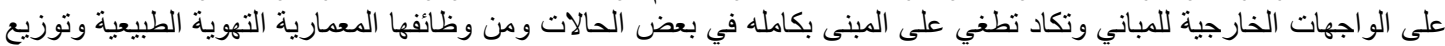

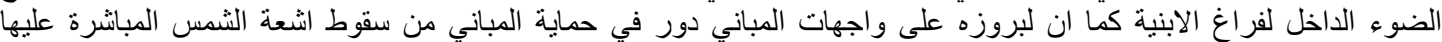

(ابو علي، 2011، 107-117).

4 معلومات العمل الميداني: جمع المعلومات الميدانية لهذه الدراسة المهندس (زاهر عبد الحميد ادم) الذي عمل ضمن فريق الاشر اف

بمشروع نطوير حي (الدحو).

5اعمال التوثيق: تكون في اولي مراحل مشاريع حفظ التراث وهناك أنواع عدة للتوثيق، منها التقارير الأولية، وهي تقارير فنية

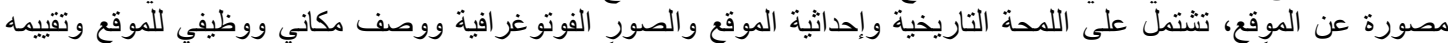

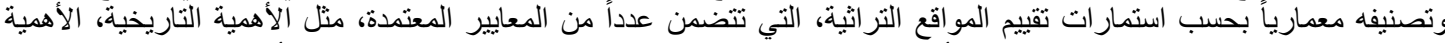

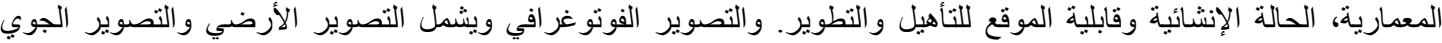

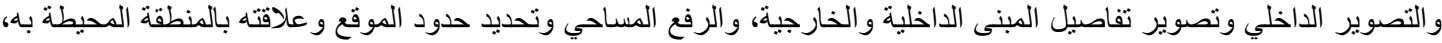

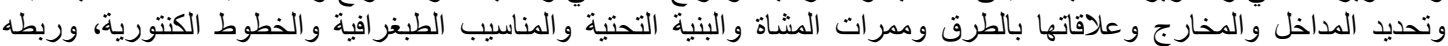

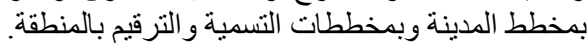

6المجبب: يعرف باسم الساباط (يجمع على سو ابيط وساباطات) فى العمارة الإسلامية القديمة. و الساباط منتشر في الكثبر من البلدان

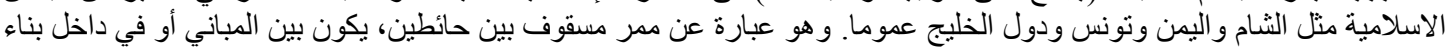

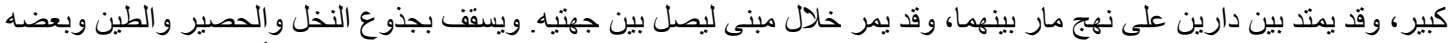

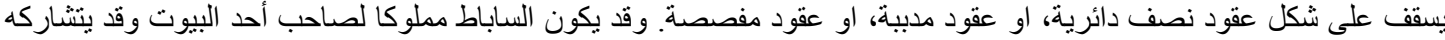

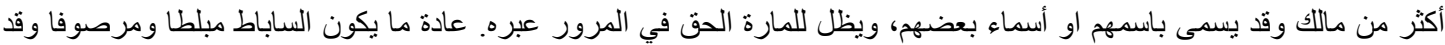

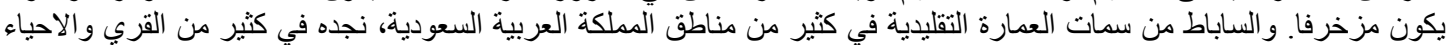

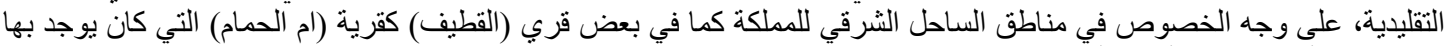
8 ساباطات أطلقت عليها أسماء أصحابها و لا يز ال ال بعضها موجودا. 


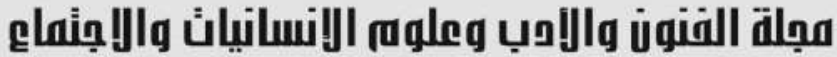

vifuieat in

Journal of Arts, Literature, Humanities and Social Sciences

www.jalhss.com

\section{Volume (67) May 2021}

العدد (67) مايو 2021

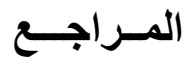

1. أبو علي، نايف بن نائل بن عبد الرحمن، التنمبة المستدامة في العمارة الثقلبية في المدلكة العربية السعودية:(در استة حالة منطقة الحجاز)، رسالة مقدمة لنيل درجة الماجستير، كلية الهندسة والعمارة الإسلامية،

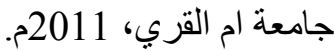

2. الاحبابى، شيماء حميد حسن، الحفاظ العدرانسي المستد/م في المناطق التراثية، بغداد: مجلة كلية الهندة، النها، جامعة النهرين، المجلد 17، العدد 2، 2014، (صن 25 14)

3.التويجري، عبد العزيز عثمان، التراث والهوية ، منشورات المنظمة الاسلامية للتربية والعلوم و الثقافة، الرباط، 2011

4. الحنيش، جميلة الهادي و الرميح، رضا الصادق، إعادة استخدام المبنى التاربخي والأثري ذو القبهة كمدخل

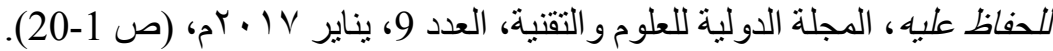
5.الحنيش، جميلة الهادي والمنفوخ، على عبد الرحمن عبد السلام، المباني التاريخية في المدن وأسالبب الحفاظ عليها (المدينة القدبية في طر ابلس)، المجلة الدولية للعلوم و التقنية، العدد 9، ديسمبر 2016م، (ص120). 6.الماجدي، باسم حسن هاشم، و الطائي، حارث خليف: الحفظ الوقائسي المستد/م للأبنبة التاريخبة ، المجلة العراقية

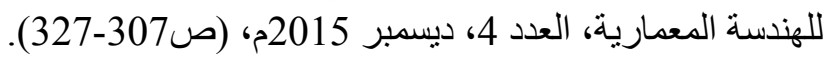
7.المالكي، قبيلة فارس، التراث العدرانسي والمعداري في الوطن العربي: الحفاظ ـ الصبانة ــ اعادة التأهيل، عمان: الوراق للنشر و التوزيع، 2004م.

8.المحاري، سلمان احمد: حفظ المباني التاريخبة (مبانسي من مدبنة المحرق)، الشارقة: مطبوعات ايكروم

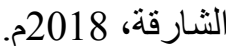

9.المصري، مجد نجدي ناجي، تقبيم تقنيات وأساليب الترمبم في فلسطبن (نابلس دراسة حالة)، أطروحة مقدمة لنيل درجة الماجستير في هندسـة العمـارة بكليـة الدراسات العليا، جامعة النجاح الوطنية، نابلس، فلسطين، 2010

10.النمرة، نادر جو اد، مقاربة مقترحة لإعادة تأهبل المبانسي الاثرية ذات القبية في مدينة غزة (دراسة تحلبلية

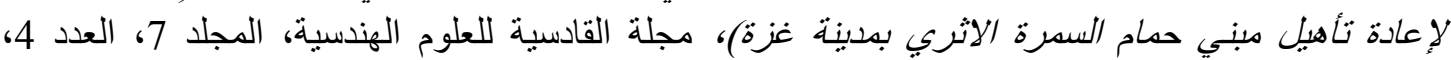

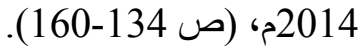

11. الهياجي، ياسر هاثم عماد، نحو استر/تيجية فاعلة للتوظبف السباحي في المدن التراثبة العربية ، ورقة مقدمة لمؤتمر تطوير السياحة والفندقة في الوطن العربي، وقائع اعمال المؤتمر الدولي لتطوير السياحة والفندقة في

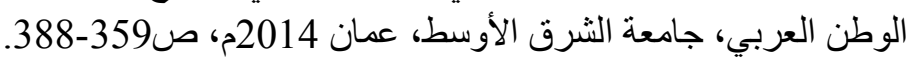




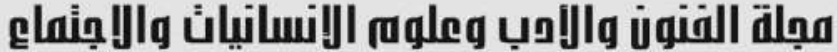

velloieat in

Journal of Arts, Literature, Humanities and Social Sciences www.jalhss.com

\section{Volume (67) May 2021}

العدد (67) مايو 2021

12.باهمام، علي بن سالم بن عمر: الخصائص المعدارية والعدرانية للمساكن التقلبيةية في المعلكة العربية

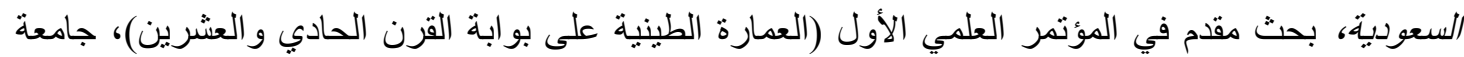

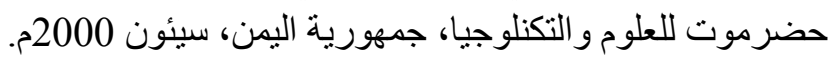

13.نوما، جابي، دلبل سياحي (محمية سبيوة وبلدة سالي القبيمة)، القاهرة: وزارة الدولة لثئون البيئة، 2012م.

14.زريق، ثريا، المواثيق الدولية التي ظهرت للحفاظ على التراث العالمي، سوريا: حلب عاصمة الثقافة

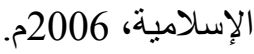

15.شاهين، عبد المعز، ترمبم وصبانة العباني الاثرية والتاريخية، القاهرة: مطابع المجلس الأعلى للآثار،

16.صبحي، محمود جمال: إعادة توظيف المباني التراثية بين الواقع والمأمول، دراسة حالة الدباني التراثية

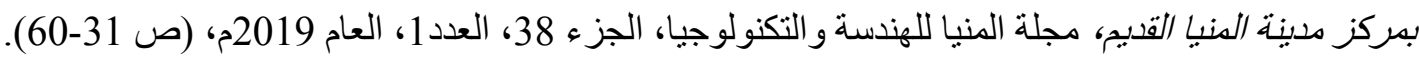

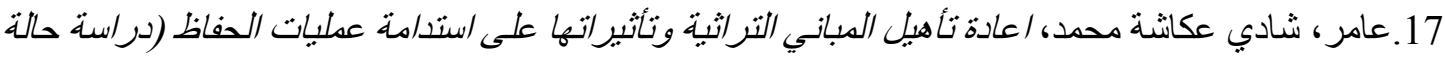

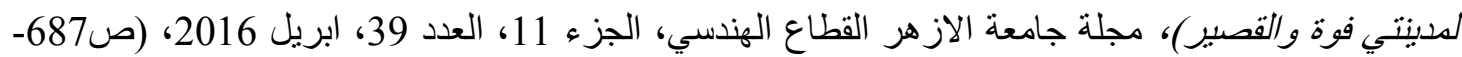

18. عبد الوارث، امل، الحفاظ على المباني التاريخية وسبل توظبفها فى الددينة الدصرية امثلة من القاهرة،

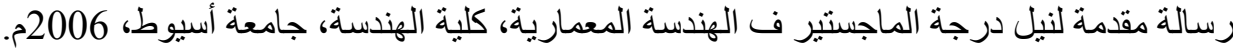

19.عتمة، محمد علام فوزي، إعادة تأهيل المباني التاريخية في فلسطين (حالة دراسية تجربة مدينة نابلس منذ 1994م)، رسالة مقدمة لنيل درجة الماجستير، كلية هندسة العمارة، جامعة النجاح، فلسطين، 2007م.

20.مصطفي، بسام محمد، دور عمليات إعادة البناء في الحفاظ على المباني الأثرية والمواقع التناريخية، مجلة العادية

الاتحاد العام للآثاريين العرب، القاهرة: الاتحاد العام للآثاريين العرب، العدد 10، 2009م، (ص 100-152).

21. Feilden, Bernard, Conservation of historic building, London: Butterworth Scientific, 1982.

22.United Nations Development Program (UNDP), Supreme Council for Antiquities: (SCA): Rehabilitation of Historic Cairo, December ,1997. 


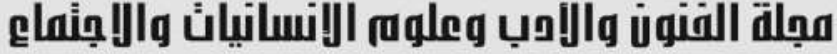 \\ Journal of Arts, Literature, Humanities and Social Sciences www.jalhss.com}

Volume (67) May 2021

العدد (67) مايو 2021

\section{References:}

1.Abdel-Warith, Amal, Preservation of Historic Buildings and Ways to Use them in the Egyptian City, (Examples from Cairo), Thesis Submitted for a Master's Degree in Architecture Engineering, Faculty of Engineering, Assiut University, 2006.

2. Abu Ali, Nayef bin Nael bin Abdul Rahman, Sustainable Development in Traditional Architecture in the Kingdom of Saudi Arabia: (A Case Study of Hijaz Region), Thesis Submitted for a Master's Degree in Architecture Engineering, College of Engineering and Islamic Architecture, Umm Al-Qura University, 2011.

3. Al-Ahbabi, Shaima Hamid Hassan, Sustainable Urban Conservation in Heritage Areas, Baghdad: Journal of the College of Engineering, Al-Nahrain University, Volume 17, No 2, 2014, (pp. 14-25).

4. Al-Hanish, Jamila Al-Hadi and Al-Rumaih, Reda Al-Sadiq, Reuse of the Historical and Archaeological Building of Value as an Entry Point for its Preservation, International Journal of Science and Technology, No 9, January 2017, (pp. 1-20).

5.Al-Hanish, Jamila Al-Hadi and Al-Manfukh, Ali Abdel-Rahman Abdel-Salam, Historical Buildings in Cities and Methods of Preservation (The Old City of Tripoli)، International Journal of Science and Technology, No 9, December 2016, (pp. 1-20).

6. Al-Hayyji, Yasser Hashem Emad, Towards an Effective Strategy for Tourism Employment in Arab Heritage Cities, Paper presented to the Conference of Tourism and Hotel Development in the Arab World, Work Reports of the International Conference for the Development of Tourism and Hotel in the Arab World, Middle East University, Amman 2014, pp 359-388.

7.Al-Mahari, Salman Ahmad: Preserving Historical Buildings (Buildings from the City of Muharraq)، Sharjah: ICCROM publications, Sharjah, 2018.

8.Al-Majidi, Basem Hasan Hashem, and Al-Ta'i, Harith Khalif: Sustainable Preventive Preservation of Historic Buildings, Iraqi Journal of Architecture, No 4, December 2015, (pp. 307-327).

9.Al-Maliki, Faris Qabila, Urban and Architectural Heritage in the Arab World: Preservation - Maintenance - Rehabilitation, Oman: Al-Warraq for Publishing and Distribution, 2004.

10.Al-Masry, Majd Najdi Naji, Evaluation of techniques and methods of restoration in Palestine (Nablus as case study)، Thesis Submitted for a Master's Degree in 


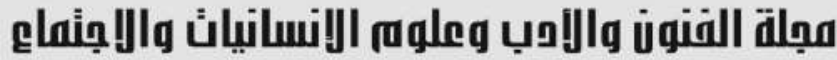 \\ Journal of Arts, Literature, Humanities and Social Sciences www.jalhss.com}

Volume (67) May 2021

العدد (67) مايو 2021

Architecture Engineering, College of Graduate Studies, An-Najah National University, Nablus, Palestine, 2010.

11.Al-Nimrah, Nader Jawad, A Suggested Approach to Rehabilitation of the valuable Ancient Buildings in Gaza City (An Analytical Study for the Rehabilitation of the AlSamra Archaeological Bath Building in Gaza City), Al-Qadisiyah Journal of Engineering Sciences, Volume 7, Issue 4, 2014 AD, (pp. 134-160).

12.Al Towijiri, Abdelaziz Osman, Heritage and Identity, publications of the Islamic Educational, and Cultural Organization, Rabat, 2011.

13.Amer, Shadi Okasha Muhammad, Rehabilitation of heritage buildings and their effects on the sustainability of conservation operations (a case study of the cities of Fuwa and Al-Qusayr)، Journal of Al Azhar University Engineering Sector, Vol 11, No 39, April 2016, (pp. 687-697).

14. Atma, Muhammad Allam Fawzi, Rehabilitation of Historic Buildings in Palestine (a case study, the experience of Nablus since 1994), a thesis submitted for a master's degree, Faculty of Architecture, An-Najah University, Palestine, 2007.

15.Bahamam, Ali bin Salem bin Omar: Architectural and Urban Characteristics of Traditional Dwellings in the Kingdom of Saudi Arabia, a paper presented at the First Scientific Conference (Mud Architecture at the Gate of the Twenty-First Century), Hadramout University of Science and Technology, Republic of Yemen, Seiyun 2000.

16.Feilden, Bernard, Conservation of historic building, London: Butterworth Scientific, 1982.

17.Mustafa, Bassam Mohamed, The Role of Reconstruction in Preserving Archaeological Buildings and Historical Sites, Journal of the General Union of Arab Archaeologists, Cairo: General Union of Arab Archaeologists, No 10, 2009, (pp. 100152).

18.Shaheen, Abdel Moez, Restoration and Maintenance of Archaeological and Historical Buildings, Cairo: Supreme Council of Antiquities Press, 1994.

19.Subhi Mahmoud Gamal: Re-employment of heritage buildings between reality and expectations, a case study of heritage buildings in the old city center of Minya, Minia journal of Engineering and Technology 38, No1, 2019, (pp31-60).

20.Touma, Gabi, A Tourist Guide (Siwa reserve and the old town of Sally), Cairo: Ministry of State for Environmental Affairs, 2012. 


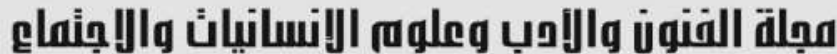 \\ Journal of Arts, Literature, Humanities and Social Sciences www.jalhss.com}

21.United Nations Development Program (UNDP), Supreme Council for Antiquities: (SCA): Rehabilitation of Historic Cairo, December ,1997.

22.Zureik, Thuraya, the International Conventions that Emerged to Preserve the World Heritage, Syria: Aleppo, the Capital of Islamic Culture, 2006. 